\title{
Surveillance for Health Care Access and Health Services Use, Adults Aged 18-64 Years Behavioral Risk Factor Surveillance System, United States, 2014
}




\section{CONTENTS}

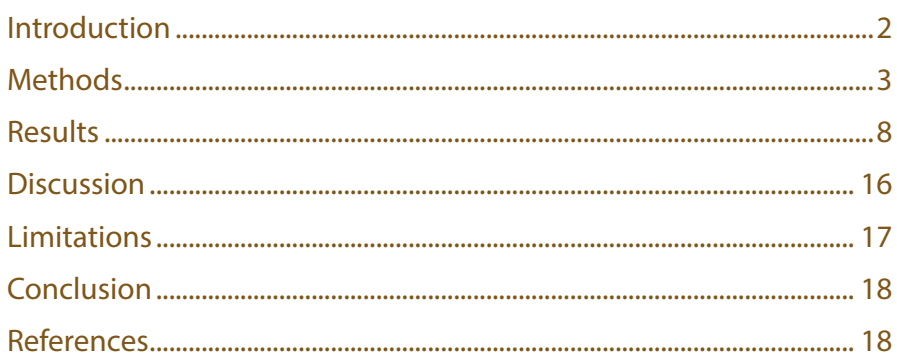

The MMWR series of publications is published by the Center for Surveillance, Epidemiology, and Laboratory Services, Centers for Disease Control and Prevention (CDC), U.S. Department of Health and Human Services, Atlanta, GA 30329-4027.

Suggested citation: [Author names; first three, then et al., if more than six.] [Title]. MMWR Surveill Summ 2017;66(No. SS-\#):[inclusive page numbers].

\section{Centers for Disease Control and Prevention}

Anne Schuchat, MD, Acting Director

Patricia M. Griffin, MD, Acting Associate Director for Science

Joanne Cono, MD, ScM, Director, Office of Science Quality

Chesley L. Richards, MD, MPH, Deputy Director for Public Health Scientific Services

Michael F. Iademarco, MD, MPH, Director, Center for Surveillance, Epidemiology, and Laboratory Services

\section{MMWR Editorial and Production Staff (Serials)}

Sonja A. Rasmussen, MD, MS, Editor-in-Chief

Charlotte K. Kent, PhD, MPH, Executive Editor

Christine G. Casey, MD, Editor

Teresa F. Rutledge, Managing Editor

David C. Johnson, Lead Technical Writer-Editor

Marella Meadows, Project Editor

Timothy F. Jones, MD, Chairman

Matthew L. Boulton, MD, MPH

Virginia A. Caine, MD

Katherine Lyon Daniel, PhD

Jonathan E. Fielding, MD, MPH, MBA

David W. Fleming, MD
Martha F. Boyd, Lead Visual Information Specialist Maureen A. Leahy, Julia C. Martinroe, Stephen R. Spriggs, Tong Yang, Visual Information Specialists

Quang M. Doan, MBA, Phyllis H. King, Terraye M. Starr, Moua Yang, Information Technology Specialists

MMWR Editorial Board

William E. Halperin, MD, DrPH, MPH

King K. Holmes, MD, PhD

Robin Ikeda, MD, MPH

Rima F. Khabbaz, MD

Phyllis Meadows, PhD, MSN, RN

Jewel Mullen, MD, MPH, MPA
Jeff Niederdeppe, PhD
Patricia Quinlisk, MD, MP

Patricia Quinlisk, MD, MPH
Patrick L. Remington, MD, MPH Carlos Roig, MS, MA

William L. Roper, MD, MPH

William Schaffner, MD 


\title{
Surveillance for Health Care Access and Health Services Use, Adults Aged 18-64 Years - Behavioral Risk Factor Surveillance System, United States, 2014
}

\author{
Catherine A. Okoro, $\mathrm{PhD}^{1}$ \\ Guixiang Zhao, $\mathrm{MD}, \mathrm{PhD}^{1}$ \\ Jared B. Fox, $\mathrm{PhD}^{2}$ \\ Paul I. Eke, $\mathrm{PhD}^{3}$ \\ Kurt J. Greenlund, $\mathrm{PhD}^{3}$ \\ Machell Town, $\mathrm{PhD}^{1}$ \\ ${ }^{1}$ Population Health Surveillance Branch, Division of Population Health, National Center for Chronic Disease Prevention and Health Promotion, CDC \\ ${ }^{2}$ Policy Research, Analysis, and Development Office, Office of the Associate Director for Policy, CDC \\ ${ }^{3}$ Division of Population Health, Office of the Director, National Center for Chronic Disease Prevention and Health Promotion, CDC
}

\begin{abstract}
Problem/Condition: As a result of the 2010 Patient Protection and Affordable Care Act, millions of U.S. adults attained health insurance coverage. However, millions of adults remain uninsured or underinsured. Compared with adults without barriers to health care, adults who lack health insurance coverage, have coverage gaps, or skip or delay care because of limited personal finances might face increased risk for poor physical and mental health and premature mortality.
\end{abstract}

Period Covered: 2014.

Description of System: The Behavioral Risk Factor Surveillance System (BRFSS) is an ongoing, state-based, landline- and cellular-telephone survey of noninstitutionalized adults aged $\geq 18$ years residing in the United States. Data are collected from states, the District of Columbia, and participating U.S. territories on health risk behaviors, chronic health conditions, health care access, and use of clinical preventive services (CPS). An optional Health Care Access module was included in the 2014 BRFSS.

This report summarizes 2014 BRFSS data from all 50 states and the District of Columbia on health care access and use of selected CPS recommended by the U.S. Preventive Services Task Force or the Advisory Committee on Immunization Practices among working-aged adults (aged 18-64 years), by state, state Medicaid expansion status, expanded geographic region, and federal poverty level (FPL). This report also provides analysis of primary type of health insurance coverage at the time of interview, continuity of health insurance coverage during the preceding 12 months, and other health care access measures (i.e., unmet health care need because of cost, unmet prescription need because of cost, medical debt [medical bills being paid off over time], number of health care visits during the preceding year, and satisfaction with received health care) from 43 states that included questions from the optional BRFSS Health Care Access module.

Results: In 2014, health insurance coverage and other health care access measures varied substantially by state, state Medicaid expansion status, expanded geographic region (i.e., states categorized geographically into nine regions), and FPL category. The following proportions refer to the range of estimated prevalence for health insurance and other health care access measures by examined geographical unit (unless otherwise specified), as reported by respondents. Among adults with health insurance coverage, the range was $70.8 \%-94.5 \%$ for states, 78.8\%-94.5\% for Medicaid expansion states, 70.8\%-89.1\% for nonexpansion states, $73.3 \%-91.0 \%$ for expanded geographic regions, and $64.2 \%-95.8 \%$ for FPL categories. Among adults who had a usual source of health care, the range was $57.2 \%-86.6 \%$ for states, $57.2 \%-86.6 \%$ for Medicaid expansion states, $61.8 \%-83.9 \%$ for nonexpansion states, $64.4 \%-83.6 \%$ for expanded geographic regions, and $61.0 \%-81.6 \%$ for FPL categories. Among adults who received a routine checkup, the range was $52.1 \%-75.5 \%$ for states, $56.0 \%-75.5 \%$ for Medicaid expansion states, $52.1 \%-71.1 \%$ for nonexpansion states, $56.8 \%-70.2 \%$ for expanded geographic regions, and $59.9 \%-69.2 \%$ for FPL categories. Among adults who had unmet health care need because of cost, the range was $8.0 \%-23.1 \%$ for states, $8.0 \%-21.9 \%$ for Medicaid expansion states, $11.9 \%-23.1 \%$ for nonexpansion states, $11.6 \%-20.3 \%$ for expanded geographic regions, and 5.3\%-32.9\% for FPL categories. Estimated prevalence of cancer screenings, influenza vaccination, and having ever been tested for human immunodeficiency virus also varied by state, state Medicaid expansion status, expanded geographic region, and FPL category.

Corresponding author: Division of Population Health, National Center for Chronic Disease Prevention and Health Promotion, CDC. Telephone: 770-488-5220; E-mail: cokoro@cdc.gov.
The prevalence of insurance coverage varied by approximately 25 percentage points among racial/ethnic groups (range: $63.9 \%$ among Hispanics to $88.4 \%$ among non-Hispanic Asians) and by approximately 32 percentage points by FPL category (range: $64.2 \%$ among adults with household income $<100 \%$ of FPL to 
95.8\% among adults with household income $>400 \%$ of FPL). The prevalence of unmet health care need because of cost varied by nearly 14 percentage points among racial/ethnic groups (range: $11.3 \%$ among non-Hispanic Asians to $25.0 \%$ among Hispanics), by approximately 17 percentage points among adults with and without disabilities (30.8\% versus 13.7\%), and by approximately 28 percentage points by FPL category (range: 5.3\% among adults with household income $>400 \%$ of FPL to $32.9 \%$ among adults with household income $<100 \%$ of FPL).

Among the 43 states that included questions from the optional module, a majority of adults reported private health insurance coverage (63.4\%), followed by public health plan coverage (19.4\%) and no primary source of insurance (17.1\%). Financial barriers to health care (unmet health care need because of cost, unmet prescribed medication need because of cost, and medical bills being paid off over time [medical debt]) were typically lower among adults in Medicaid expansion states than those in nonexpansion states regardless of source of insurance. Approximately $75.6 \%$ of adults reported being continuously insured during the preceding 12 months, $12.9 \%$ reported a gap in coverage, and $11.5 \%$ reported being uninsured during the preceding 12 months. The largest proportion of adults reported $\geq 3$ visits to a health care professional during the preceding 12 months (47.3\%), followed by $1-2$ visits (37.1\%), and no health care visits (15.6\%). Adults in expansion and nonexpansion states reported similar levels of satisfaction with received health care by primary source of health insurance coverage and by continuity of health insurance coverage during the preceding 12 months.

Interpretation: This report presents for the first time estimates of population-based health care access and use of CPS among adults aged 18-64 years. The findings in this report indicate substantial variations in health insurance coverage; other health care access measures; and use of CPS by state, state Medicaid expansion status, expanded geographic region, and FPL category. In 2014, health insurance coverage, having a usual source of care, having a routine checkup, and not experiencing unmet health care need because of cost were higher among adults living below the poverty level (i.e., household income $<100 \%$ of FPL) in states that expanded Medicaid than in states that did not. Similarly, estimates of breast and cervical cancer screening and influenza vaccination were higher among adults living below the poverty level in states that expanded Medicaid than in states that did not. These disparities might be due to larger differences to begin with, decreased disparities in Medicaid expansion states versus nonexpansion states, or increased disparities in nonexpansion states.

Public Health Action: BRFSS data from 2014 can be used as a baseline by which to assess and monitor changes that might occur after 2014 resulting from programs and policies designed to increase access to health care, reduce health disparities, and improve the health of the adult population. Post-2014 changes in health care access, such as source of health insurance coverage, attainment and continuity of coverage, financial barriers, preventive care services, and health outcomes, can be monitored using these baseline estimates.

\section{Introduction}

The number of adults with health insurance coverage fluctuates because of economic conditions, demographics, geographic location, and policy changes that affect access to health care such as the 2010 Patient Protection and Affordable Care Act (ACA). Since the 2010 passage of ACA, approximately 20 million uninsured working-aged adults (aged 18-64 years) have gained health insurance coverage (1). During 2013-2014, when many of the major coverage provisions of ACA went into effect (e.g., creation of the Health Insurance Marketplace, barring coverage exclusions for pre-existing health conditions, expansion of Medicaid, establishment of tax credits, reductions in cost sharing, and other provisions to increase availability and affordability of coverage), the percentage of working-aged adults with health insurance increased by approximately 3 percentage points, according to the Behavioral Risk Factor Surveillance System (BRFSS) and other surveys (1-7). During 2011-2014 at the state level, all but Hawaii, Maine, New Hampshire, and the
District of Columbia experienced significant gains in health insurance coverage among working-aged adults (3). Under ACA, states have the option of expanding Medicaid to increase coverage, and the gains in health insurance coverage have occurred to varying degrees in Medicaid expansion states and nonexpansion states $(1,4-6,8-13)$.

Health insurance coverage has been associated with increased access to clinical preventive services (CPS) and other medical services and, as a result, improvements in adult health (e.g., self-reported health and clinical depression), mortality, and financial security $(12,14-33)$. However, adults who lack health insurance coverage or have inadequate coverage, gaps in coverage, or difficulties accessing or navigating the U.S. health care system might delay or forgo CPS and other needed medical care (34-38). Such delays might lead to poor physical and mental health, premature mortality, increased health disparities, and increased financial risk, particularly among racial/ethnic minorities, persons with disabilities, and other vulnerable population groups (e.g., homeless persons, cancer 
survivors, or pregnant women) (35,36,38-42). In addition to increasing access to affordable insurance coverage, ACA requires most health plans to cover CPS without copays or deductibles for services given an A or B recommendation by the U.S. Preventive Services Task Force (USPSTF) (https:// www.uspreventiveservicestaskforce.org/Page/Name/uspstfa-and-b-recommendations), vaccinations recommended by the Advisory Committee on Immunization Practices (ACIP) (https://www.cdc.gov/vaccines/hcp/acip-recs/), and preventive health care services recommended by the Health Resources and Services Administration for women (https://www.hrsa.gov/ womensguidelines/) and children (https://www.aap.org/en-us/ Documents/periodicity_schedule.pdf); ACA also includes provisions aimed at improving the quality of care (43).

Population health indicators that can be used to assess national and state policies intending to improve the availability of health insurance coverage, access to CPS and other medical services, and the quality of care received are essential measures in monitoring and improving the health of adults in the United States $(5,44)$. Since 1984, national, state, and local public health professionals and policymakers have used population-based data from the BRFSS to monitor health of the adult population. Specifically, BRFSS has provided uniformly collected state-specific data on demographic characteristics, health-related behaviors, chronic health conditions, health care access, and use of preventive health services that are associated with the leading causes of death and disability in the United States.

This report summarizes 2014 BRFSS data on health care access and use of selected CPS recommended by USPSTF and ACIP among working-aged adults (aged 18-64 years), by state, state Medicaid expansion status, expanded geographic region, and federal poverty level (FPL). This report also provides analysis of primary type of health insurance coverage at the time of interview, continuity of health insurance coverage during the preceding 12 months, and other health care access measures (i.e., cost barrier to prescribed medication need, medical bills being paid off over time [medical debt], number of health care visits in the preceding 12 months, and satisfaction with received health care) in states that included an optional Health Care Access module in the 2014 BRFSS survey. The state-specific BRFSS data were collected during the first year that several provisions of ACA went into effect; therefore, findings in this report might provide public health professionals, policymakers, and researchers a baseline to monitor effects that might occur after 2014 of programs and policies designed to increase access to health care, reduce health disparities, and improve the health of the adult population.

\section{Methods}

To assess health insurance coverage, access to health care, and use of selected CPS recommended by USPSTF and ACIP by state, state Medicaid expansion status, expanded geographic region, and FPL among noninstitutionalized adults aged 18-64 years, CDC analyzed 2014 BRFSS data from 50 states and the District of Columbia (hereafter referred to as states) (Figure 1). To further assess health care access, CPS use, number of health care visits during the preceding 12 months, and satisfaction with received health care among workingaged adults by type of insurance coverage (i.e., public, private) and continuity of coverage during the preceding 12 months (i.e., continuously insured, gaps in coverage, uninsured) and state Medicaid expansion status, CDC analyzed 2014 data from 43 states that used questions from an optional BRFSS Health Care Access module. These states were Alabama, Alaska, Arizona, Colorado, Connecticut, Delaware, District of Columbia, Georgia, Idaho, Illinois, Indiana, Iowa, Kentucky, Louisiana, Maine, Maryland, Massachusetts, Michigan, Minnesota, Mississippi, Missouri,* Montana, Nebraska, Nevada, New Hampshire, New Jersey, New Mexico, New York, North Carolina, North Dakota, Ohio, Oklahoma, Oregon, Pennsylvania, Rhode Island, South Carolina, Tennessee, Utah, Vermont, Virginia, Washington, West Virginia, and Wisconsin.

\section{Project Description}

BRFSS is an ongoing, state-based system of landline- and cellular-telephone health surveys $(45,46)$. Since 1984, BRFSS has provided state-specific, population-based data on demographic characteristics, health risk behaviors, health care access, and use of CPS that are associated with the leading causes of illness, disability, and death in the United States. BRFSS uses a multistage sampling design to select a representative sample of the noninstitutionalized civilian population aged $\geq 18$ years residing in states and participating U.S. territories. Additional details on survey methodology, random sampling procedures, design, and reliability and validity of measures used in BRFSS have been described elsewhere $(47,48)$.

In 2014 , a total of 456,119 adults aged $\geq 18$ years completed interviews by landline and cellular telephones in all states. For data collected by landline telephone, 293,226 respondents completed the interview and the number of respondents ranged from 2,371 in Nevada to 12,962 in Nebraska (median: 4,981). For data collected by cellular telephone, 162,893 respondents completed the interview and the number of respondents ranged from 798 in the District of Columbia to 9,952 in Nebraska (median: 2,906). Response rates for BRFSS were calculated

\footnotetext{
* Missouri included these questions in the state-added section of its survey; these data are available from the Missouri Department of Health and Senior Services.
} 
FIGURE 1. Expanded geographic regions* and state Medicaid expansion status ${ }^{\dagger}$ as of January 1, 2014

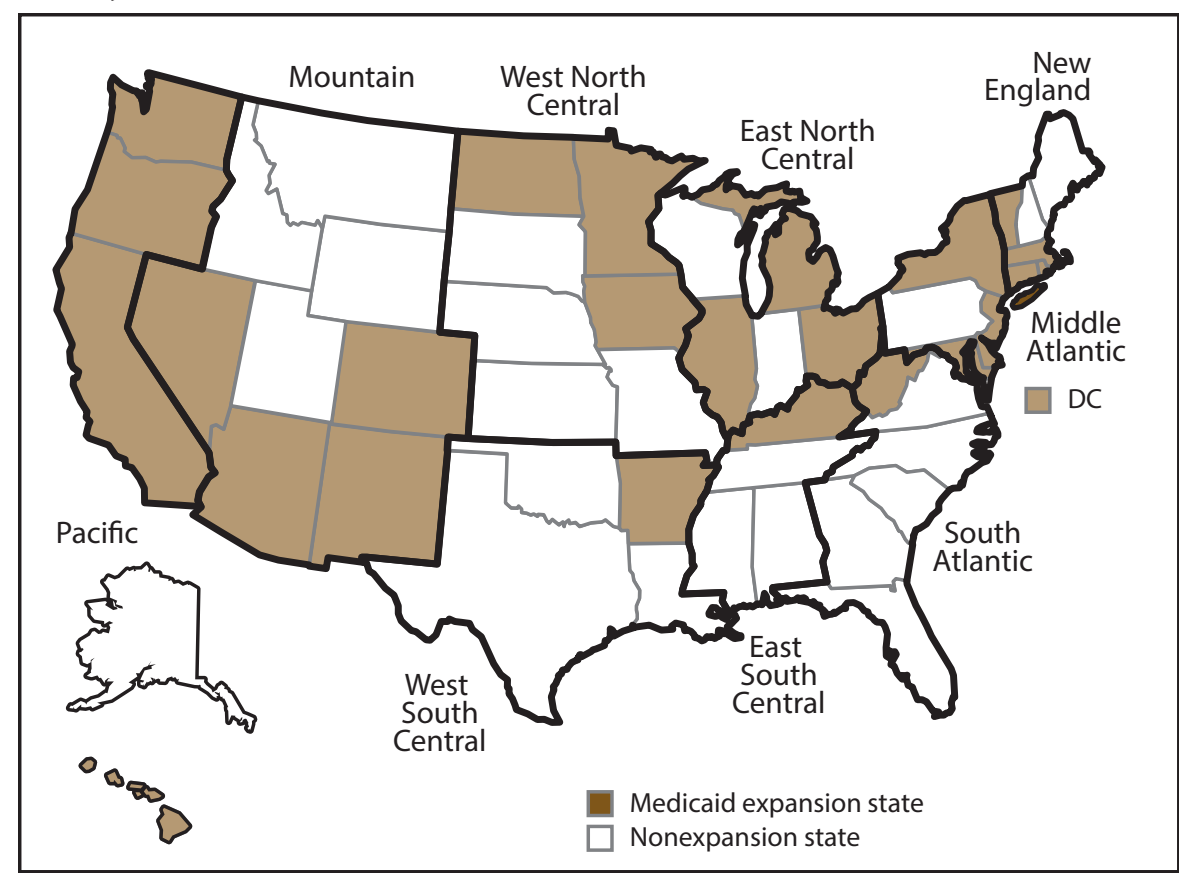

Abbreviation: DC = District of Columbia.

* Expanded geographic regions are the four U.S. census regions subdivided into nine regions. For this report, the nine census regions were modified by moving Delaware, District of Columbia, and Maryland into the Middle Atlantic region. New England: Connecticut, Maine, Massachusetts, New Hampshire, Rhode Island, and Vermont. Middle Atlantic: Delaware, District of Columbia, Maryland, New Jersey, New York, and Pennsylvania. East North Central: Illinois, Indiana, Michigan, Ohio, and Wisconsin. West North Central: lowa, Kansas, Minnesota, Missouri, Nebraska, North Dakota, and South Dakota. South Atlantic: Florida, Georgia, North Carolina, South Carolina, Virginia, and West Virginia. East South Central: Alabama, Kentucky, Mississippi, and Tennessee. West South Central: Arkansas, Louisiana, Oklahoma, and Texas. Mountain: Arizona, Colorado, Idaho, Montana, Nevada, New Mexico, Utah, and Wyoming. Pacific: Alaska, California, Hawaii, Oregon, and Washington.

† States were categorized by Medicaid expansion status as of January 1,2014, into two groups: Medicaid expansion states $(n=26)$ and nonexpansion states $(n=25)$. Medicaid expansion states: Arizona, Arkansas, California, Colorado, Connecticut, Delaware, District of Columbia, Hawaii, Illinois, lowa, Kentucky, Maryland, Massachusetts, Michigan, Minnesota, Nevada, New Jersey, New Mexico, New York, North Dakota, Ohio, Oregon, Rhode Island, Vermont, Washington, and West Virginia. Nonexpansion states: Alabama, Alaska, Florida, Georgia, Idaho, Indiana, Kansas, Louisiana, Maine, Mississippi, Missouri, Montana, Nebraska, New Hampshire, North Carolina, Oklahoma, Pennsylvania, South Carolina, South Dakota, Tennessee, Texas, Utah, Virginia, Wisconsin, and Wyoming.

using the standard set by the American Association of Public Opinion Research response rate formula 4 (RR4), which is the number of respondents who completed the survey as a proportion of all eligible and likely eligible persons (15). For landline telephone data, the RR4 response rate ranged from $26.7 \%$ in California to $61.6 \%$ in Kentucky (median: $48.7 \%$ ); for cellular telephone data, the RR4 response rate ranged from $22.2 \%$ in California to $60.0 \%$ in Alaska (median: $40.5 \%$ ). For combined landline telephone and cellular telephone data, the weighted response rate (determined using a combination of the landline telephone response rate with the cellular telephone response rate proportional to the total sample used to collect the data for a state) ranged from $25.1 \%$ in California to $60.1 \%$ in South Dakota (median: 47.0\%). Detailed information on response, cooperation, and refusal rates for landline and cellular telephone data collection, including data from participating territories, can be found in the BRFSS 2014 Summary Data Quality Report (49).

\section{Data Collection}

Trained interviewers use a standardized BRFSS data collection process to collect uniform data (50). The standard BRFSS questionnaire consists of three sections: 1) core questions, 2) optional modules that include sets of questions on specific topics, and 3) state-added questions. Trained interviewers ask the same core questions of survey respondents (45). States can select from optional BRFSS modules and include state-added questions according to the specific needs and goals of the programs in their health departments.

In 2014, all states collected answers to the core questions via landline and cellular telephones, as did 43 states that asked questions from the optional Health Care Access module. As in previous years, 2014 BRFSS included four health care access measures (i.e., health insurance coverage, usual health care provider, cost barrier to health care need, and receipt of a routine checkup) and selected CPS recommended by USPSTF (i.e., colorectal, breast, and cervical cancer screenings and human immunodeficiency virus [HIV] testing) and for selected vaccinations recommended by ACIP (e.g., influenza vaccination) in the core survey module (51). In 2014, BRFSS included an optional Health Care Access module that assessed primary source of health insurance coverage, continuity of health insurance during the preceding 12 months, cost barrier to prescribed medication need, medical debt (i.e., medical bills being paid off over time), number of health care visits during the preceding 12 months, and satisfaction with received health care (51).

\section{Questionnaire}

For this report, four health care access measures and five CPS recommended by USPSTF or ACIP for which data are collected in the core section of BRFSS by all states were analyzed (Box 1). In addition, the following health care access measures derived from questions in the optional Health Care Access module 


\begin{tabular}{|c|c|c|}
\hline Measure & Definition & Age group (yrs) \\
\hline \multicolumn{3}{|l|}{ Health care access } \\
\hline Health insurance coverage & Had any kind of health care coverage at the time of interview & $18-64$ \\
\hline Usual source of health care & Had personal doctor(s) or health care provider(s) & $18-64$ \\
\hline Cost barrier to health care need & Had unmet health care need because of cost during preceding 12 months & $18-64$ \\
\hline Routine medical checkup & Received routine checkup within preceding 12 months & $18-64$ \\
\hline \multicolumn{3}{|l|}{ Clinical preventive services } \\
\hline Breast cancer screening ${ }^{\dagger}$ & Received mammogram in past 2 years (women) & $50-64$ \\
\hline Cervical cancer screening & Received Pap test in past 3 years (women with an intact uterus) & $21-64$ \\
\hline Colorectal cancer screening & $\begin{array}{l}\text { Received FOBT within the past year, or sigmoidoscopy within the past } 5 \text { years and } \\
\text { an FOBT within the past } 3 \text { years, or colonoscopy within the past } 10 \text { years }\end{array}$ & $50-64$ \\
\hline HIV test & Ever received HIV test (excluding tests done for blood donations) & $18-64$ \\
\hline Influenza immunization & Received influenza vaccine in past year & $18-64$ \\
\hline
\end{tabular}

conducted in 43 states were summarized: primary type of health insurance coverage at the time of interview, continuity of health insurance coverage during the preceding 12 months, cost barrier to prescribed medication, medical debt, number of health care visits during the preceding 12 months, and satisfaction with received health care (Box 2).

In the survey's core section, respondents were asked whether they had any kind of health care coverage, including health insurance, prepaid plans such as health maintenance organizations, government plans such as Medicare, or Indian Health Service (IHS). Respondents who answered yes were defined as having health insurance coverage at the time of interview. Responses for having a usual health care provider were dichotomized into one or more and none, and responses for having had a routine checkup within the preceding 12 months were dichotomized into within the past year or not within the past year. Cost barrier to health care need during the preceding 12 months was assessed with the question "Was there a time in the past 12 months when you needed to see a doctor but could not because of cost?" Respondents who answered yes were defined as having unmet health care need because of cost during the preceding 12 months.

To summarize these measures, states were categorized by Medicaid expansion status and expanded geographic region and respondents by FPL. Under ACA, effective January 1, 2014, states can choose at any time to expand Medicaid eligibility to adults in households with incomes $\leq 138 \%$ of FPL. For analysis, states were categorized by Medicaid expansion status as of January 1, 2014, into two groups: Medicaid expansion states $(\mathrm{n}=26)$ and nonexpansion states $(\mathrm{n}=25)$ (Figure 1). The Medicaid expansion states were Arizona, Arkansas, California, Colorado, Connecticut, Delaware, District of Columbia, Hawaii, Illinois, Iowa, Kentucky, Maryland, Massachusetts,
Michigan, ${ }^{\dagger}$ Minnesota, Nevada, New Jersey, New Mexico, New York, North Dakota, Ohio, Oregon, Rhode Island, Vermont, Washington, and West Virginia. The nonexpansion states were Alabama, Alaska, Florida, Georgia, Idaho, Indiana, Kansas, Louisiana, Maine, Mississippi, Missouri, Montana, Nebraska, New Hampshire, ${ }^{\S}$ North Carolina, Oklahoma, Pennsylvania, South Carolina, South Dakota, Tennessee, Texas, Utah, Virginia, Wisconsin, and Wyoming.

Similar to methodology used by the National Center for Health Statistics (7) and other researchers (52), the four U.S. census regions were subdivided into nine geographic regions. The regions were then modified by moving Delaware, the District of Columbia, and Maryland into the Middle Atlantic region. The expanded geographic regions and respective states were New England (Connecticut, Maine, Massachusetts, New Hampshire, Rhode Island, and Vermont); Middle Atlantic (Delaware, District of Columbia, Maryland, New Jersey, New York, and Pennsylvania); East North Central (Illinois, Indiana, Michigan, Ohio, and Wisconsin); West North Central (Iowa, Kansas, Minnesota, Missouri, Nebraska, North Dakota, and South Dakota); South Atlantic (Florida, Georgia, North Carolina, South Carolina, Virginia, and West Virginia); East South Central (Alabama, Kentucky, Mississippi, and Tennessee); West South Central (Arkansas, Louisiana, Oklahoma, and Texas); Mountain (Arizona, Colorado, Idaho, Montana, Nevada, New Mexico, Utah, and Wyoming); and Pacific (Alaska, California, Hawaii, Oregon, and Washington) (Figure 1).

\footnotetext{
${ }^{\dagger}$ Michigan implemented Medicaid expansion on April 1,2014, and is categorized as a Medicaid expansion state because the expansion was in effect for the majority of the year.

${ }^{\S}$ New Hampshire implemented Medicaid expansion on August 15, 2014, and is categorized as a Medicaid nonexpansion state because the expansion was not in effect for the majority of the year.
} 
1) Do you have Medicare?

2) What is the primary source of your health care coverage? Is it ... a plan purchased through an employer or union (includes plans purchased through another person's employer); a plan that you or another family member buys on your own; Medicare; Medicaid or other state program; TRICARE (formerly CHAMPUS), VA, or military; Alaska Native, Indian Health Service, Tribal Health Services; or some other source; none (no coverage)?

Interviewer note: If the respondent indicates that they purchased health insurance through the Health Insurance Marketplace (name of state marketplace), ask if it was a private health insurance plan purchased on their own or by a family member (private) or if they received Medicaid (state plan)? If purchased on their own (or by a family member), select 02 (a plan that you or another family member buys on your own), if Medicaid select 04 (Medicaid or other state program).

3) Other than cost, there are many other reasons people delay getting needed medical care. Have you delayed getting needed medical care for any of the following reasons in the past 12 months? Select the most important reason. You couldn't get through on the telephone; you couldn't get an appointment soon enough; once you got there, you had to wait too long to see the doctor; the (clinic/doctor's) office wasn't open when you got there; or you didn't have transportation.

4a) If respondent has health care coverage, ask: In the past 12 months was there any time when you did not have any health insurance or coverage?

4b) If respondent does not have health care coverage, doesn't know, or refused to answer, ask: About how long has it been since you last had health care coverage?

5) How many times have you been to a doctor, nurse, or other health professional in the past 12 months?

6) Was there a time in the past 12 months when you did not take your medication as prescribed because of cost? Do not include over-the-counter (OTC) medication.

7) In general, how satisfied are you with the health care you received? Would you say very satisfied, somewhat satisfied, or not at all satisfied?

8) Do you currently have any medical bills that are being paid off over time?

Interviewer note: This could include medical bills being paid off with a credit card, through personal loans, or bill paying arrangements with hospitals or other providers. The bills can be from earlier years as well as this year.

Interviewer note: Health care bills can include medical, dental, physical therapy, and/or chiropractic cost.

Abbreviation: $\mathrm{VA}=$ Veterans Affairs

* In this report, data were analyzed from 41 states and the District of Columbia that fielded the questions as an optional BRFSS module and for one state (Missouri) that fielded the questions as state-added questions. The data for 41 states and the District of Columbia are available as public use data sets on the BRFSS website at https://www.cdc.gov/brfss/annual_data/annual_2014.html. Data from Missouri are available from the Missouri Department of Health and Senior Services.

ACA provides tax credits to assist with the cost of health insurance premiums for persons in households with incomes between $100 \%$ and $400 \%$ of FPL. In Medicaid expansion states, persons in households with incomes between $0 \%$ and $400 \%$ of FPL are eligible for coverage options through tax credits and expanded Medicaid eligibility ( $\leq 138 \%$ of FPL). In nonexpansion states, persons in households with incomes between $100 \%$ and $400 \%$ of FPL are eligible for a tax credit to assist with the cost of coverage, but no new financial assistance was provided for those with household incomes below 100\% of FPL. FPL categories for 2014 tax credit eligibility were determined on the basis of the ratio of the adult's annual household income to the appropriate simplified 2013 federal poverty threshold (given family size and number of children) defined by FPL Guidelines for the Health Insurance Marketplace (53). Three core variables were used to calculate federal poverty threshold: 1) annual household income, 2) number of adults (1-14) in the household, and $3)$ number of children $(\geq 0)$ in the household. Federal poverty thresholds were then used to categorize respondents into four FPL categories: 1 ) $<100 \%$ of FPL, 2 ) $\geq 100 \%-\leq 400 \%$ of FPL, 3) $>400 \%$ of FPL, and 4) unknown. Additional details on this variable have been described elsewhere (54).

The following sociodemographic characteristics were described overall and by state for two health care access measures (health insurance at the time of interview and unmet health care need because of cost): age (18-24, 25-44, and 45-64 years); sex; race/ethnicity (non-Hispanic white, non-Hispanic black, Hispanic, non-Hispanic Asian, non-Hispanic American Indian or Alaskan Native [AIAN], non-Hispanic Native Hawaiian or other Pacific Islander [NHPI], non-Hispanic multiple race, and other); educational attainment (less than high school, high school, and greater than high school); marital status (married, previously married [including divorced, widowed, 
and separated] and never married or member of an unmarried couple); employment status (employed, unemployed, or not in labor market [including homemaker, student, retired, and unable to work]); FPL $(<100 \%, \geq 100 \%-\leq 400 \%,>400 \%$, or unknown); and self-reported disability indicated by a yes response to either of two questions: 1) "Are you limited in any way in any activities because of physical, mental, or emotional problems?" and 2) "Do you now have any health problem that requires you to use special equipment, such as a cane, a wheelchair, a special bed, or a special telephone?"

Data from 43 states that administered questions from the optional Health Care Access module were analyzed for the following measures: health care access and CPS measures (Box 1); cost barrier to prescribed medication need during the preceding 12 months; medical bills being paid off over time (i.e., medical debt); number of health care visits during the preceding 12 months; and satisfaction with received health care, by type of insurance coverage (i.e., none, public, private) and continuity of coverage during the preceding year (i.e., continuously insured, a gap or gaps in coverage, uninsured), by state Medicaid expansion status and FPL. To classify respondents by type of health insurance, respondents were asked the core question that assessed health insurance coverage at the time of interview and the optional module question: "What is the primary source of your health care coverage? Is it a plan purchased through an employer or union (includes plans purchased through another person's employer); a plan that you or another family member buys on your own; Medicare; Medicaid or other state program; TRICARE (formerly CHAMPUS), VA [Veterans Affairs], or military; Alaska Native, Indian Health Service, Tribal Health Services; or some other source?" Respondents were then categorized into three groups: 1) no primary source of health care coverage, 2) public health plan coverage, and 3) private health insurance coverage. No primary source of health care coverage included respondents who answered no to the core question as well as respondents who answered yes but, subsequently, indicated they had no primary source of health care coverage (i.e., none). The public health plan coverage category was defined as Medicare, Medicaid or other state program, military (i.e., TRICARE, VA [Veterans Affairs], or military), IHS (i.e., Alaska Native, Indian Health Service, or Tribal Health Services), or some other source. The private health insurance coverage category was defined as an employer-based plan or a self-purchased plan (i.e., a plan that a person or another family member buys on their own).

To classify respondents by continuity of coverage during the preceding year, the core question was used that assessed health insurance coverage at the time of interview, as well as two optional module questions: 1 ) "In the past 12 months was there any time when you did not have any health insurance or coverage?" and 2) "About how long has it been since you last had health care coverage?" Respondents were then categorized into three groups: 1) continuously insured in the preceding 12 months before interview, 2) having a gap in insurance in the preceding 12 months before interview, and 3) having no health insurance for $>12$ months. The continuously insured category included respondents who were insured and had not been uninsured at any time in the preceding 12 months. The gap in insurance category included respondents who were insured but had been uninsured at some time during the preceding 12 months or who were uninsured but had been insured at some time during the preceding 12 months. The no health insurance category included respondents who were uninsured and had been uninsured for $>12$ months.

The optional Health Care Access module included asking respondents how many times they had been to a health care professional during the preceding year. Number of health care visits was categorized as none, $1-2$, and $\geq 3$. Among respondents who had $\geq 1$ health care visit, health care satisfaction was assessed using the question "In general, how satisfied are you with the health care you received? Would you say very satisfied, satisfied, or not at all satisfied?" Data from the optional module were also examined for the following financial-related barriers to medical care: cost barrier to prescribed medication need during the preceding 12 months and health care bills that are being paid off over time (Box 2).

\section{Data Weighting and Statistical Analysis}

An iterative proportional fitting (or raking) was used to weight each state in the BRFSS. BRFSS raking includes categories of age by gender, detailed race/ethnicity groups, educational attainment, marital status, regions within states, sex by race/ ethnicity, telephone source, home renter or owner status, and age group by race/ethnicity. Raking adjusts the data so that groups underrepresented in the sample are more accurately represented in the final data set, and this weighting method has been shown to reduce bias within estimates (47). In 2014, the inclusion of cellular telephone respondents who also have landline telephones in their household required an adjustment to the design weights to account for the overlapping sample (55).

For the optional Health Care Access module, four states (Colorado, Indiana, Maine, and Oklahoma) used multiple questionnaires to collect data on a subset of the state sample rather than on the entire sample. For these states, the survey weights provided in the multiple questionnaire data files were used. Details on the weighting methodology and the weights to be used for each of these states have been described elsewhere $(54,56)$. 
To account for the complex sampling design of BRFSS, all the prevalence estimates were computed on the basis of a statistical analysis (SAS version 9.3, SAS Institute Inc., Cary, North Carolina, USA; SAS-callable SUDAAN version 11.0.1, RTI International, Research Triangle Park, North Carolina, USA) using weights and strata. Prevalence estimates are presented as percentages with 95\% confidence intervals (CI). Both crude and age-standardized (standardized to the 2000 projected U.S. population) (57) prevalence estimates are provided in all tables but, unless otherwise noted, only age-standardized estimates are provided in the text. Prevalence estimates are not presented if the sample size for the denominator was $<50$ or the relative standard error (RSE) was $>30 \%$. Prevalence estimates are flagged as unstable if the RSE is $20 \%-30 \%$. RSE was calculated by dividing the standard error by the estimated prevalence and multiplying by 100 (for percent). Differences were considered statistically significant if the CIs of the age-standardized estimates did not overlap. While the use of CIs in this way is conservative, it might identify some estimates as similar when they are statistically different.

\section{Results}

\section{Health Care Access, Overall and by State}

\section{Health Insurance Coverage}

Of 299,157 BRFSS respondents aged 18-64 years, 297,734 answered the question on insurance coverage; among these adults, 82.4\% ( $\mathrm{n}=262,611 ; \mathrm{N}=163.8$ million) reported having health insurance at the time of the interview. The median estimated prevalence of adults who were insured at the time of interview was $84.2 \%$ but varied by state. For example, $94.5 \%$ and $91.2 \%$ were insured in Massachusetts and Vermont, respectively, whereas $74.6 \%$ and $70.8 \%$ were insured in Georgia and Texas, respectively (Table 1) (Figure 2). The estimated prevalence of insurance coverage was higher for adults aged $45-64$ years $(88.0 \%)$ than for adults aged $18-24$ years $(79.9 \%)$ and $25-44$ years $(79.0 \%)$ (Figure 3$)$. The estimated prevalence of insurance coverage was higher among women $(84.0 \%)$ than men $(80.8 \%)$. By race/ethnicity, the estimated prevalence for adults insured at the time of interview was as follows: $63.9 \%$ (Hispanic), 80.0\% (non-Hispanic black), 82.6\% (non-Hispanic NHPI), 83.5\% (non-Hispanic multiple race), $84.0 \%$ (non-Hispanic AIAN), 84.6\% (nonHispanic other race), $88.0 \%$ (non-Hispanic white), and 88.4\% (non-Hispanic Asian). The estimated prevalence of insurance coverage at the time of interview increased with
FIGURE 2. Age-standardized* prevalence estimates of current health insurance coverage ${ }^{\dagger}$ among adults aged 18-64 years - Behavioral Risk Factor Surveillance System, United States, ${ }^{\S} 2014$

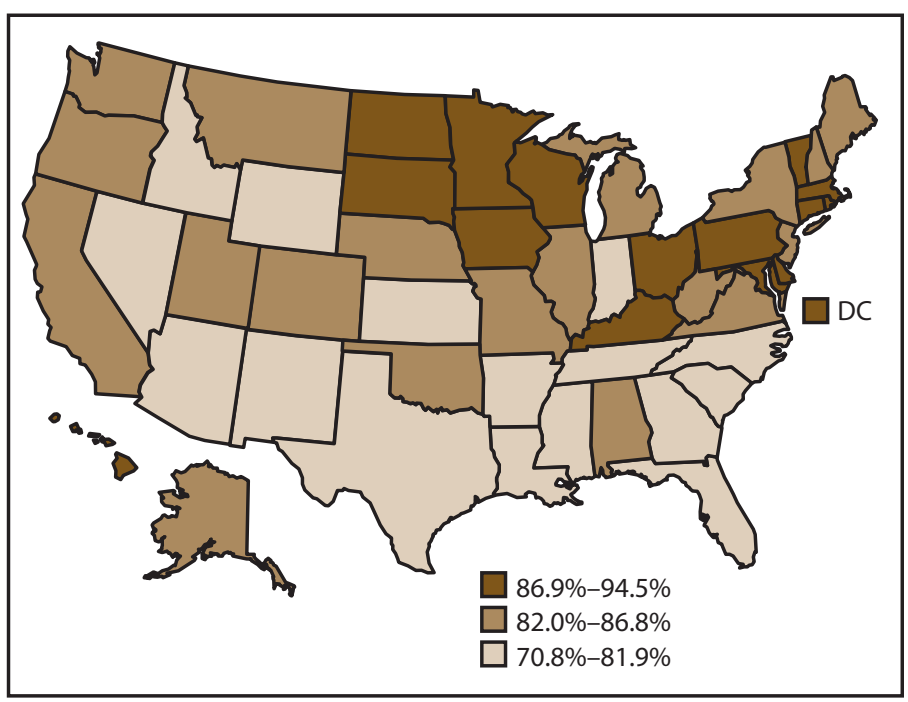

Abbreviation: $\mathrm{DC}=$ District of Columbia.

* Age standardized to the 2000 projected population for the United States.

† Survey question used to assess current health insurance coverage: Do you have any kind of health care coverage, including health insurance, prepaid plans such as health maintenance organizations, government plans such as Medicare, or Indian Health Service?

$\S$ States are divided into tertiles.

increasing level of educational attainment: $59.6 \%$ of adults with less than high school education, $78.7 \%$ of adults with a high school education, and $89.8 \%$ of adults with greater than high school education had insurance coverage. Married adults $(86.7 \%)$ were more likely to be insured at the time of interview than those who were previously married (divorced, separated, widowed) $(73.9 \%)$ or never married $(76.9 \%)$. A majority of employed adults $(84.1 \%)$ were insured at the time of interview, whereas $62.5 \%$ of unemployed adults were insured. Adults with household income $<100 \%$ of FPL were less likely to be insured $(64.2 \%)$ than adults in other income groups (80.8\% and $95.8 \%$ among adults with household income $\geq 100 \%-\leq 400 \%$ of FPL and $>400 \%$ of FPL, respectively). No difference in the estimated prevalence of insurance coverage by disability status was found. Unadjusted state-specific estimates of insurance coverage by sociodemographic characteristics are available at (supplemental Table S1 https://stacks.cdc.gov/ view/cdc/43255).

\section{Usual Source of Health Care}

Among adults aged 18-64 years, the median estimated prevalence of having a usual source of health care was $71.2 \%$. The range was $57.2 \%$ in Nevada to $86.6 \%$ in Massachusetts (Table 1) (Figure 4). 
FIGURE 3. Age-standardized* prevalence estimates of current health insurance coverage among adults aged 18-64 years, by sociodemographic characteristics - Behavioral Risk Factor Surveillance System, United States, 2014

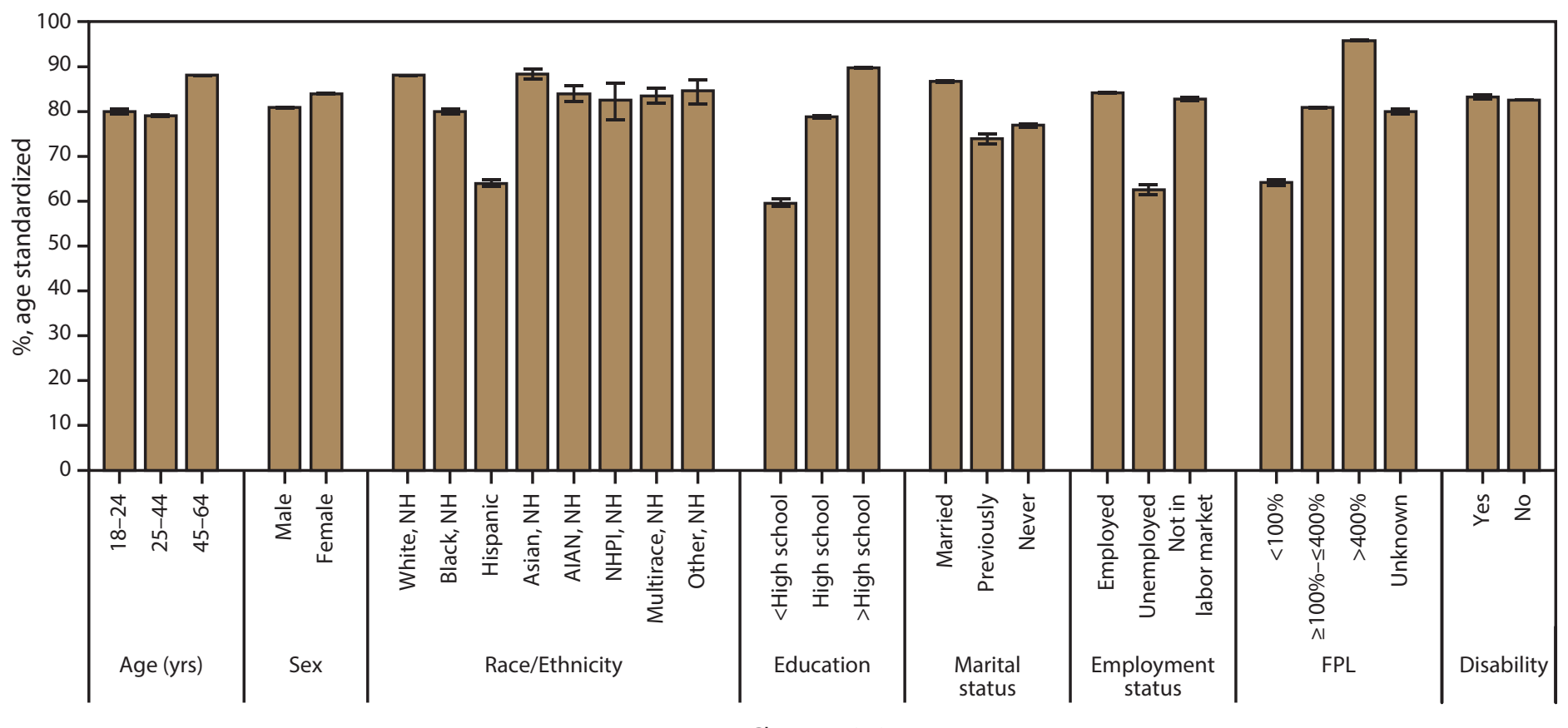

Characteristic

Abbreviations: AIAN = American Indian or Alaskan Native; FPL = federal poverty level; $\mathrm{NH}=$ non-Hispanic; $\mathrm{NHPI}=\mathrm{Native} \mathrm{Hawaiian} \mathrm{or} \mathrm{other} \mathrm{Pacific} \mathrm{Islander.}$

* Age standardized to the 2000 projected U.S. population, except for age groups. Bars represent $95 \%$ confidence intervals.

FIGURE 4. Age-standardized* prevalence estimates of usual source of health care ${ }^{\dagger}$ among adults aged 18-64 years - Behavioral Risk Factor Surveillance System, United States,§ 2014

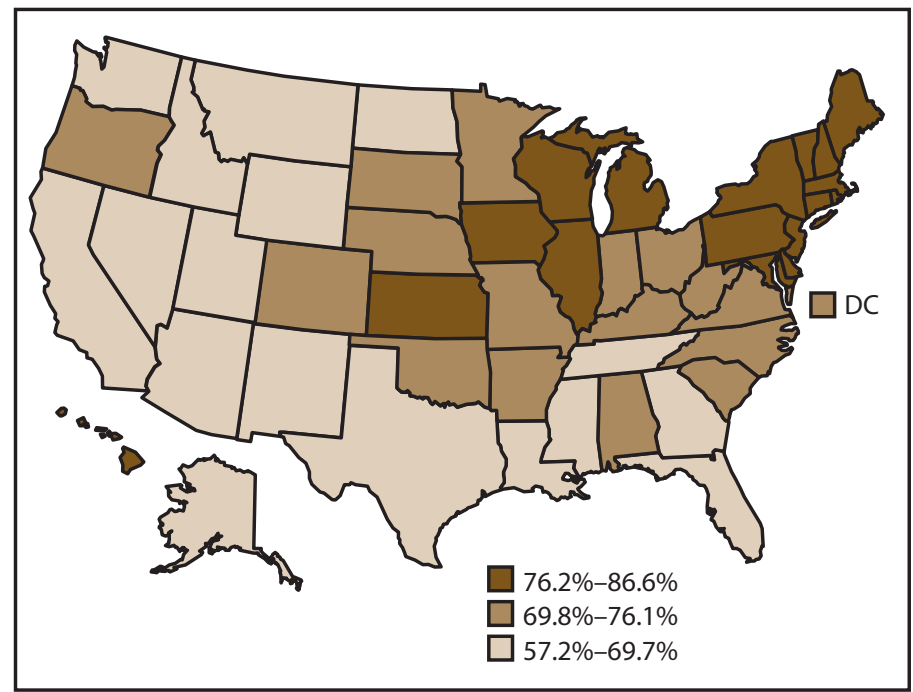

Abbreviation: $\mathrm{DC}=$ District of Columbia.

* Age standardized to the 2000 projected population for the United States.

t Survey question used to assess usual source of health care: Do you have one person you think of as your personal doctor or health care provider?

$\S$ States are divided into tertiles.
FIGURE 5. Age-standardized* prevalence estimates of routine checkup ${ }^{\dagger}$ within preceding 12 months among adults aged 18-64 years Behavioral Risk Factor Surveillance System, United States, $\$ 2014$

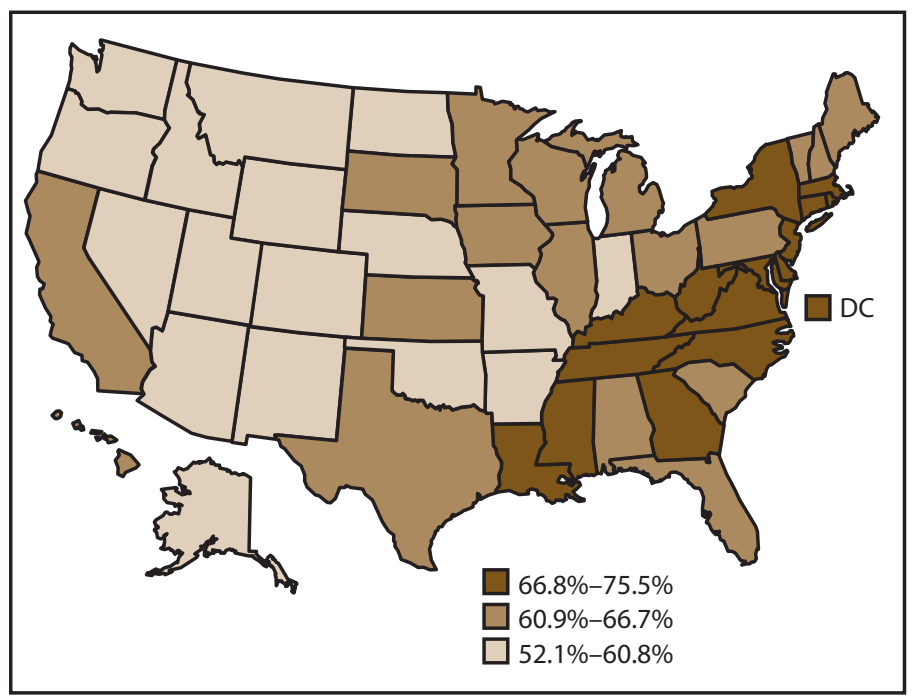

Abbreviation: $\mathrm{DC}=$ District of Columbia.

* Age standardized to the 2000 projected population for the United States.

† Survey question used to assess routine checkup within preceding 12 months: About how long has it been since you last visited a doctor for a routine checkup? A routine checkup is a general physical exam, not an exam for a specific injury, illness, or condition.

$\S$ States are divided into tertiles. 


\section{Routine Checkup within the Preceding 12 Months}

Among adults aged 18-64 years, the median estimated prevalence of receiving a routine checkup within the preceding 12 months was $64.5 \%$. The range was $52.1 \%$ in Idaho to $75.5 \%$ in Rhode Island (Table 1) (Figure 5).

\section{Unmet Health Care Need Because of Cost}

Among adults aged 18-64 years, the median estimated prevalence of unmet health care need because of cost during the preceding 12 months was $15.3 \%$ and ranged from $8.0 \%$ in North Dakota to $23.1 \%$ in Mississippi (Table 1) (Figure 6). The estimated prevalence of unmet health care need because of cost was higher for adults aged 25-44 years (18.9\%) than for adults aged $18-24$ years $(14.4 \%)$ and $45-64$ years $(15.0 \%)$ (Figure 7). The estimated prevalence of unmet health care need because of cost was higher among women (19.4\%) than men $(14.2 \%)$. By race/ethnicity, the estimated prevalence of adults reporting unmet health care need because of cost was as follows: 11.3\% (non-Hispanic Asian), 13.9\% (nonHispanic white), 14.4\% (non-Hispanic other race), 14.9\% (non-Hispanic NHPI), 18.4\% (non-Hispanic AIAN), 21.0\% (non-Hispanic black), 21.2\% (non-Hispanic multiple race), and $25.0 \%$ (Hispanic). The estimated prevalence of unmet health care need because of cost decreased with increasing level of educational attainment: $29.8 \%$ of adults with less than high school education, $18.7 \%$ of adults with a high school education, and $12.8 \%$ of adults with greater than high school education had unmet health care need because of cost. By marital status, $13.9 \%$ of married adults had unmet health care need because of cost, whereas $20.2 \%$ of never married adults and $26.2 \%$ of previously married (divorced, separated, widowed) adults had unmet health care need because of cost. By employment status, $14.4 \%$ of employed adults had unmet health care need because of cost, whereas $20.0 \%$ of adults not in the labor market and $31.9 \%$ of unemployed adults reported a cost barrier to health care need. Adults with household income $<100 \%$ of FPL were the most likely to have unmet health care need because of cost $(32.9 \%)$, compared with adults in other income groups (19.5\% and 5.3\% among adults with household income $\geq 100 \%-\leq 400 \%$ of FPL and $>400 \%$ of FPL, respectively). The estimated prevalence of unmet health care need because of cost was higher for adults with disabilities (30.8\%) than for adults without disabilities (13.7\%). Crude state-specific estimates of cost barrier to health care need during the preceding 12 months by sociodemographic characteristics are available (supplemental Table S2 https://stacks.cdc.gov/view/cdc/43255).
FIGURE 6. Age-standardized* prevalence estimates of cost barrier to health care need during preceding 12 months ${ }^{\dagger}$ among adults aged 18-64 years - Behavioral Risk Factor Surveillance System, United States, $\$ 2014$

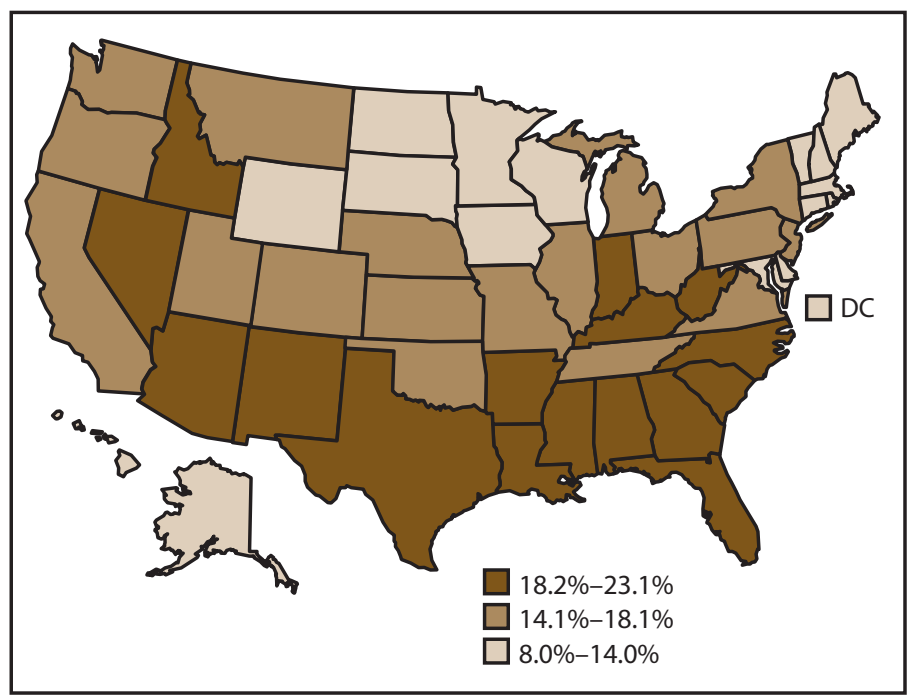

Abbreviation: $\mathrm{DC}=$ District of Columbia.

* Age standardized to the 2000 projected population for the United States.

t Survey question used to assess cost barrier to health care need during preceding 12 months: Was there a time in the past 12 months when you needed to see a doctor but could not because of cost?

$\S$ States are divided into tertiles.

\section{Health Care Access by State Medicaid Expansion Status, Expanded Geographic Region, and FPL}

Under provisions of ACA, states have the option to expand Medicaid coverage to persons in households with incomes $\leq 138 \%$ of FPL (Figure 1). In Medicaid expansion states, the median estimated prevalence of working-aged adults who were insured at the time of interview was $87.0 \%$ and ranged from $78.8 \%$ in Nevada to $94.5 \%$ in Massachusetts (Table 1). In nonexpansion states, the median estimated prevalence of insurance coverage at the time of interview was $81.9 \%$ and ranged from $70.8 \%$ in Texas to $89.1 \%$ in Wisconsin (Table 1). In the nine expanded geographic regions, the estimated prevalence of insurance coverage at time of interview ranged from $73.3 \%$ in the West South Central region to 91.0\% in the New England region (Table 2). The estimated prevalence of adults who were insured at the time of interview increased with increasing level of income (\% of FPL) in Medicaid expansion states and nonexpansion states and in each expanded geographic region. For example, in the West South Central region, the estimated prevalence of insurance coverage at the time of interview was $47.0 \%$ among adults with household income $<100 \%$ of FPL, $72.9 \%$ among adults 
FIGURE 7. Age-standardized* prevalence estimates of cost barrier to health care need during preceding 12 months among adults aged 18-64 years, by sociodemographic characteristics — Behavioral Risk Factor Surveillance System, United States, 2014

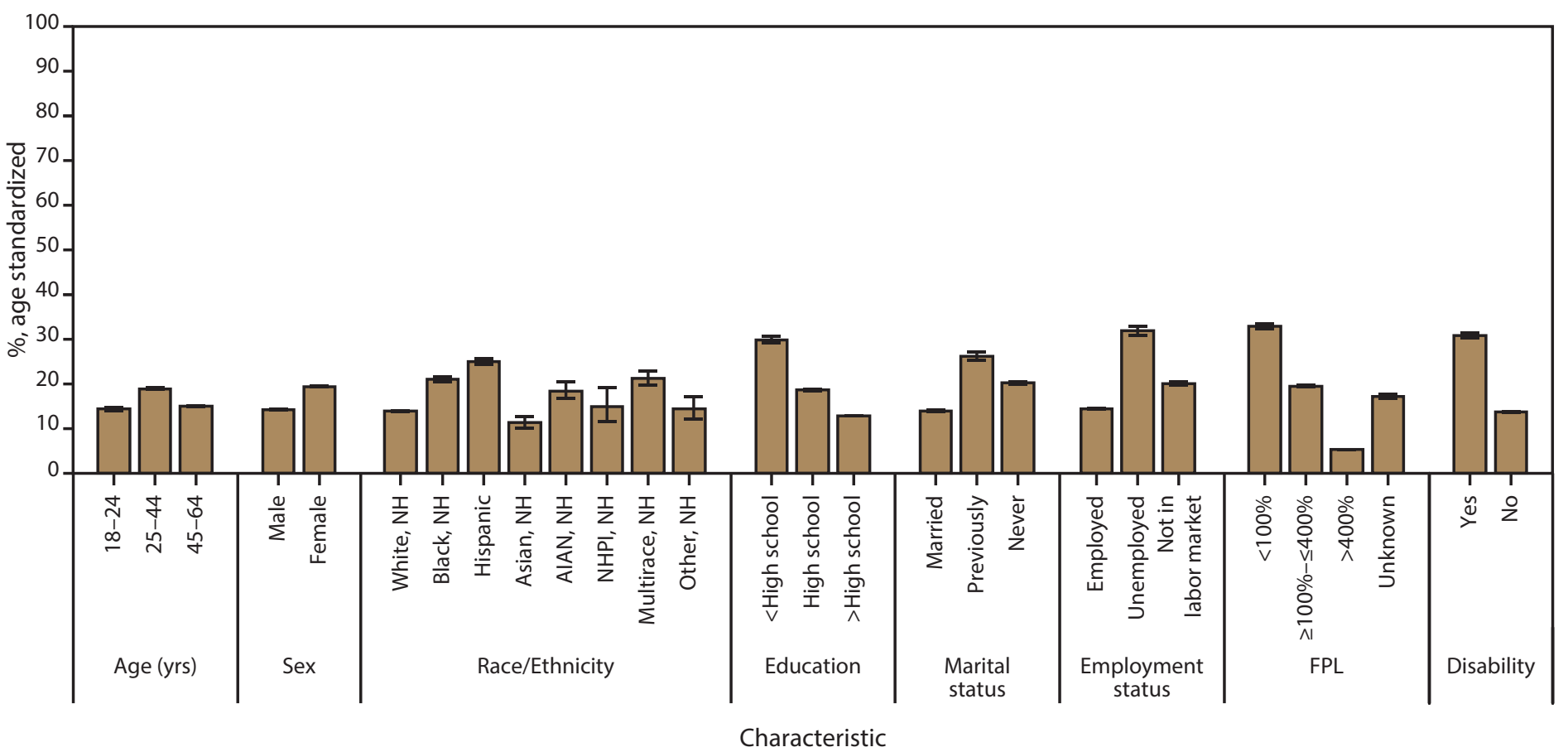

Abbreviations: $\mathrm{AIAN}=$ American Indian or Alaskan Native; $\mathrm{FPL}=$ federal poverty level; $\mathrm{NH}=$ non-Hispanic; $\mathrm{NHPI}=$ Native Hawaiian or other Pacific Islander. * Age standardized to the 2000 projected U.S. population, except for age groups. Bars represent $95 \%$ confidence intervals.

with household income $\geq 100 \%-\leq 400 \%$ of FPL, and $94.8 \%$ among adults with household income $>400 \%$ of FPL; in the New England region, these percentages were 79.4\%, 88.0\%, and $97.9 \%$, respectively (Table 3 ).

\section{Other Health Care Access Measures}

In Medicaid expansion states, the median estimated prevalence of working-aged adults who had a usual source of health care was $74.6 \%$ and ranged from $57.2 \%$ in Nevada to $86.6 \%$ in Massachusetts (Table 1). In nonexpansion states, the median estimated prevalence of adults who had a usual source of health care was $70.3 \%$ and ranged from $61.8 \%$ in Alaska to $83.9 \%$ in Maine. The estimated prevalence of adults who had a routine checkup within the preceding 12 months varied by approximately 19 percentage points in Medicaid expansion states (median: $64.8 \%$, range: $56.0 \%$ in Oregon to $75.5 \%$ in Rhode Island) and nonexpansion states (median: 63.1\%, range: $52.1 \%$ in Idaho to $71.1 \%$ in Louisiana), respectively. The estimated prevalence of adults who had unmet health care need because of cost varied by 13.9 percentage points in Medicaid expansion states (median: $14.7 \%$, range: $8.0 \%$ in North Dakota to $21.9 \%$ in Arkansas) and 11.2 percentage points in nonexpansion states (median: $16.8 \%$, range: $11.9 \%$ in South Dakota to $23.1 \%$ in Mississippi), respectively (Table 1).
In the nine expanded geographic regions, the estimated prevalence of adults who had a usual source of health care ranged from $64.4 \%$ in the West South Central region to 83.6\% in the New England region (Table 2). The estimated prevalence of adults who had a routine checkup within the preceding 12 months ranged from $56.8 \%$ in the Mountain region to $70.2 \%$ in the New England region. The estimated prevalence of adults who had unmet health care need because of cost ranged from $11.6 \%$ in the New England region to $20.3 \%$ in the South Atlantic region.

By FPL, the estimated prevalence of adults who had a usual source of health care and no unmet health care need because of cost increased with increasing level of income (\% of FPL) in Medicaid expansion states and nonexpansion states and in each expanded geographic region, although the magnitude of these estimates varied across the examined categories. For example, in Medicaid expansion states, the estimated prevalence of a usual source of health care was $63.9 \%$ among adults with household income $<100 \%$ of FPL, $71.3 \%$ among adults with household income $\geq 100 \%-\leq 400 \%$ of FPL, and $82.9 \%$ among adults with household income $>400 \%$ of FPL; in nonexpansion states, these percentages were $57.7 \%, 68.7 \%$, and $80.0 \%$, respectively (Table 3). In another example, the estimated prevalence of unmet health care need because of cost among adults with household income $<100 \%$ of FPL ranged from $22.6 \%$ in the 
New England region to $40.9 \%$ in the South Atlantic region. Among adults with household income $\geq 100 \%-\leq 400 \%$ of FPL, estimates ranged from $15.5 \%$ in the West North Central region to $21.6 \%$ in the South Atlantic region. Among adults with household income $>400 \%$ of FPL, estimates ranged from $3.9 \%$ in the West North Central region to $6.3 \%$ in both the Mountain region and the South Atlantic region (Table 3). In contrast, the estimated prevalence of a routine checkup within the preceding 12 months had less variability by FPL category (except for increasing estimates with increasing level of income in the South Atlantic region and the West South Central region and in nonexpansion states) (Table 3).

\section{Selected Clinical Preventive Services}

\section{Colorectal Cancer Screening for Adults Aged 50-64 Years}

Among adults aged 50-64 years, the median estimated prevalence of having received colorectal cancer screening as recommended by USPSTF was $59.1 \%$ and ranged from $49.2 \%$ in Nevada to $72.4 \%$ in Massachusetts. Crude and agestandardized state-specific estimates for CPS use (including colorectal cancer screening) are available (supplemental Table S3 https://stacks.cdc.gov/view/cdc/43255). The estimated prevalence was $61.1 \%$ in Medicaid expansion states and $58.6 \%$ in nonexpansion states (Table 4). Among expanded geographic regions, the estimated prevalence ranged from $54.1 \%$ in the West South Central region to $70.5 \%$ in the New England region (Table 4).

The estimated prevalence of colorectal cancer screening generally increased with increasing level of income (\% of FPL) in Medicaid expansion states and nonexpansion states and in each expanded geographic region (except for similar estimates among adults with household income $<100 \%$ of FPL and those with household income $\geq 100 \%-\leq 400 \%$ of FPL in the New England and Middle Atlantic regions), although the magnitude of these estimates varied across the examined categories. For example, the estimated prevalence of colorectal cancer screening among adults with household income $<100 \%$ of FPL ranged from $38.7 \%$ in the West South Central region to $57.7 \%$ in the New England region. Among adults with household income $\geq 100 \%-\leq 400 \%$ of FPL, estimates ranged from $50.0 \%$ in the Mountain region to $64.8 \%$ in the New England region. Among adults with household income $>400 \%$ of FPL, estimates ranged from $65.4 \%$ in the Mountain region to $77.2 \%$ in the New England region (Table 5).

\section{HIV Testing for Adults Aged 18-64 Years}

Among adults aged 18-64 years, the median estimated prevalence of having ever been tested for HIV was
$40.4 \%$ and ranged from $24.4 \%$ in Utah to $74.4 \%$ in the District of Columbia. Crude and age-standardized statespecific estimates for CPS use (including HIV testing) are available (supplemental Table S3 https://stacks.cdc.gov/view/ cdc/43255). No difference in the estimated prevalence by state Medicaid expansion status was found (Table 4). Among expanded geographic regions, the estimated prevalence ranged from $33.7 \%$ in the West North Central region to $50.0 \%$ in the South Atlantic region (Table 4).

The estimated prevalence of HIV testing generally decreased with increasing level of income (\% of FPL) in Medicaid expansion states and nonexpansion states, and in each expanded geographic region, except in the Pacific region where no difference by FPL category was found and in the West South Central region where no difference among adults with household income $\geq 100 \%-\leq 400 \%$ of FPL and those with household income $>400 \%$ of FPL was found (Table 5).

\section{Influenza Vaccination}

Among adults aged 18-64 years, the median estimated prevalence of influenza vaccination within the preceding 12 months was $34.6 \%$ and ranged from $24.1 \%$ in Florida to $44.7 \%$ in South Dakota. Crude and age-standardized statespecific estimates for CPS use (including influenza vaccination) are available (supplemental Table S3 https://stacks.cdc.gov/ view/cdc/43255). No difference in the estimated prevalence by state Medicaid expansion status was found (Table 4). Among expanded geographic regions, the estimated prevalence ranged from $31.3 \%$ in the South Atlantic region to $38.2 \%$ in the New England region (Table 4).

In Medicaid expansion states, the estimated prevalence of influenza vaccination was similar among adults with household income $<100 \%$ of FPL $(29.9 \%)$ and those with household income $\geq 100 \%-\leq 400 \%$ of FPL (30.2\%); in nonexpansion states, the estimated prevalence of influenza vaccination increased with increasing level of income (\% of FPL). Estimates of influenza vaccination were similar among adults with household income $<100 \%$ of FPL and those with household income $\geq 100 \%-\leq 400 \%$ of FPL in six of the nine expanded geographic regions (New England, Middle Atlantic, East North Central, West North Central, Mountain, and Pacific), whereas estimates of influenza vaccination increased with increasing level of income (\% of FPL) in the South Atlantic, East South Central, and West South Central regions (Table 5).

\section{Breast Cancer Screening for Women Aged 50-64 Years}

Among women aged 50-64 years, the median estimated prevalence of having a mammogram within the preceding 2 years was $76.2 \%$ and ranged from $62.9 \%$ in Arkansas 
to $87.3 \%$ in Massachusetts. Crude and age-standardized state-specific estimates for CPS use (including breast cancer screening) are available (supplemental Table S3 https://stacks. cdc.gov/view/cdc/43255). The estimated prevalence was $78.5 \%$ in Medicaid expansion states and $75.5 \%$ in nonexpansion states (Table 6). Among expanded geographic regions, the estimated prevalence ranged from $71.7 \%$ in the Mountain region to 84.3\% in the New England region (Table 6).

In Medicaid expansion states, the estimated prevalence of breast cancer screening was similar among women aged 50-64 years with household income $<100 \%$ of FPL (71.4\%) and those with household income $\geq 100 \%-\leq 400 \%$ of FPL (74.5\%); in nonexpansion states, estimates of breast cancer screening increased with increasing level of income (\% of FPL). Estimates of breast cancer screening were similar among women with household income $<100 \%$ of FPL and those with household income $\geq 100 \%-\leq 400 \%$ of FPL in five of the nine expanded geographic regions (New England, Middle Atlantic, West South Central, Mountain, and Pacific); estimates increased with increasing level of income (\% of FPL) in the remaining expanded geographic regions (Table 7).

\section{Cervical Cancer Screening for Women Aged 21-64 Years}

Among women aged 21-64 years, the median estimated prevalence of having received cervical cancer screening within the preceding 3 years was $82.7 \%$ and ranged from $76.2 \%$ in Idaho to $87.8 \%$ in Massachusetts. Crude and age-standardized state-specific estimates for CPS use (including cervical cancer screening) are available (supplemental Table S3 https://stacks. cdc.gov/view/cdc/43255). The estimated prevalence was $83.0 \%$ in Medicaid expansion states and $81.5 \%$ in nonexpansion states (Table 6). Among expanded geographic regions, the estimated prevalence ranged from $78.5 \%$ in the West South Central region to $87.0 \%$ in the New England region (Table 6).

The estimated prevalence of cervical cancer screening ranged from $69.8 \%$ among women with household income $<100 \%$ of FPL in the West North Central region to $92.6 \%$ among women with household income $>400 \%$ of FPL in the East South Central region. The estimated prevalence of cervical cancer screening increased with increasing level of income ( $\%$ of FPL) in Medicaid expansion and nonexpansion states. Among the expanded geographic regions, however, less variability by FPL category was found. For example, the estimated prevalence of cervical cancer screening was similar among women with household income $<100 \%$ of FPL and those with household income $\geq 100 \%-\leq 400 \%$ of FPL in five of the nine expanded geographic regions (New England, Middle Atlantic, East North Central, East South Central, and Pacific). The estimated prevalence of cervical cancer screening among women with household income $<100 \%$ of FPL ranged from $69.8 \%$ in the West North Central region to $81.5 \%$ in the New England region. Among women with household income $\geq 100 \%-\leq 400 \%$ of FPL, estimates ranged from $77.8 \%$ in the West South Central region to $86.2 \%$ in the New England region. Among women with household income $>400 \%$ of FPL, estimates ranged from $87.8 \%$ in the Mountain and West South Central regions to $92.5 \%$ in the New England region and $92.6 \%$ in the East South Central region (Table 7).

\section{Primary Source of Health Insurance Coverage}

\section{Overall and by State Medicaid Expansion Status, State, and FPL}

In the 43 states using questions from the optional module, $17.1 \%$ of adults aged $18-64$ years had no primary source of health insurance coverage, $19.4 \%$ had public health plan coverage, and $63.4 \%$ had private health insurance coverage. In states expanding Medicaid eligibility, $15.0 \%$ had no primary source of health insurance, $21.1 \%$ had public health plan coverage, and $63.9 \%$ had private health insurance coverage. In nonexpansion states, $19.9 \%$ had no primary source of health insurance, $17.2 \%$ had public health plan coverage, and 62.9\% had private health insurance coverage (Table 8).

Variations in primary source of health insurance coverage existed by FPL category and state Medicaid expansion status. Among working-aged adults with no primary source of health insurance coverage or public health plan coverage, the magnitude of the variation diminished with increasing FPL category by expansion status, whereas among adults with private health insurance, estimates were similar by FPL category regardless of state Medicaid expansion status. For example, among adults with household income $<100 \%$ of FPL in Medicaid expansion and nonexpansion states, the estimated prevalence of no primary source of health insurance coverage was $29.6 \%$ and $41.6 \%$, respectively, and the estimated prevalence of public health plan coverage was $50.7 \%$ and $37.9 \%$, respectively. Among adults with household income $\geq 100 \%-\leq 400 \%$ of FPL in Medicaid expansion and nonexpansion states, the estimated prevalence of no primary source of health insurance coverage was $17.3 \%$ and $20.7 \%$, respectively, and the estimated prevalence of public health plan coverage was $22.1 \%$ and $16.7 \%$, respectively. Among adults with household income $>400 \%$ of FPL, similar prevalence patterns by primary source of insurance coverage were found in Medicaid expansion states and nonexpansion states (Table 8).

The median estimated prevalence of adults in 43 states who had Medicaid as their primary source of health insurance 
coverage was $7.8 \%$ and ranged from $3.5 \%$ in both Idaho and Utah to $17.9 \%$ in the District of Columbia. The median estimated prevalence of other public insurance was $11.1 \%$ and ranged from $6.5 \%$ in Iowa to $18.8 \%$ in Alaska. The median estimated prevalence of employer-based coverage was $53.8 \%$ and ranged from $41.3 \%$ in New Mexico to $63.1 \%$ in Iowa. The median estimated prevalence of other private coverage was $9.3 \%$ and ranged from $5.3 \%$ in Massachusetts to $14.7 \%$ in Idaho. The median estimated prevalence of no primary source of health insurance coverage was $16.5 \%$ and ranged from $5.9 \%$ in Massachusetts to $28.4 \%$ in Georgia. Crude and age-standardized state-specific estimates for primary source of health insurance coverage are available (supplemental Table $\$ 4$ https://stacks.cdc.gov/view/cdc/43255).

\section{Health Care Access and CPS Use}

Among adults aged 18-64 years, those with no primary source of insurance were approximately half as likely ( $42.7 \%$ versus $79.8 \%$ and $81.0 \%$, respectively) to have a usual source of health care, and approximately three fifths as likely (42.0\% versus $74.4 \%$ and $68.9 \%$, respectively) to have had a routine checkup within the preceding 12 months, compared with adults who had public health plan coverage and private health insurance coverage, respectively (Table 9). The estimated prevalence of having unmet health care need because of cost or unmet prescribed medication need because of cost was highest among adults with no primary source of insurance coverage ( $43.9 \%$ and $18.8 \%$, respectively), followed by those with public health plan coverage (18.3\% and $14.4 \%$, respectively), and lowest among those with private health insurance coverage (9.0\% and $6.3 \%$, respectively). The estimated prevalence of medical debt was highest among adults with no primary source of insurance $(27.8 \%)$, but similar among publically and privately insured adults ( $21.9 \%$ and $22.1 \%$, respectively). For these health care access measures, similar prevalence patterns by primary source of health insurance coverage were found in Medicaid expansion states and nonexpansion states (Table 9).

The estimated prevalence of financial barriers to health care (i.e., unmet health care need because of cost, unmet prescribed medication need because of cost, and medical debt) were generally lower among working-aged adults residing in Medicaid expansion states than those residing in nonexpansion states regardless of primary source of health insurance coverage. For example, in Medicaid expansion states, the estimated prevalence of having medical bills that were being paid off over time was $24.5 \%$ among adults without a primary source of health insurance coverage, $20.2 \%$ among adults with public health plan coverage, and $19.8 \%$ among adults with private health insurance coverage; in nonexpansion states, the estimated prevalence was $31.0 \%, 24.5 \%$, and $25.2 \%$, respectively (Table 9).
The median estimated prevalence of adults who had a cost barrier to prescribed medication need was $9.1 \%$ and ranged from $5.6 \%$ in North Dakota to $13.8 \%$ in Mississippi. The median estimated prevalence of having medical debt (i.e., medical bills being paid off over time) was $24.0 \%$ and ranged from $11.3 \%$ in the District of Columbia to $34.2 \%$ in West Virginia. Crude and age-standardized state-specific estimates of financial barriers to health care are available (supplemental Table S5 https://stacks. cdc.gov/view/cdc/43255).

Overall and by state Medicaid expansion status, the estimated prevalence of breast, cervical, and colorectal cancer screening was typically lowest among working-aged adults without a primary source of health insurance coverage, followed by those who had public health plan coverage, and highest among those who had private health insurance coverage. For example, in Medicaid expansion states, the estimated prevalence of having a mammogram within the preceding 2 years was $48.5 \%$ among women without a primary source of health insurance coverage, $75.3 \%$ among women with public health plan coverage, and $81.9 \%$ among women with private health insurance coverage; in nonexpansion states, the estimated prevalence was $47.1 \%$, $73.6 \%$, and $80.8 \%$, respectively. In contrast, the estimated prevalence of having ever been tested for HIV was highest among adults with public health care plans and lowest among those with private health insurance coverage. The estimated prevalence of influenza vaccination was lowest among adults with no primary source of insurance and generally similar for publically and privately insured adults. Similar estimates of these CPS by primary source of health insurance coverage were reported in Medicaid expansion and nonexpansion states (except for having ever been tested for HIV among adults without a primary source of coverage [ $42.7 \%$ versus $46.4 \%$ ] and influenza vaccination among publically insured adults [35.6\% versus $40.1 \%]$ ) (Table 9).

\section{Number of Health Care Visits in the Preceding 12 Months}

Among adults aged 18-64 years, $15.6 \%$ had no health care visits during the preceding 12 months, $37.1 \%$ had $1-2$ visits, and $47.3 \%$ had $\geq 3$ visits. Adults without a primary source of health insurance coverage were more than three times as likely (37.0\% versus $9.7 \%$ and $11.8 \%$, respectively) to not have seen a health care professional during the preceding 12 months, compared with those who had public health plan coverage and private health insurance coverage, respectively (Table 10). Similar prevalence patterns by primary source of insurance coverage were found in expansion and nonexpansion states. The median estimated prevalence of adults who had not seen a health care professional during the preceding 12 months was $15.6 \%$ and ranged from $10.8 \%$ in Massachusetts to $24.7 \%$ in 
Nevada. The median estimated prevalence of adults who had $1-2$ visits to a health care professional during the preceding 12 months was $37.4 \%$ and ranged from $33.4 \%$ in both Oregon and West Virginia to $43.3 \%$ in North Dakota. The median estimated prevalence of adults who had $\geq 3$ visits to a health care professional during the preceding 12 months was $47.7 \%$ and ranged from $38.7 \%$ in Idaho to $52.0 \%$ in Massachusetts. Crude and age-standardized state-specific estimates of number of health care visits are available (supplemental Table S6 https:// stacks.cdc.gov/view/cdc/43255).

\section{Satisfaction with Received Health Care}

Among adults aged 18-64 years who had received health care during the preceding 12 months, $62.3 \%$ were very satisfied with the health care they received, $33.7 \%$ were somewhat satisfied, and $4.0 \%$ were not at all satisfied. The median estimated prevalence of adults who were very or somewhat satisfied was $96.1 \%$ and ranged from $92.7 \%$ in Nevada to $98.0 \%$ in Colorado. Crude and age-standardized state-specific estimates for satisfaction with received health care are available (supplemental Table S6 https://stacks.cdc. gov/view/cdc/43255). Among adults who had received health care during the preceding 12 months, those in expansion and nonexpansion states reported similar levels of satisfaction with received health care by primary source of health insurance coverage. For example, overall and in Medicaid expansion states and nonexpansion states, adults without a primary source of insurance were more than twice as likely to report that they were not at all satisfied with the health care they received, compared with those with public health care plans (overall: $11.4 \%$ versus $4.6 \%$; Medicaid expansion states: $11.3 \%$ versus 4.5\%; nonexpansion states: $11.5 \%$ versus $4.8 \%$ ). In addition, adults without a primary source of insurance were about five times as likely to report that they were not at all satisfied with the health care they received, compared with those with private health insurance coverage (Table 11).

\section{Continuity of Health Insurance Coverage}

\section{Overall and by State Medicaid Expansion Status, State, and FPL}

In the 43 states using questions from the optional module, $75.6 \%$ of adults aged $18-64$ years had continuous health insurance coverage, $12.9 \%$ had a gap in coverage, and $11.5 \%$ had been uninsured for $>12$ months. In Medicaid expansion states, $77.4 \%$ were continuously insured during the preceding 12 months, $13.0 \%$ experienced a gap in insurance, and $9.6 \%$ were uninsured during the preceding 12 months. In nonexpansion states, $73.4 \%$ were continuously insured during the preceding 12 months, $12.8 \%$ experienced a gap in insurance, and $13.9 \%$ were uninsured during the preceding 12 months (Table 12).

For every income group, estimated prevalence of adults with continuous insurance in Medicaid expansion states was higher relative to nonexpansion states whereas, for two of the three income groups, estimated prevalence of uninsured adults in expansion states was lower compared with nonexpansion states. For example, among working-aged adults with household income $<100 \%$ of FPL, $57.6 \%$ of those in Medicaid expansion states were continuously insured during the preceding 12 months, compared with $48.6 \%$ in nonexpansion states. Among adults with household income $<100 \%$ of FPL and $\geq 100 \%-\leq 400 \%$ of FPL, $20.6 \%$ and $11.5 \%$, respectively, of those residing in expansion states were uninsured for $>12$ months compared with $30.9 \%$ and $14.6 \%$, respectively, in nonexpansion states. Among adults with household income $>400 \%$ of FPL, similar estimates of no health insurance coverage during the preceding year were found in Medicaid expansion states and nonexpansion states (Table 12).

The median estimated prevalence of adults who had continuous health insurance coverage during the preceding 12 months was $75.9 \%$ and ranged from $65.6 \%$ in Georgia to $89.0 \%$ in Massachusetts. The median estimated prevalence of adults who had a gap in coverage was $13.0 \%$ and ranged from $8.7 \%$ in Massachusetts to $17.9 \%$ in Kentucky. The median estimated prevalence of adults who were uninsured during the preceding 12 months was $11.2 \%$ and ranged from $2.3 \%$ in Massachusetts to $20.0 \%$ in Georgia. Crude and agestandardized state-specific estimates for continuity of health insurance coverage are available (supplemental Table S7 https:// stacks.cdc.gov/view/cdc/43255).

\section{Health Care Access and CPS Use}

Among adults aged 18-64 years, those who were continuously insured were twice as likely to have a usual source of health care $(82.1 \%$ versus $37.6 \%)$ and to have had a routine checkup within the preceding 12 months (71.6\% versus $34.2 \%)$, compared with those who had no health insurance for $>12$ months (Table 13). Working-aged adults with continuous health insurance were approximately one sixth as likely $(7.7 \%$ versus $47.1 \%$ ) to have unmet health care need because of cost and about one third as likely (6.5\% versus $18.4 \%)$ to have unmet prescribed medication need because of cost, compared with those with no health insurance during the preceding 12 months. The estimated prevalence of having a cost barrier to prescribed medication need or medical bills being paid off over time was highest among adults with a gap in health insurance coverage during the preceding 12 months $(22.9 \%$ and $34.1 \%$, respectively), followed by those without health 
insurance for $>12$ months ( $18.4 \%$ and $27.1 \%$, respectively), and was lowest among those with continuous insurance $(6.5 \%$ and $20.4 \%$, respectively). For these health care access measures, similar prevalence patterns by health insurance status during the preceding 12 months were found in Medicaid expansion states and nonexpansion states (Table 13).

Among adults with continuous coverage, $83.0 \%$ of those in Medicaid expansion states had a usual source of health care, compared with $80.8 \%$ in nonexpansion states. Similarly, among adults with continuous coverage, $7.3 \%$ of those in expansion states had unmet health care need because of cost, $5.9 \%$ had unmet prescription need because of cost, and $18.3 \%$ had medical bills being paid off over time, compared with $8.2 \%, 7.3 \%$, and $23.4 \%$, respectively, in nonexpansion states. Among adults who were without health insurance for $>12$ months, $45.1 \%$ of those in expansion states had unmet health care need because of cost, $15.8 \%$ had unmet prescription need because of because of cost, and $23.5 \%$ had medical bills being paid off over time, compared with $48.7 \%, 20.7 \%$, and $30.3 \%$, respectively, in nonexpansion states. Among adults who had a gap in coverage during the preceding 12 months, $31.4 \%$ of those in expansion states had medical bills being paid off over time, compared with $37.7 \%$ in nonexpansion states (Table 13).

Overall and by state Medicaid expansion status, the estimated prevalence of breast, cervical, and colorectal cancer screening and influenza vaccination was highest among adults who were continuously insured, followed by those who had a gap in insurance coverage, and lowest among those who were without health insurance for $>12$ months, respectively. For example, in Medicaid expansion states, the estimated prevalence of colorectal cancer screening as recommended by USPSTF was $65.9 \%$ among adults with continuous coverage, $44.8 \%$ among those who had a gap in coverage, and $24.9 \%$ among those uninsured for $>12$ months; in nonexpansion states, these percentages were $65.6 \%, 44.4 \%$, and $24.3 \%$, respectively. The estimated prevalence of having ever been tested for HIV was highest among adults who had a gap in insurance coverage during the preceding 12 months, compared with those who were either continuously insured or uninsured during the preceding 12 months. Similar estimates of these CPS by continuity of health insurance coverage during the preceding 12 months were reported in Medicaid expansion and nonexpansion states (except for cervical cancer screening among continuously insured women [85.9\% versus $87.5 \%$ ] and having ever been tested for HIV among uninsured adults [40.4\% versus $46.1 \%]$ ) (Table 13 ).

\section{Number of Health Care Visits During the Preceding 12 Months}

Among adults aged 18-64 years, those who were without health insurance for $>12$ months were four times as likely $(43.5 \%$ versus $10.8 \%)$ to not have seen a health care professional during the preceding 12 months, compared with those who were continuously insured. Among adults with no health insurance during the preceding 12 months, the estimated prevalence of not having seen a health care professional during the preceding 12 months was higher in Medicaid expansion states (47.0\%) than nonexpansion states (40.4\%). The estimated prevalence of health care visits (i.e., none, $1-2$, or $\geq 3$ ) among adults who were continuously insured or who had a gap in coverage during the preceding 12 months was similar by state Medicaid expansion status (Table 14).

\section{Satisfaction with Received Health Care}

Among adults aged 18-64 years, similar levels of satisfaction with received health care by continuity of health insurance coverage during the preceding 12 months were reported in Medicaid expansion and nonexpansion states. For example, overall and by state Medicaid expansion status, adults without health insurance coverage for $>12$ months were approximately five times as likely to report that they were not at all satisfied with the health care they received, compared with those who were continuously insured (overall: $13.1 \%$ versus $2.5 \%$; Medicaid expansion states: $12.6 \%$ versus $2.4 \%$; nonexpansion states: $13.4 \%$ versus $2.6 \%$ ) (Table 15 ).

\section{Discussion}

Certain policy changes related to the ACA took effect on or before January 1,2014, including required coverage without cost sharing of certain CPS, the option for states to broaden Medicaid eligibility and expand coverage, and tax credits to help make insurance coverage affordable. Post-2014 changes in health care access, such as source of health insurance coverage, attainment and continuity of coverage, financial barriers, preventive care services, and health outcomes, can be assessed and monitored with these 2014 state-specific data as baseline information.

The findings in this report indicate many disparities in health care access in 2014, including disparities between states that expanded Medicaid coverage and those states that did not expand it. In nonexpansion states, legal residents with household income between $100 \%$ and $400 \%$ of FPL could receive a tax credit to offset the cost of insurance premiums, but no new financial assistance was provided for those with household income below $100 \%$ of FPL (58). However, in Medicaid expansion states, legal residents with household 
income between $0 \%$ and $400 \%$ of FPL became eligible for affordable coverage options through tax credits and expanded Medicaid eligibility. Findings presented in this report show that prevalence estimates for many indicators of health care access, such as having health care coverage, having a usual source of care, having a routine checkup within the preceding 12 months, and not experiencing a cost barrier to health care need during the preceding 12 months, were higher among adults living below the poverty level in states that expanded Medicaid than in states that did not. Similarly, adults living below the poverty level in states that expanded Medicaid had higher prevalence estimates of breast and cervical cancer screening and influenza vaccination than those in states that did not expand Medicaid. These disparities could be partly explained by factors other than differences in eligibility for Medicaid because persons with income above the poverty level living in states that expanded Medicaid had higher rates of insurance coverage, having a usual source of health care, and not experiencing a cost barrier to health care need during the preceding 12 months than persons of comparable income living in states that did not expand Medicaid. Differences between the Medicaid expansion states and nonexpansion states in demographics, social, cultural, and economic factors, as well as state-level policy decisions, might also have a role in health care access and use among residents. However, the adjustment was made for differences in age, sex, race/ethnicity, and FPL and did not substantially change the results presented in this report. Further research is needed to clarify the effects of policy and investigate the effects of these and other factors such as health status, urbanicity (i.e., conditions that are unique to urban areas or more prevalent than in nonurban areas), and provider density on these disparities.

Researchers have found changes in health care access and use following expansion in Medicaid eligibility (16-18,20,23,24,27). In 2008, Oregon expanded Medicaid to persons selected by a lottery. Persons who were selected to receive Medicaid had an increased probability of having a usual source of health care, having a usual doctor, receiving CPS, and having improved self-reported mental and physical health compared with those who were not selected $(18,20,23)$. Similarly, those selected for Medicaid also experienced reduced financial strain overall and a decreased probability of having financial trouble because of medical expenses $(18,20,23)$. Another study found that mortality rates decreased in Maine, Arizona, and New York following expansions of Medicaid in those states, when compared with neighboring states (16). In future years it might be possible to use the BRFSS Health Care Access module to conduct similar studies to examine the effects of ACA on health care access and CPS use over time.

\section{Limitations}

The findings in this report are subject to at least five limitations. First, the BRFSS survey design excludes persons living in institutions, nursing homes, long-term care facilities, military installations, and correctional institutions. In addition, persons who do not have either a landline number or cellular telephone are excluded from the survey. The optional module results might not be generalizable to the entire U.S. population aged 18-64 years, or subpopulations within this age group, overall or by state Medicaid expansion status because not all states fielded the module in 2014 (Arkansas, California, Florida, Hawaii, Kansas, South Dakota, Texas, and Wyoming did not). Second, BRFSS data are self-reported, so the information is subject to recall (e.g., time since last mammogram and type of colorectal cancer screening received) and social desirability bias (e.g., underreporting of HIV test and medical debt). Third, FPL was not calculated for persons who did not respond to the income question $(-13 \%)$ or the number of children in the household question $(<1 \%)$ or who had $>14$ adults in the household or were missing these data $(<2 \%)$. In addition, the BRFSS question used to assess household income asks respondents to indicate whether their household income falls within specific income ranges; therefore, the mean of each range was used to estimate FPL and, for the top-end income level (i.e., $\geq \$ 75,000$ ), the weighted mean of income from census data was used. Fourth, although BRFSS surveys are conducted in several languages other than English (i.e., Spanish, Mandarin, and Portuguese), the survey does not cover persons who speak other languages exclusively. Finally, although the measures examined in this report are reliable indicators of access to health care (e.g., insurance, usual health care provider, routine checkup, use of preventive health services, number of visits to a health care professional, and satisfaction with received health care), they also might be associated with other factors such as age, health status, and income. For example, persons with chronic conditions, whose health care need is ongoing, are more likely than those without chronic conditions to have health insurance coverage (33). Conversely, young adults and persons in good health might be less likely to have insurance coverage or to use health care services. Nevertheless, an examination of the effects of extending dependent coverage to young adults (aged 18-25 years) during 2009-2011 found that removal of one access barrier, no insurance coverage, accounted for almost all of the significant increases in past-year routine examination (from $44.1 \%$ to $47.8 \%$ ) and past-year blood pressure screening (from $65.2 \%$ to $68.3 \%$ ) and part of the significant increases in cholesterol screening (from $24.3 \%$ to $29.1 \%$ ) and annual dental visit (55.2\% to $60.9 \%$ ) (59). Type of insurance coverage, continuity of coverage, or both also might 
be associated with other factors, such as health status, income level, and employment status $(19,31,33,34,37)$. For example, poor health status or low income might increase the likelihood of having public health insurance because Medicaid eligibility includes having a severe disability, low income, or both (33).

\section{Conclusion}

BRFSS is a cost-effective, timely, and flexible survey that makes data available to a broad range of audiences, including state health departments and policymakers, so they can assess and monitor the adverse health behaviors, chronic conditions, access to health care, use of CPS and other health care, and disabilities of state populations. The prevalence and trends from the BRFSS survey might differ from other national, state, and nongovernmental surveys because of differences in the survey instrument (e.g., wording of questions, number of questions focusing on a measure or topic, length of questionnaire, format of the questionnaire), mode of data collection (telephone, in person, online), and sampling frame. For example, unlike other federal surveys, BRFSS estimates of health insurance coverage include IHS coverage. In 2011, the core BRFSS question used to assess current health insurance coverage since 1993 was modified to include IHS as an example of health insurance. BRFSS 2014 data can be used to estimate the state-specific proportion of working-aged adults with IHS as their primary source of coverage in states that used the optional Health Care Access module.

One of the goals of BRFSS is to provide state-level data on health care access and use of CPS that can be used by state health departments, health care organizations, and policymakers. This report highlights findings from the 2014 BRFSS on health care access and use of preventive health services during the first year that many of the main provisions of the ACA were implemented. Adults who had been uninsured or who had inadequate coverage might experience improved access to health care, preventive health services and other health care, and, as a result, better health outcomes. Changes in health care access, CPS use, and health that might occur after 2014 can be assessed and monitored using BRFSS statespecific estimates from 2014.

\section{Acknowledgments}

State BRFSS coordinators and CDC Population Health Surveillance Branch, Division of Population Health.

\section{References}

1. Uberoi N, Finegold K, Gee E. Health insurance coverage and the Affordable Care Act, 2010-2016. ASPW Issue Brief March 3, 2016. Washington, DC: Office of the Assistant Secretary for Planning and Evaluation, US Department of Health and Human Services. https:// aspe.hhs.gov/sites/default/files/pdf/187551/ACA2010-2016.pdf

2. Smith JC, Medalia C. Health insurance coverage in the United States: 2014. Report No. P60-253, September 2015. Washington, DC: US Census Bureau. http://www.census.gov/content/dam/Census/library/ publications/2015/demo/p60-253.pdf

3. Zhao G, Okoro CA, Dhingra SS, Xu F, Zack M. Trends of lack of health insurance among US adults aged 18-64 years: findings from the Behavioral Risk Factor Surveillance System, 1993-2014. Public Health. In press.

4. Vistnes JP, Lipton BJ. The uninsured in America: estimates of the percentage of non-elderly adults uninsured throughout each calendar year, by selected population subgroups and state Medicaid expansion status: 2013 and 2014. Statistical brief \#488. Rockville, MD: Agency for Healthcare Research and Quality. 2016. https://meps.ahrq.gov/ data_files/publications/st488/stat488.shtml

5. Burwell SM, Frieden TR, Rothwell CJ. Health, United States, 2015: with special feature on racial and ethnic health disparities. Hyattsville, MD: National Center for Health Statistics. Report No.: 2016-1232. 2016. https://www.cdc.gov/nchs/data/hus/hus15.pdf

6. Obama B. United States health care reform: progress to date and next steps. JAMA 2016;316:525-32. http://dx.doi.org/10.1001/ jama.2016.9797

7. Cohen RA, Martinez ME. Health insurance coverage: early release of estimates from the National Health Interview Survey, 2013. Hyattsville, MD: National Center for Health Statistics. 2014. https://www.cdc.gov/ nchs/data/nhis/earlyrelease/insur201605.pdf

8. Okoro CA, Zhao G, Dhingra SS, Xu F. Lack of health insurance among adults aged 18 to 64 years: findings from the 2013 Behavioral Risk Factor Surveillance System. Prev Chronic Dis 2015;12:E231.

9. Black LI, Cohen RA. Insurance status by state Medicaid expansion status: early release of estimates from the National Health Interview Survey, 2013-September 2014. Atlanta, GA: US Department of Health and Human Services. 2015. https://www.cdc.gov/nchs/data/nhis/ health_insurance/MedExAUER.pdf

10. Witters D. Arkansas, Kentucky set pace in reducing uninsured rate. Gallup. Feb. 4, 2016. http://www.gallup.com/poll/189023/arkansaskentucky-set-pace-reducing-uninsured-rate.aspx

11. Blumberg LJ, Garrett B, Holahan J. Estimating the counterfactual: how many uninsured adults would there be today without the ACA? Inquiry 2016;53:0046958016634991.

12. Sommers BD, Gunja MZ, Finegold K, Musco T. Changes in Selfreported Insurance Coverage, Access to Care, and Health Under the Affordable Care Act. JAMA 2015;314:366-74. http://dx.doi. org/10.1001/jama.2015.8421

13. Courtemanche C, Marton J, Ukert B, Yelowtize A, Zapata D. Impacts of the Affordable Care Act on health insurance coverage in Medicaid expansion and non-expansion states [NBER working paper No. 22182]. April 2016. Cambridge, MA: National Bureau of Economic Research. http://www.nber.org/papers/w22182

14. Fox JB, Shaw FE; Office of Health System Collaboration, Office of the Associate Director for Policy, CDC. Relationship of income and health care coverage to receipt of recommended clinical preventive services by adults-United States, 2011-2012. MMWR Morb Mortal Wkly Rep 2014;63:666-70.

15. Fox JB, Shaw FE. Receipt of Selected Clinical Preventive Services by Adults-United States, 2011-2012. MMWR Morb Mortal Wkly Rep 2015;64:738-42. 
16. Sommers BD, Baicker K, Epstein AM. Mortality and access to care among adults after state Medicaid expansions. N Engl J Med 2012;367:1025-34. http://dx.doi.org/10.1056/NEJMsa1202099

17. Sommers BD, Long SK, Baicker K. Changes in mortality after Massachusetts health care reform: a quasi-experimental study. Ann Intern Med 2014;160:585-93. http://dx.doi.org/10.7326/M13-2275

18. Baicker K, Taubman SL, Allen HL, et al.; Oregon Health Study Group. The Oregon experiment-effects of Medicaid on clinical outcomes. N Engl J Med 2013;368:1713-22. http://dx.doi.org/10.1056/ NEJMsa1212321

19. D’Angelo DV, Le B, O’Neil ME, et al. Patterns of health insurance coverage around the time of pregnancy among women with Live-born infants-Pregnancy Risk Assessment Monitoring System, 29 States, 2009. MMWR Surveill Summ 2015;64(No. 4).

20. Baicker K, Finkelstein A. The effects of Medicaid coverage-learning from the Oregon experiment. N Engl J Med 2011;365:683-5. http:// dx.doi.org/10.1056/NEJMp1108222

21. Chua KP, Sommers BD. Changes in health and medical spending among young adults under health reform. JAMA 2014;311:2437-9. http:// dx.doi.org/10.1001/jama.2014.2202

22. Wallace J, Sommers BD. Effect of dependent coverage expansion of the Affordable Care Act on health and access to care for young adults. JAMA Pediatr 2015;169:495-7. http://dx.doi.org/10.1001/ jamapediatrics.2014.3574

23. Finkelstein A, Taubman S, Wright B, et al.; Oregon Health Study Group. The Oregon Health Insurance Experiment: Evidence from the First Year. Q J Econ 2012;127:1057-106. http://dx.doi.org/10.1093/qje/qjs020

24. Courtemanche CJ, Zapata D. Does universal coverage improve health? The Massachusetts experience. J Policy Anal Manage 2014;33:36-69. http://dx.doi.org/10.1002/pam.21737

25. Ogundipe B, Alam F, Gazula L, et al. Remaking the American health care system: a positive reflection on the Affordable Care Act with emphasis on mental health care. J Health Care Poor Underserved 2015;26:49-61. http://dx.doi.org/10.1353/hpu.2015.0020

26. Strine TW, Zack M, Dhingra S, Druss B, Simoes E. Uninsurance among nonelderly adults with and without frequent mental and physical distress in the United States. Psychiatr Serv 2011;62:1131-7. http://dx.doi. org/10.1176/ps.62.10.pss6210_1131

27. Dhingra SS, Zack MM, Strine TW, Druss BG, Simoes E. Change in health insurance coverage in Massachusetts and other New England States by perceived health status: potential impact of health reform. Am J Public Health 2013;103:e107-14. http://dx.doi.org/10.2105/ AJPH.2012.300997

28. Barbaresco S, Courtemanche CJ, Qi Y. Impacts of the Affordable Care Act dependent coverage provision on health-related outcomes of young adults. J Health Econ 2015;40:54-68. http://dx.doi.org/10.1016/j. jhealeco.2014.12.004

29. Dillender M. Do more health insurance options lead to higher wages? Evidence from states extending dependent coverage. J Health Econ 2014;36:84-97. http://dx.doi.org/10.1016/j.jhealeco.2014.03.012

30. Ali MM, Chen J, Mutter R, Novak P, Mortensen K. The ACA's dependent coverage expansion and out-of-pocket spending by young adults with behavioral health conditions. Psychiatr Serv 2016;67:977-82. http://dx.doi.org/10.1176/appi.ps.201500346

31. Mulcahy AW, Eibner C, Finegold K. Gaining coverage through Medicaid or private insurance increased prescription use and lowered out-of-pocket spending. Health Aff (Millwood) 2016;35:1725-33. http://dx.doi. org/10.1377/hlthaff.2016.0091

32. Burns ME, Wolfe BL. The effects of the Affordable Care Act adult dependent coverage expansion on mental health. J Ment Health Policy Econ 2016;19:3-20.

33. Hoffman C, Paradise J. Health insurance and access to health care in the United States. Ann N Y Acad Sci 2008;1136:149-60. http://dx.doi. org/10.1196/annals. 1425.007
34. Fox JB, Richards CL. Vital signs: health insurance coverage and health care utilization-United States, 2006-2009 and January-March 2010. MMWR Morb Mortal Wkly Rep 2010;59:1448-54.

35. McWilliams JM. Health consequences of uninsurance among adults in the United States: recent evidence and implications. Milbank Q 2009;87:443-94. http://dx.doi.org/10.1111/j.1468-0009.2009.00564.x

36. Institute of Medicine. America's uninsured crisis: consequences for health and health care. Washington, DC: The National Academies Press; 2009.

37. Weaver KE, Rowland JH, Bellizzi KM, Aziz NM. Forgoing medical care because of cost: assessing disparities in healthcare access among cancer survivors living in the United States. Cancer 2010;116:3493-504. http:// dx.doi.org/10.1002/cncr.25209

38. Davidoff AJ, Hill SC, Bernard D, Yabroff KR. The Affordable Care Act and expanded insurance eligibility among nonelderly adult cancer survivors. J Natl Cancer Inst 2015;107:djv181. http://dx.doi. org/10.1093/jnci/djv181

39. Benard VB, Thomas CC, King J, Massetti GM, Doria-Rose VP, Saraiya M. Vital signs: cervical cancer incidence, mortality, and screening-United States, 2007-2012. MMWR Morb Mortal Wkly Rep 2014;63:1004-9.

40. Berry DA, Cronin KA, Plevritis SK, et al.; Cancer Intervention and Surveillance Modeling Network (CISNET) Collaborators. Effect of screening and adjuvant therapy on mortality from breast cancer. N Engl J Med 2005;353:1784-92. http://dx.doi.org/10.1056/NEJMoa050518

41. Institute of Medicine. A shared destiny: community effects of uninsurance. Washington, DC: The National Academies Press; 2003.

42. Ahluwalia IB, Bolen J, Garvin B. Health insurance coverage and use of selected preventive services by working-age women, BRFSS, 2006. J Womens Health (Larchmt) 2007;16:935-40. http://dx.doi.org/10.1089/ jwh.2007.CDC8

43. Fox JB, Shaw FE. Clinical preventive services coverage and the Affordable Care Act. Am J Public Health 2015;105:e7-10. http://dx.doi. org/10.2105/AJPH.2014.302289

44. Coates RJ, Yoon PW, Zaza S, Ogden L, Thacker SB. Rationale for periodic reporting on the use of adult clinical preventive services of public health priority - United States. In: CDC. Use of selected clinical preventive services among adults_-United States 2007-2010. MMWR Suppl 2012;61(No. Suppl 2).

45. CDC. The BRFSS Data User Guide August 15, 2013. Atlanta, GA: US Department of Health and Human Services. https://www.cdc.gov/brfss/ data_documentation/PDF/UserguideJune2013.pdf

46. Mokdad AH. The Behavioral Risk Factors Surveillance System: past, present, and future. Annu Rev Public Health 2009;30:43-54. http:// dx.doi.org/10.1146/annurev.publhealth.031308.100226

47. Pierannunzi C, Hu SS, Balluz L. A systematic review of publications assessing reliability and validity of the Behavioral Risk Factor Surveillance System (BRFSS), 2004-2011. BMC Med Res Methodol 2013;13:49. http://dx.doi.org/10.1186/1471-2288-13-49

48. Nelson DE, Holtzman D, Bolen J, Stanwyck CA, Mack KA. Reliability and validity of measures from the Behavioral Risk Factor Surveillance System (BRFSS). Soz Praventivmed 2001;46(Suppl 1):S3-42.

49. CDC. Behavioral Risk Factor Surveillance System: 2014 Summary Data Quality Report. Atlanta, GA: US Department of Health and Human Services; 2015. https:/www.cdc.gov/brfss/annual_data/2014/ pdf/2014_dqr.pdf

50. CDC. At a glance: conducting the 2011 Behavioral Risk Factor Surveillance System (BRFSS). US Department of Health and Human Services; 2011. https://www.cdc.gov/brfss/pdf/238974_BRFSS-AAG. pdf

51. CDC. 2014 Behavioral Risk Factor Surveillance System Questionnaire. Atlanta, GA: US Department of Health and Human Services. https:// www.cdc.gov/brfss/questionnaires/pdf-ques/2014_brfss.pdf 
52. Holahan J, Buettgens M, Caroll C, Dorn S. The cost and coverage implications of the ACA Medicaid expansion: National and state-bystate analysis. November 1, 2012. Menlo Park, CA: Kaiser Commission on Medicaid and the Uninsured. http://kff.org/health-reform/report/ the-cost-and-coverage-implications-of-the

53. Office of the Assistant Secretary for Planning and Evaluation. 2013 Poverty Guidelines. Washington, DC: US Department of Health and Human Services. 2013. https://aspe.hhs.gov/2013-poverty-guidelines

54. CDC. Behavioral Risk Factor Surveillance System: Statistical brief on the Health Care Access module, 2013 and 2014. Atlanta, GA: US Department of Health and Human Services. 2015. https://www.cdc. gov/brfss/data_documentation/pdf/2013-2014_hcs.pdf

55. CDC. Behavioral Risk Factor Surveillance System: Overview: BRFSS 2014. Atlanta, GA: US Department of Health and Human Services. 2015. https:/www.cdc.gov/brfss/annual_data/2014/pdf/ overview_2014.pdf
56. CDC. Behavioral Risk Factor Surveillance System: Module data for analysis for 2014 BRFSS. Atlanta, GA: US Department of Health and Human Services. 2015. https://www.cdc.gov/brfss/annual_data/2014/ pdf/2014moduleanalysis.pdf

57. Klein RJ, Schoenborn CA. Age adjustment using the 2000 projected U.S. population. Healthy People 2010 Statistical Notes, No. 20. Atlanta, GA: CDC. January 2001. https://www.cdc.gov/nchs/data/statnt/statnt20.pdf

58. Artiga S, Damico A, Garfield R. The impact of the coverage gap for adults in states not expanding Medicaid by race and ethnicity. October 26, 2015. Menlo Park, CA: The Henry J. Kaiser Family Foundation. http:// $\mathrm{kff}$.org/disparities-policy/issue-brief/the-impact-of-the-coverage-gap-instates-not-expanding-medicaid-by-race-and-ethnicity/

59. Lau JS, Adams SH, Park MJ, Boscardin WJ, Irwin CE Jr. Improvement in preventive care of young adults after the affordable care act: the affordable care act is helping. JAMA Pediatr 2014;168:1101-6. http:// dx.doi.org/10.1001/jamapediatrics.2014.1691 
TABLE 1. Crude and age-standardized* prevalence estimates of health insurance coverage, usual source of health care, routine checkup within the preceding 12 months, and cost barrier to health care need during the preceding 12 months among adults aged 18-64 years, by state Medicaid expansion status - Behavioral Risk Factor Surveillance System, United States, 2014

\begin{tabular}{|c|c|c|c|c|c|c|c|c|c|}
\hline \multirow{2}{*}{$\begin{array}{l}\text { State } \\
\text { Medicaid } \\
\text { expansion } \\
\text { status }\end{array}$} & \multirow[b]{2}{*}{$n^{\dagger}$} & \multicolumn{2}{|c|}{$\begin{array}{l}\text { Insured at the time } \\
\text { of interview } \\
\S\end{array}$} & \multicolumn{2}{|c|}{$\begin{array}{l}\text { Usual source } \\
\text { of health care }\end{array}$} & \multicolumn{2}{|c|}{$\begin{array}{l}\text { Routine checkup within } \\
\text { preceding } 12 \text { mos }\end{array}$} & \multicolumn{2}{|c|}{$\begin{array}{l}\text { Cost barrier to health care need } \\
\text { during preceding } 12 \text { mos }\end{array}$} \\
\hline & & $\begin{array}{c}\text { Crude } \\
\% \text { ๆ }(95 \% \mathrm{Cl})\end{array}$ & $\begin{array}{c}\text { Age } \\
\text { standardized } \\
\%(95 \% \mathrm{Cl})\end{array}$ & $\begin{array}{c}\text { Crude } \\
\%(95 \% \mathrm{CI})\end{array}$ & $\begin{array}{c}\text { Age } \\
\text { standardized } \\
\%(95 \% \mathrm{Cl})\end{array}$ & $\begin{array}{c}\text { Crude } \\
\%(95 \% \mathrm{CI})\end{array}$ & $\begin{array}{c}\text { Age } \\
\text { standardized } \\
\%(95 \% \mathrm{Cl})\end{array}$ & $\begin{array}{c}\text { Crude } \\
\%(95 \% \mathrm{CI})\end{array}$ & $\begin{array}{c}\text { Age } \\
\text { standardized } \\
\%(95 \% \mathrm{Cl})\end{array}$ \\
\hline $\begin{array}{l}\text { Medicaid } \\
\text { expansion } \\
\text { states** }^{*}\end{array}$ & 150,756 & & & & & & & & \\
\hline Arizona & 8,282 & $82.1(80.7-83.5)$ & $81.8(80.3-83.3)$ & $66.6(65.0-68.3)$ & $65.9(64.2-67.6)$ & $58.1(56.4-59.8)$ & $57.5(55.8-59.2)$ & $18.1(16.8-19.5)$ & $18.2(16.9-19.7)$ \\
\hline Arkansas & 2,845 & $79.9(77.5-82.1)$ & $79.3(76.8-81.6)$ & $73.3(70.7-75.8)$ & $72.0(69.3-74.5)$ & $61.4(58.7-64.0)$ & $60.5(57.8-63.2)$ & $21.7(19.6-24.0)$ & $21.9(19.7-24.3)$ \\
\hline California & 6,612 & $82.4(81.2-83.6)$ & $82.1(80.8-83.3)$ & $70.5(69.1-71.9)$ & $69.7(68.2-71.1)$ & $62.8(61.3-64.3)$ & $62.3(60.8-63.8)$ & $15.2(14.2-16.4)$ & $15.4(14.3-16.5)$ \\
\hline Colorado & 9,108 & $84.8(83.8-85.8)$ & $84.3(83.2-85.3)$ & $72.4(71.2-73.6)$ & $71.4(70.1-72.6)$ & $59.0(57.7-60.2)$ & $58.3(57.0-59.6)$ & $14.9(14.0-15.9)$ & $15.1(14.1-16.1)$ \\
\hline Connecticut & 5,317 & $89.6(88.3-90.8)$ & $88.8(87.3-90.1)$ & $81.3(79.7-82.7)$ & $79.3(77.6-80.9)$ & $68.3(66.5-70.1)$ & $67.0(65.1-68.8)$ & $12.9(11.8-14.2)$ & $13.4(12.1-14.8)$ \\
\hline Delaware & 2,732 & $89.3(87.6-90.8)$ & $88.6(86.7-90.2)$ & $83.4(81.3-85.2)$ & $82.2(80.0-84.2)$ & $69.4(66.9-71.9)$ & $68.2(65.5-70.8)$ & $12.5(10.9-14.3)$ & $12.6(11.0-14.5)$ \\
\hline $\begin{array}{l}\text { District of } \\
\text { Columbia }\end{array}$ & 2,531 & $90.5(87.9-92.5)$ & $90.6(88.1-92.6)$ & $72.0(68.9-74.8)$ & $72.5(69.6-75.3)$ & $71.4(68.5-74.2)$ & $71.8(68.9-74.5)$ & $11.7(9.6-14.2)$ & $11.7(9.6-14.1)$ \\
\hline Hawaii & 5,097 & $90.4(89.1-91.5)$ & 90.1 (88.7-91.3) & $82.0(80.4-83.5)$ & $81.2(79.6-82.8)$ & $63.0(61.1-64.8)$ & $62.2(60.3-64.1)$ & $10.1(9.0-11.3)$ & $10.1(9.0-11.3)$ \\
\hline Illinois & 3,410 & $85.7(83.9-87.3)$ & $85.1(83.2-86.7)$ & $77.7(75.8-79.5)$ & 76.9 (74.9-78.7) & $65.4(63.3-67.4)$ & $64.8(62.7-66.9)$ & $13.9(12.4-15.5)$ & $14.1(12.5-15.8)$ \\
\hline lowa & 5,178 & $90.4(89.3-91.5)$ & $89.9(88.6-91.0)$ & $77.0(75.4-78.5)$ & $76.2(74.5-77.8)$ & $66.8(65.1-68.4)$ & $65.8(64.0-67.5)$ & $10.3(9.3-11.5)$ & $10.7(9.6-11.9)$ \\
\hline Kentucky & 7,250 & $87.9(86.4-89.2)$ & $87.4(85.8-88.8)$ & 75.7 (73.9-77.4) & $74.4(72.6-76.2)$ & $67.8(66.0-69.6)$ & $66.8(64.9-68.7)$ & $18.4(16.9-19.9)$ & $18.8(17.2-20.4)$ \\
\hline Maryland & 7,891 & $89.1(87.5-90.5)$ & $88.2(86.4-89.7)$ & $79.7(77.9-81.4)$ & $78.4(76.5-80.2)$ & $72.0(70.2-73.8)$ & $71.2(69.2-73.0)$ & $11.6(10.3-13.0)$ & $12.1(10.7-13.6)$ \\
\hline Massachusetts & 10,001 & 94.7 (93.9-95.4) & $94.5(93.7-95.3)$ & $87.5(86.4-88.5)$ & $86.6(85.4-87.7)$ & $75.2(73.8-76.4)$ & $74.2(72.8-75.6)$ & $9.5(8.6-10.5)$ & $9.7(8.8-10.7)$ \\
\hline Michigan & 5,578 & $87.4(86.2-88.5)$ & $86.8(85.5-88.0)$ & $80.7(79.3-82.0)$ & $79.4(77.8-80.8)$ & $67.8(66.2-69.3)$ & $66.5(64.8-68.1)$ & $16.8(15.6-18.1)$ & $17.4(16.0-18.8)$ \\
\hline Minnesota & 11,892 & $91.3(90.5-91.9)$ & $90.8(90.0-91.6)$ & $72.1(71.1-73.1)$ & 70.7 (69.6-71.7) & $65.6(64.6-66.7)$ & $64.8(63.6-65.8)$ & 10.6 (9.9-11.3) & $10.9(10.1-11.6)$ \\
\hline Nevada & 2,467 & 79.4 (76.7-81.9) & $78.8(76.0-81.4)$ & $58.5(55.5-61.4)$ & $57.2(54.2-60.2)$ & $59.0(56.0-62.0)$ & $58.4(55.3-61.4)$ & $20.1(17.8-22.7)$ & $20.3(17.9-23.0)$ \\
\hline New Jersey & 9,095 & $85.0(83.9-86.1)$ & $84.2(82.9-85.3)$ & $78.5(77.3-79.8)$ & $77.2(75.8-78.6)$ & $72.3(70.9-73.7)$ & $71.3(69.8-72.7)$ & $15.9(14.8-17.0)$ & $16.2(15.1-17.4)$ \\
\hline New Mexico & 5,977 & $81.2(79.5-82.8)$ & $80.4(78.6-82.0)$ & $64.5(62.6-66.4)$ & $63.3(61.3-65.2)$ & $57.7(55.8-59.6)$ & $56.7(54.7-58.7)$ & $19.9(18.4-21.5)$ & $20.3(18.8-22.0)$ \\
\hline New York & 4,785 & $85.4(84.0-86.7)$ & $84.7(83.2-86.1)$ & $78.3(76.8-79.8)$ & $77.3(75.7-78.9)$ & $71.5(69.8-73.1)$ & $70.6(68.9-72.3)$ & $15.8(14.5-17.2)$ & $16.3(14.9-17.7)$ \\
\hline North Dakota & 5,009 & $89.6(88.0-91.0)$ & 89.5 (87.9-90.9) & $66.1(63.9-68.2)$ & $65.5(63.3-67.6)$ & $59.7(57.5-61.8)$ & $59.2(57.0-61.4)$ & $7.9(6.8-9.3)$ & $8.0(6.9-9.4)$ \\
\hline Ohio & 6,941 & $87.6(86.2-88.8)$ & $87.1(85.6-88.5)$ & $76.3(74.6-77.9)$ & $74.8(73.0-76.5)$ & $66.0(64.3-67.7)$ & $64.5(62.7-66.3)$ & $15.1(13.9-16.5)$ & $15.3(13.9-16.7)$ \\
\hline Oregon & 3,199 & $86.5(84.8-88.1)$ & $85.9(84.1-87.6)$ & $72.7(70.6-74.6)$ & $71.2(69.0-73.3)$ & $56.9(54.7-59.1)$ & $56.0(53.7-58.3)$ & $17.1(15.5-18.8)$ & $17.6(15.9-19.4)$ \\
\hline Rhode Island & 4,270 & $90.3(88.7-91.7)$ & $89.7(88.0-91.2)$ & 83.7 (81.9-85.4) & $82.6(80.6-84.4)$ & $76.7(74.8-78.5)$ & $75.5(73.5-77.5)$ & $13.7(12.2-15.3)$ & $14.1(12.5-15.8)$ \\
\hline Vermont & 4,659 & $91.7(90.6-92.6)$ & $91.2(90.0-92.3)$ & $84.2(82.7-85.5)$ & $83.0(81.4-84.4)$ & $63.3(61.6-65.0)$ & $61.6(59.8-63.4)$ & $10.5(9.4-11.6)$ & 10.6 ( 9.6-11.8) \\
\hline Washington & 6,465 & $87.1(85.8-88.3)$ & $86.6(85.2-87.9)$ & $70.4(68.8-72.0)$ & $68.9(67.2-70.5)$ & $60.4(58.8-62.0)$ & $59.6(57.9-61.3)$ & $14.0(12.9-15.2)$ & $14.2(13.1-15.5)$ \\
\hline West Virginia & 4,165 & $87.0(85.6-88.3)$ & $86.2(84.7-87.6)$ & $72.6(70.9-74.3)$ & $70.4(68.6-72.2)$ & $72.7(71.0-74.4)$ & $71.2(69.3-73.0)$ & $19.7(18.2-21.2)$ & $20.4(18.9-22.1)$ \\
\hline Median & & 87.5 & 87.0 & 76.0 & 74.6 & 65.8 & 64.8 & 14.5 & 14.7 \\
\hline Range & & $79.4-94.7$ & $78.8-94.5$ & $58.5-87.5$ & $57.2-86.6$ & $56.9-76.7$ & $56.0-75.5$ & $7.9-21.7$ & $8.0-21.9$ \\
\hline
\end{tabular}

See table footnotes on next page. 
TABLE 1. (Continued) Crude and age-standardized* prevalence estimates of health insurance coverage, usual source of health care, routine checkup within the preceding 12 months, and cost barrier to health care need during the preceding 12 months among adults aged 18-64 years, by state Medicaid expansion status - Behavioral Risk Factor Surveillance System, United States, 2014

\begin{tabular}{|c|c|c|c|c|c|c|c|c|c|}
\hline \multirow{2}{*}{$\begin{array}{l}\text { State } \\
\text { Medicaid } \\
\text { expansion } \\
\text { status }\end{array}$} & \multirow[b]{2}{*}{$\mathrm{n}^{\dagger}$} & \multicolumn{2}{|c|}{$\begin{array}{c}\text { Insured at the time } \\
\text { of interview } \\
\end{array}$} & \multicolumn{2}{|c|}{$\begin{array}{l}\text { Usual source } \\
\text { of health care }\end{array}$} & \multicolumn{2}{|c|}{$\begin{array}{l}\text { Routine checkup within } \\
\text { preceding } 12 \text { mos }\end{array}$} & \multicolumn{2}{|c|}{$\begin{array}{l}\text { Cost barrier to health care need } \\
\text { during preceding } 12 \text { mos }\end{array}$} \\
\hline & & $\begin{array}{c}\text { Crude } \\
\%{ }^{\text {ๆ }}(95 \% \mathrm{Cl})\end{array}$ & $\begin{array}{c}\text { Age } \\
\text { standardized } \\
\%(95 \% \mathrm{Cl})\end{array}$ & $\begin{array}{c}\text { Crude } \\
\%(95 \% \mathrm{Cl})\end{array}$ & $\begin{array}{c}\text { Age } \\
\text { standardized } \\
\%(95 \% \mathrm{Cl})\end{array}$ & $\begin{array}{c}\text { Crude } \\
\%(95 \% \mathrm{Cl})\end{array}$ & $\begin{array}{c}\text { Age } \\
\text { standardized } \\
\%(95 \% \mathrm{Cl})\end{array}$ & $\begin{array}{c}\text { Crude } \\
\%(95 \% \mathrm{CI})\end{array}$ & $\begin{array}{c}\text { Age } \\
\text { standardized } \\
\%(95 \% \mathrm{Cl})\end{array}$ \\
\hline $\begin{array}{l}\text { Medicaid } \\
\text { nonexpansion } \\
\text { states }^{\dagger \dagger}\end{array}$ & 148,401 & & & & & & & & \\
\hline Alabama & 5,516 & $82.7(81.1-84.1)$ & $81.9(80.2-83.4)$ & $71.6(69.8-73.3)$ & $70.3(68.5-72.1)$ & $67.7(65.8-69.4)$ & $66.7(64.8-68.6)$ & $20.3(18.8-21.8)$ & $20.5(19.0-22.1)$ \\
\hline Alaska & 3,400 & $83.0(81.0-84.8)$ & $82.6(80.6-84.4)$ & $62.9(60.5-65.2)$ & $61.8(59.4-64.1)$ & $54.6(52.2-56.9)$ & $53.9(51.5-56.3)$ & $13.4(11.8-15.1)$ & $13.6(12.0-15.4)$ \\
\hline Florida & 5,504 & $77.3(75.8-78.9)$ & 76.7 (75.0-78.3) & $69.8(68.1-71.4)$ & $68.0(66.3-69.7)$ & $67.3(65.7-68.9)$ & $66.3(64.6-68.0)$ & $21.8(20.4-23.3)$ & $22.1(20.6-23.7)$ \\
\hline Georgia & 4,162 & $75.2(73.2-77.0)$ & $74.6(72.6-76.4)$ & $67.2(65.1-69.1)$ & $66.1(64.1-68.1)$ & $68.0(66.0-69.9)$ & $67.3(65.3-69.3)$ & $21.5(19.8-23.2)$ & $21.7(20.0-23.5)$ \\
\hline Idaho & 3,552 & $79.9(77.9-81.7)$ & $79.4(77.4-81.3)$ & $65.5(63.2-67.8)$ & $64.7(62.3-67.0)$ & $52.9(50.6-55.2)$ & $52.1(49.7-54.4)$ & $18.3(16.5-20.2)$ & $18.7(16.9-20.6)$ \\
\hline Indiana & 7,365 & $82.1(80.9-83.3)$ & $81.4(80.0-82.6)$ & $76.8(75.5-78.1)$ & $75.6(74.1-76.9)$ & $60.5(59.0-62.0)$ & $59.5(58.0-61.1)$ & $17.9(16.7-19.1)$ & $18.4(17.2-19.7)$ \\
\hline Kansas & 9,319 & $82.5(81.4-83.4)$ & $81.9(80.8-82.9)$ & $77.1(75.9-78.1)$ & $76.2(75.1-77.3)$ & $63.4(62.2-64.6)$ & $62.5(61.2-63.7)$ & $14.5(13.6-15.4)$ & $14.8(13.9-15.8)$ \\
\hline Louisiana & 4,698 & $77.4(75.8-78.9)$ & $76.9(75.3-78.5)$ & $69.8(68.1-71.5)$ & $68.8(67.1-70.6)$ & $71.8(70.1-73.4)$ & $71.1(69.4-72.8)$ & $19.9(18.5-21.4)$ & $20.1(18.6-21.6)$ \\
\hline Maine & 5,784 & $86.1(84.8-87.3)$ & $85.5(84.0-86.9)$ & $85.3(83.9-86.6)$ & $83.9(82.3-85.3)$ & $67.2(65.5-68.8)$ & $65.2(63.3-67.0)$ & $13.4(12.2-14.6)$ & $13.8(12.5-15.2)$ \\
\hline Mississippi & 2,632 & $77.1(74.7-79.3)$ & 76.6 (74.1-78.9) & $69.1(66.6-71.6)$ & $68.6(66.1-71.0)$ & $68.9(66.4-71.3)$ & $68.4(65.8-70.8)$ & $22.7(20.7-25.0)$ & $23.1(20.9-25.4)$ \\
\hline Missouri & 4,304 & $83.9(82.2-85.5)$ & $83.2(81.4-84.9)$ & $75.0(73.0-76.9)$ & 73.7 (71.6-75.7) & $62.1(60.0-64.1)$ & $60.8(58.6-62.9)$ & $16.2(14.7-17.8)$ & $16.8(15.2-18.5)$ \\
\hline Montana & 4,684 & $83.9(82.2-85.4)$ & $83.5(81.8-85.1)$ & $65.4(63.4-67.3)$ & $63.7(61.6-65.8)$ & $58.4(56.4-60.4)$ & $57.4(55.3-59.5)$ & $14.0(12.6-15.5)$ & $14.1(12.7-15.7)$ \\
\hline Nebraska & 14,554 & $84.8(83.7-85.8)$ & $84.2(83.1-85.2)$ & $76.1(74.9-77.3)$ & $75.3(74.1-76.5)$ & $58.6(57.3-59.9)$ & $57.8(56.4-59.1)$ & $13.8(12.8-14.7)$ & $14.1(13.2-15.1)$ \\
\hline New Hampshire & 3,981 & $85.9(84.2-87.5)$ & $85.0(83.0-86.7)$ & $82.0(80.0-83.8)$ & $80.1(78.0-82.1)$ & $64.6(62.5-66.8)$ & $62.1(59.8-64.3)$ & $12.9(11.5-14.5)$ & $13.5(12.0-15.3)$ \\
\hline North Carolina & 4,960 & $80.2(78.9-81.5)$ & 79.3 (77.9-80.7) & $71.7(70.2-73.2)$ & $70.4(68.8-71.9)$ & $71.8(70.3-73.3)$ & $70.7(69.1-72.2)$ & $18.7(17.5-20.0)$ & $18.9(17.6-20.3)$ \\
\hline Oklahoma & 5,422 & $82.9(81.5-84.1)$ & $82.4(81.0-83.7)$ & $70.5(68.9-72.1)$ & $69.7(68.1-71.3)$ & $59.2(57.5-60.8)$ & $58.5(56.8-60.2)$ & $17.6(16.4-19.0)$ & $17.9(16.6-19.3)$ \\
\hline Pennsylvania & 7,013 & $87.4(86.2-88.6)$ & $86.9(85.5-88.1)$ & $81.7(80.3-83.0)$ & $80.2(78.7-81.6)$ & $67.9(66.4-69.4)$ & $66.5(64.9-68.1)$ & $14.2(13.0-15.4)$ & $14.7(13.5-16.1)$ \\
\hline South Carolina & 7,034 & $78.7(77.4-80.1)$ & 78.1 (76.7-79.5) & $72.0(70.5-73.5)$ & $70.7(69.2-72.2)$ & $62.3(60.8-63.9)$ & $61.2(59.6-62.8)$ & $21.3(20.1-22.6)$ & $21.7(20.4-23.1)$ \\
\hline South Dakota & 4,874 & $87.8(85.8-89.5)$ & $87.6(85.5-89.4)$ & $71.7(69.3-73.9)$ & $70.7(68.3-73.0)$ & $65.3(62.9-67.6)$ & $64.6(62.1-67.0)$ & $11.7(10.2-13.4)$ & $11.9(10.3-13.8)$ \\
\hline Tennessee & 3,137 & $82.4(80.3-84.3)$ & $81.8(79.6-83.8)$ & $70.9(68.5-73.2)$ & $69.6(67.1-71.9)$ & $70.3(67.9-72.6)$ & $69.4(66.9-71.8)$ & $18.2(16.4-20.1)$ & $18.1(16.3-20.1)$ \\
\hline Texas & 10,086 & $71.0(69.6-72.4)$ & $70.8(69.3-72.2)$ & $62.6(61.0-64.1)$ & $62.0(60.5-63.5)$ & $63.5(62.0-65.0)$ & $63.1(61.6-64.6)$ & $19.8(18.6-21.1)$ & $19.9(18.7-21.2)$ \\
\hline Utah & 11,430 & $83.9(83.0-84.7)$ & 84.1 (83.2-84.9) & $67.7(66.6-68.7)$ & $68.3(67.3-69.3)$ & $54.1(53.0-55.2)$ & $54.4(53.3-55.5)$ & $15.9(15.1-16.8)$ & $16.0(15.2-16.8)$ \\
\hline Virginia & 6,587 & $84.3(83.0-85.6)$ & $83.8(82.4-85.1)$ & $72.2(70.6-73.7)$ & $70.9(69.3-72.5)$ & $69.8(68.2-71.3)$ & $68.9(67.3-70.5)$ & $15.0(13.8-16.2)$ & $15.1(13.9-16.4)$ \\
\hline Wisconsin & 4,777 & $89.6(88.2-90.9)$ & 89.1 (87.5-90.5) & $78.1(76.3-79.8)$ & 76.6 (74.7-78.4) & $65.4(63.5-67.3)$ & $64.5(62.5-66.5)$ & $12.5(11.2-13.9)$ & $12.6(11.2-14.1)$ \\
\hline Wyoming & 3,626 & $81.6(79.3-83.7)$ & $81.1(78.6-83.3)$ & $65.1(62.5-67.7)$ & $64.0(61.3-66.7)$ & $54.3(51.7-56.9)$ & $53.2(50.4-55.9)$ & $13.5(11.7-15.5)$ & $13.8(11.9-16.0)$ \\
\hline Median & & 82.7 & 81.9 & 71.6 & 70.3 & 64.6 & 63.1 & 16.2 & 16.8 \\
\hline Range & & $71.0-89.6$ & $70.8-89.1$ & $62.6-85.3$ & $61.8-83.9$ & $52.9-71.8$ & $52.1-71.1$ & $11.7-22.7$ & $11.9-23.1$ \\
\hline Overall median & & 84.8 & 84.2 & 72.4 & 71.2 & 65.4 & 64.5 & 15.1 & 15.3 \\
\hline Overall range & & $71.0-94.7$ & $70.8-94.5$ & $58.5-87.5$ & $57.2-86.6$ & $52.9-76.7$ & $52.1-75.5$ & $7.9-22.7$ & $8.0-23.1$ \\
\hline
\end{tabular}

Abbreviations: $\mathrm{Cl}=$ confidence interval; $\mathrm{n}=$ sample size; $\mathrm{N}=$ weighted population.

* Age standardized to the 2000 projected population for the United States.

† Unweighted sample size.

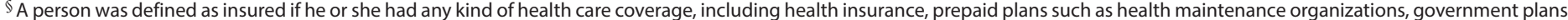

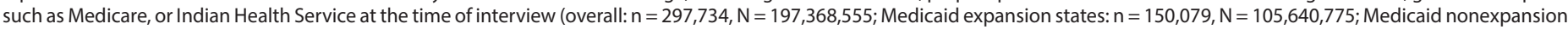
states: $\mathrm{n}=147,655, \mathrm{~N}=91,727,780)$.

Weighted percentage.

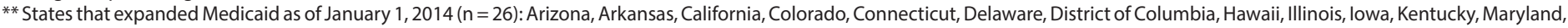
Massachusetts, Michigan, Minnesota, Nevada, New Jersey, New Mexico, New York, North Dakota, Ohio, Oregon, Rhode Island, Vermont, Washington, and West Virginia.

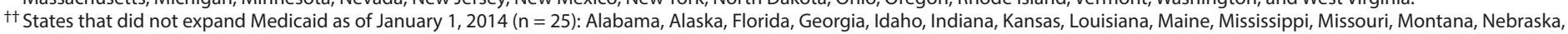
New Hampshire, North Carolina, Oklahoma, Pennsylvania, South Carolina, South Dakota, Tennessee, Texas, Utah, Virginia, Wisconsin, and Wyoming. 
TABLE 2. Crude and age-standardized* prevalence estimates of health insurance coverage, usual source of health care, routine checkup within the preceding 12 months, and cost barrier to health care need during the preceding 12 months among adults aged 18-64 years, by state Medicaid expansion status and expanded geographic regions - Behavioral Risk Factor Surveillance System, United States, 2014

\begin{tabular}{|c|c|c|c|c|c|c|c|c|}
\hline \multirow[b]{2}{*}{ Category } & \multicolumn{2}{|c|}{$\begin{array}{l}\text { Insured at the time } \\
\text { of interview }\end{array}$} & \multicolumn{2}{|c|}{$\begin{array}{l}\text { Usual source } \\
\text { of health care }\end{array}$} & \multicolumn{2}{|c|}{$\begin{array}{l}\text { Routine checkup } \\
\text { within preceding } 12 \text { mos }\end{array}$} & \multicolumn{2}{|c|}{$\begin{array}{l}\text { Cost barrier to health care need during } \\
\text { preceding } 12 \text { mos }\end{array}$} \\
\hline & $\begin{array}{c}\text { Crude } \\
\% \S(95 \% \mathrm{Cl})\end{array}$ & $\begin{array}{c}\text { Age } \\
\text { standardized } \\
\%(95 \% \mathrm{Cl})\end{array}$ & $\begin{array}{c}\text { Crude } \\
\%(95 \% \mathrm{Cl})\end{array}$ & $\begin{array}{c}\text { Age } \\
\text { standardized } \\
\%(95 \% \mathrm{Cl})\end{array}$ & $\begin{array}{c}\text { Crude } \\
\%(95 \% \mathrm{Cl})\end{array}$ & $\begin{array}{c}\text { Age } \\
\text { standardized } \\
\%(95 \% \mathrm{Cl})\end{array}$ & $\begin{array}{c}\text { Crude } \\
\%(95 \% \mathrm{Cl})\end{array}$ & $\begin{array}{c}\text { Age } \\
\text { standardized } \\
\%(95 \% \mathrm{Cl})\end{array}$ \\
\hline \multicolumn{9}{|c|}{ State Medicaid expansion status } \\
\hline $\begin{array}{l}\text { Medicaid } \\
\text { expansion } \\
\text { states }\end{array}$ & $85.8(85.4-86.2)$ & $85.3(84.8-85.7)$ & $75.0(74.5-75.4)$ & $73.8(73.4-74.3)$ & $65.8(65.4-66.3)$ & $65.0(64.5-65.5)$ & $15.0(14.6-15.4)$ & $15.3(14.9-15.7)$ \\
\hline $\begin{array}{l}\text { Medicaid } \\
\text { nonexpansion } \\
\text { states** }^{* *}\end{array}$ & $79.7(79.3-80.1)$ & $79.1(78.7-79.5)$ & $70.9(70.5-71.4)$ & $69.7(69.3-70.2)$ & $65.7(65.3-66.2)$ & $64.9(64.4-65.3)$ & $18.3(17.9-18.7)$ & $18.5(18.1-18.9)$ \\
\hline \multicolumn{9}{|c|}{ Expanded geographic regions ${ }^{\dagger \dagger}$} \\
\hline New England & $91.5(90.9-92.0)$ & $91.0(90.5-91.6)$ & $84.9(84.2-85.5)$ & $83.6(82.8-84.3)$ & $71.4(70.6-72.2)$ & $70.2(69.3-71.0)$ & $11.3(10.8-11.9)$ & $11.6(11.0-12.3)$ \\
\hline Middle Atlantic & $86.5(85.8-87.1)$ & $85.7(85.0-86.5)$ & $79.4(78.6-80.2)$ & $78.2(77.3-79.0)$ & $70.8(69.9-71.6)$ & $69.7(68.8-70.6)$ & $14.8(14.1-15.4)$ & $15.2(14.5-15.9)$ \\
\hline East North Central & $86.5(85.8-87.2)$ & $85.9(85.1-86.6)$ & $77.9(77.1-78.7)$ & $76.7(75.9-77.5)$ & $65.4(64.5-66.2)$ & $64.3(63.4-65.2)$ & $15.2(14.6-15.9)$ & $15.5(14.8-16.2)$ \\
\hline West North Central & $87.0(86.5-87.6)$ & $86.5(85.9-87.1)$ & $74.5(73.8-75.1)$ & $73.3(72.6-74.0)$ & $63.6(62.9-64.4)$ & $62.6(61.8-63.4)$ & $12.9(12.4-13.5)$ & $13.3(12.8-13.9)$ \\
\hline South Atlantic & $79.0(78.3-79.7)$ & $78.3(77.5-79.1)$ & $70.3(69.5-71.1)$ & $68.8(68.0-69.7)$ & $68.4(67.6-69.2)$ & $67.4(66.6-68.2)$ & $20.0(19.3-20.7)$ & $20.3(19.6-21.0)$ \\
\hline East South Central & $82.9(82.0-83.8)$ & $82.3(81.3-83.3)$ & $71.9(70.8-73.0)$ & $70.8(69.6-71.9)$ & $68.8(67.7-69.9)$ & $68.0(66.8-69.1)$ & $19.5(18.6-20.4)$ & $19.6(18.7-20.6)$ \\
\hline West South Central & 73.7 (72.6-74.7) & $73.3(72.2-74.4)$ & $65.1(63.9-66.2)$ & $64.4(63.2-65.5)$ & $63.9(62.8-65.0)$ & $63.4(62.3-64.5)$ & $19.8(18.9-20.7)$ & $19.9(19.0-20.8)$ \\
\hline Mountain & $82.5(81.9-83.1)$ & $82.1(81.4-82.7)$ & $66.8(66.1-67.5)$ & $66.0(65.3-66.7)$ & $57.5(56.7-58.2)$ & $56.8(56.1-57.6)$ & $17.2(16.6-17.8)$ & $17.4(16.8-18.0)$ \\
\hline Pacific & $83.6(82.7-84.5)$ & $83.2(82.2-84.1)$ & $70.8(69.8-71.9)$ & $69.9(68.8-71.0)$ & $61.9(60.8-63.1)$ & $61.3(60.2-62.5)$ & $15.0(14.2-15.9)$ & $15.2(14.4-16.1)$ \\
\hline Overall & $83.0(82.7-83.3)$ & $82.4(82.1-82.7)$ & $73.1(72.8-73.4)$ & $71.9(71.6-72.3)$ & $65.8(65.5-66.1)$ & $64.9(64.6-65.3)$ & $16.5(16.3-16.8)$ & $16.8(16.5-17.1)$ \\
\hline
\end{tabular}

Abbreviations: $\mathrm{Cl}=$ confidence interval; $\mathrm{n}=$ sample size; $\mathrm{N}=$ weighted population.

* Age standardized to the 2000 projected population for the United States.

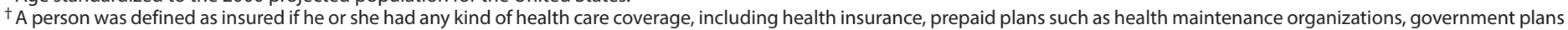

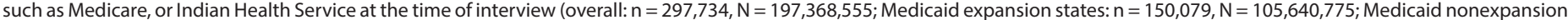
states: $\mathrm{n}=147,655, \mathrm{~N}=91,727,780)$.

$\$$ Weighted percentage.

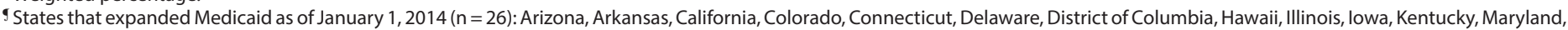
Massachusetts, Michigan, Minnesota, Nevada, New Jersey, New Mexico, New York, North Dakota, Ohio, Oregon, Rhode Island, Vermont, Washington, and West Virginia.

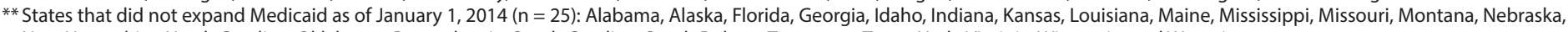
New Hampshire, North Carolina, Oklahoma, Pennsylvania, South Carolina, South Dakota, Tennessee, Texas, Utah, Virginia, Wisconsin, and Wyoming.

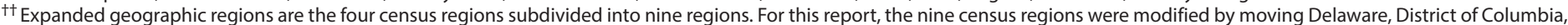

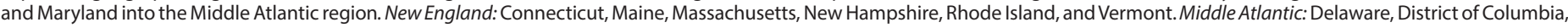

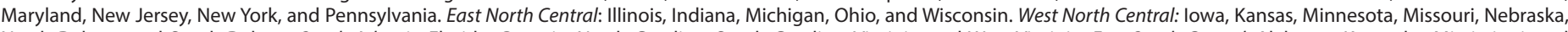

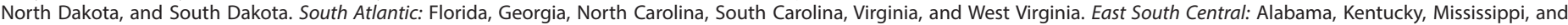

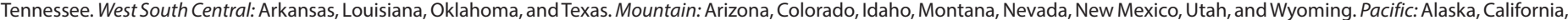
Hawaii, Oregon, and Washington. 
TABLE 3. Crude and age-standardized* prevalence estimates of health insurance coverage, usual source of health care, routine checkup within the preceding 12 months, and cost barrier to health care need during the preceding 12 months among adults aged 18-64 years, by federal poverty level, state Medicaid expansion status, and expanded geographic regions - Behavioral Risk Factor Surveillance System, United States, 2014

\begin{tabular}{|c|c|c|c|c|c|c|c|c|}
\hline \multirow[b]{2}{*}{ Category } & \multicolumn{2}{|c|}{$\begin{array}{l}\text { Insured at time } \\
\text { of interview }^{\dagger}\end{array}$} & \multicolumn{2}{|c|}{$\begin{array}{l}\text { Usual source } \\
\text { of health care }\end{array}$} & \multicolumn{2}{|c|}{$\begin{array}{c}\text { Routine checkup } \\
\text { within preceding } 12 \mathrm{mos}\end{array}$} & \multicolumn{2}{|c|}{$\begin{array}{l}\text { Cost barrier to health care need } \\
\text { during preceding } 12 \text { mos }\end{array}$} \\
\hline & $\begin{array}{c}\text { Crude } \\
\% \S(95 \% \mathrm{Cl})\end{array}$ & $\begin{array}{l}\text { Age standardized } \\
\quad \%(95 \% \mathrm{Cl})\end{array}$ & $\begin{array}{c}\text { Crude } \\
\%(95 \% \mathrm{Cl})\end{array}$ & $\begin{array}{c}\text { Age standardized } \\
\%(95 \% \mathrm{Cl})\end{array}$ & $\begin{array}{c}\text { Crude } \\
\%(95 \% \mathrm{Cl})\end{array}$ & $\begin{array}{c}\text { Age standardized } \\
\%(95 \% \mathrm{Cl})\end{array}$ & $\begin{array}{c}\text { Crude } \\
\%(95 \% \mathrm{Cl})\end{array}$ & $\begin{array}{c}\text { Age standardized } \\
\%(95 \% \mathrm{Cl})\end{array}$ \\
\hline \multicolumn{9}{|c|}{ State Medicaid expansion status } \\
\hline \multicolumn{9}{|c|}{ Medicaid expansion states } \\
\hline$<100$ of FPL & $71.4(70.1-72.7)$ & $71.4(70.1-72.7)$ & $63.0(61.6-64.4)$ & $63.9(62.5-65.2)$ & $60.8(59.4-62.2)$ & $61.2(59.8-62.5)$ & $27.6(26.4-28.9)$ & $28.1(26.8-29.3)$ \\
\hline $\begin{array}{l}\geq 100 \%-\leq 400 \% \\
\text { of FPL }\end{array}$ & $83.8(83.1-84.4)$ & $83.3(82.6-84.1)$ & $72.5(71.7-73.3)$ & $71.3(70.4-72.1)$ & $63.9(63.0-64.8)$ & $63.0(62.1-63.9)$ & $18.7(18.0-19.4)$ & $18.8(18.1-19.5)$ \\
\hline$>400 \%$ of FPL & $96.4(96.0-96.7)$ & $96.1(95.6-96.5)$ & $85.0(84.4-85.6)$ & $82.9(82.1-83.6)$ & $69.9(69.1-70.6)$ & $68.5(67.7-69.4)$ & $4.8(4.5-5.2)$ & $5.0(4.6-5.4)$ \\
\hline Unknown & $83.6(82.5-84.5)$ & $83.2(82.1-84.2)$ & $72.2(71.0-73.3)$ & $72.6(71.4-73.7)$ & $66.6(65.4-67.7)$ & $66.1(64.9-67.3)$ & $15.3(14.4-16.2)$ & $16.1(15.2-17.1)$ \\
\hline \multicolumn{9}{|c|}{ Medicaid nonexpansion states ${ }^{* *}$} \\
\hline$<100$ of FPL & $55.8(54.5-57.1)$ & $55.9(54.6-57.1)$ & $56.9(55.6-58.1)$ & $57.7(56.5-59.0)$ & $58.2(57.0-59.5)$ & $58.5(57.3-59.8)$ & $38.1(36.9-39.4)$ & $38.5(37.3-39.8)$ \\
\hline $\begin{array}{l}\geq 100 \%-\leq 400 \% \\
\text { of FPL }\end{array}$ & $78.8(78.1-79.5)$ & $78.3(77.6-79.0)$ & $69.8(69.1-70.6)$ & $68.7(67.9-69.5)$ & $64.5(63.8-65.3)$ & $63.7(63.0-64.5)$ & $20.2(19.5-20.8)$ & $20.2(19.5-20.8)$ \\
\hline$>400 \%$ of FPL & $95.7(95.3-96.1)$ & $95.4(94.9-95.8)$ & $82.7(82.0-83.3)$ & $80.0(79.2-80.8)$ & $71.7(70.9-72.4)$ & 70.1 (69.2-70.9) & $5.5(5.1-5.9)$ & $5.6(5.2-6.1)$ \\
\hline Unknown & $76.2(75.0-77.4)$ & $75.3(73.9-76.6)$ & $65.6(64.3-66.9)$ & $66.2(64.8-67.6)$ & $64.9(63.5-66.1)$ & $64.9(63.5-66.3)$ & $17.6(16.6-18.7)$ & $18.9(17.7-20.1)$ \\
\hline \multicolumn{9}{|c|}{ Expanded geographic regions ${ }^{\dagger+}$} \\
\hline \multicolumn{9}{|c|}{ New England } \\
\hline$<100$ of FPL & 79.5 (77.0-81.7) & $79.4(77.0-81.6)$ & $74.2(71.5-76.7)$ & $74.8(72.3-77.2)$ & $67.4(64.6-70.2)$ & $68.0(65.3-70.6)$ & $22.3(20.0-24.9)$ & $22.6(20.3-25.0)$ \\
\hline $\begin{array}{l}\geq 100 \%-\leq 400 \% \\
\text { of FPL }\end{array}$ & $88.4(87.4-89.3)$ & $88.0(86.9-89.0)$ & $84.4(83.2-85.5)$ & $82.7(81.3-84.0)$ & $69.6(68.1-71.0)$ & $67.8(66.2-69.4)$ & $15.6(14.5-16.8)$ & $15.7(14.5-17.0)$ \\
\hline$>400 \%$ of FPL & 98.1 (97.6-98.4) & $97.9(97.2-98.4)$ & $92.0(91.2-92.7)$ & $90.3(89.2-91.3)$ & $74.0(72.8-75.2)$ & $72.3(70.8-73.8)$ & $4.1(3.6-4.7)$ & $4.1(3.5-4.7)$ \\
\hline Unknown & 89.8 (88.5-91.0) & $89.6(88.3-90.8)$ & $79.4(77.7-81.0)$ & $80.0(78.4-81.6)$ & $71.2(69.5-73.0)$ & $71.2(69.5-72.9)$ & $13.0(11.7-14.4)$ & $13.6(12.3-15.0)$ \\
\hline \multicolumn{9}{|l|}{ Middle Atlantic } \\
\hline$<100$ of $F P L$ & $71.6(69.2-73.9)$ & $71.8(69.4-74.0)$ & $69.8(67.3-72.2)$ & $70.2(67.8-72.5)$ & $67.3(64.8-69.8)$ & $67.6(65.1-70.0)$ & $30.1(27.8-32.5)$ & $30.0(27.7-32.4)$ \\
\hline $\begin{array}{l}\geq 100 \%-\leq 400 \% \\
\text { of FPL }\end{array}$ & $83.3(81.9-84.6)$ & $82.7(81.2-84.0)$ & $77.5(76.0-78.9)$ & $76.3(74.7-77.7)$ & $69.5(67.9-71.0)$ & $68.6(67.0-70.2)$ & $19.3(18.0-20.7)$ & $19.5(18.2-20.9)$ \\
\hline$>400 \%$ of FPL & $96.7(96.1-97.2)$ & $96.5(95.8-97.1)$ & $87.0(86.0-87.9)$ & $85.2(84.0-86.4)$ & $73.1(71.9-74.3)$ & $72.2(70.8-73.6)$ & $5.0(4.4-5.6)$ & $5.2(4.5-5.9)$ \\
\hline Unknown & $83.2(81.1-85.2)$ & $82.1(79.7-84.3)$ & $74.7(72.4-76.9)$ & $74.3(71.8-76.6)$ & $71.1(68.8-73.3)$ & 69.4 (66.9-71.8) & $13.7(12.0-15.5)$ & $14.9(13.0-17.0)$ \\
\hline \multicolumn{9}{|c|}{ East North Central } \\
\hline$<100$ of FPL & $70.6(67.9-73.1)$ & $70.4(67.8-72.9)$ & $66.6(63.9-69.2)$ & $67.8(65.2-70.3)$ & $61.3(58.5-64.0)$ & $61.8(59.1-64.4)$ & $29.7(27.2-32.3)$ & $30.7(28.2-33.3)$ \\
\hline $\begin{array}{l}\geq 100 \%-\leq 400 \% \\
\text { of FPL }\end{array}$ & $84.8(83.5-85.9)$ & $84.2(82.9-85.5)$ & $76.5(75.1-77.8)$ & $75.1(73.7-76.6)$ & $63.4(61.9-64.9)$ & $62.4(60.8-63.9)$ & $18.2(17.0-19.4)$ & $18.2(17.0-19.5)$ \\
\hline$>400 \%$ of FPL & $97.1(96.4-97.7)$ & $96.8(95.9-97.6)$ & $86.6(85.5-87.6)$ & $84.5(83.1-85.8)$ & $69.6(68.2-70.9)$ & $67.9(66.3-69.5)$ & $4.7(4.1-5.4)$ & $4.8(4.1-5.5)$ \\
\hline Unknown & $83.7(82.2-85.1)$ & $83.3(81.7-84.7)$ & $74.6(72.9-76.3)$ & $74.8(73.1-76.5)$ & $64.8(63.1-66.5)$ & $64.2(62.4-65.9)$ & $16.8(15.4-18.2)$ & $17.6(16.1-19.1)$ \\
\hline \multicolumn{9}{|c|}{ West North Central } \\
\hline$<100$ of FPL & $67.7(65.4-70.0)$ & $67.5(65.3-69.7)$ & $64.3(62.0-66.6)$ & $66.1(63.9-68.2)$ & $56.0(53.7-58.4)$ & $57.3(55.0-59.5)$ & $30.7(28.5-32.9)$ & $31.9(29.8-34.1)$ \\
\hline $\begin{array}{l}\geq 100 \%-\leq 400 \% \\
\text { of } \mathrm{FPL}\end{array}$ & $85.6(84.6-86.5)$ & $85.3(84.3-86.2)$ & $71.8(70.7-72.9)$ & $70.9(69.7-72.1)$ & $60.5(59.2-61.7)$ & $59.7(58.4-60.9)$ & $15.4(14.5-16.4)$ & $15.5(14.6-16.5)$ \\
\hline$>400 \%$ of FPL & $97.2(96.6-97.7)$ & $96.7(96.0-97.4)$ & $82.4(81.4-83.3)$ & $79.7(78.4-80.9)$ & $69.8(68.8-70.9)$ & $68.4(67.1-69.7)$ & $3.9(3.4-4.4)$ & $3.9(3.4-4.6)$ \\
\hline Unknown & $81.8(79.8-83.6)$ & $81.4(79.3-83.3)$ & $70.3(68.1-72.4)$ & $70.6(68.4-72.8)$ & $62.6(60.4-64.8)$ & $61.9(59.6-64.2)$ & $13.9(12.3-15.7)$ & $16.0(14.1-18.1)$ \\
\hline \multicolumn{9}{|l|}{ South Atlantic } \\
\hline$<100$ of $\mathrm{FPL}$ & $55.9(53.8-58.1)$ & $55.9(53.8-58.0)$ & $55.8(53.6-58.0)$ & $56.5(54.4-58.6)$ & $59.4(57.3-61.5)$ & $59.5(57.4-61.6)$ & $40.5(38.4-42.6)$ & $40.9(38.9-43.0)$ \\
\hline $\begin{array}{l}\geq 100 \%-\leq 400 \% \\
\text { of FPL }\end{array}$ & $77.9(76.7-79.1)$ & $77.4(76.1-78.6)$ & $69.3(67.9-70.6)$ & $67.8(66.4-69.1)$ & $67.8(66.5-69.1)$ & $66.9(65.5-68.2)$ & $21.5(20.5-22.7)$ & $21.6(20.5-22.8)$ \\
\hline$>400 \%$ of FPL & $95.1(94.3-95.8)$ & $94.6(93.6-95.4)$ & $82.6(81.4-83.7)$ & $79.6(78.2-81.0)$ & $74.6(73.3-75.8)$ & $72.7(71.3-74.2)$ & $6.1(5.5-6.8)$ & $6.3(5.6-7.1)$ \\
\hline Unknown & $76.6(74.5-78.6)$ & $75.0(72.7-77.2)$ & $65.7(63.4-67.9)$ & $65.9(63.5-68.2)$ & $68.0(65.9-70.1)$ & $67.6(65.3-69.9)$ & $19.9(18.0-21.9)$ & $21.1(19.0-23.4)$ \\
\hline \multicolumn{9}{|c|}{ East South Central } \\
\hline$<100$ of FPL & $67.5(64.9-70.0)$ & $67.7(65.1-70.1)$ & $64.3(61.5-67.0)$ & $64.7(62.1-67.3)$ & $64.5(62.3-66.6)$ & $63.7(61.0-66.3)$ & $37.5(35.0-40.1)$ & $37.4(34.9-40.0)$ \\
\hline $\begin{array}{l}\geq 100 \%-\leq 400 \% \\
\text { of FPL }\end{array}$ & $82.8(81.2-84.3)$ & $82.2(80.5-83.7)$ & $71.3(69.5-72.9)$ & $69.8(68.0-71.6)$ & $68.7(66.7-70.7)$ & $67.3(65.4-69.1)$ & $20.4(19.0-21.9)$ & $20.3(18.8-21.8)$ \\
\hline$>400 \%$ of FPL & $96.7(95.8-97.4)$ & $96.3(95.2-97.1)$ & $81.4(79.4-83.2)$ & $77.5(75.1-79.7)$ & $73.6(71.6-75.6)$ & $71.1(68.6-73.5)$ & $5.6(4.6-6.8)$ & $6.0(4.9-7.5)$ \\
\hline Unknown & $79.6(76.8-82.2)$ & $79.9(77.0-82.5)$ & $68.0(64.9-70.8)$ & $69.6(66.6-72.4)$ & $68.7(65.8-71.5)$ & $69.1(66.1-72.0)$ & $18.0(15.9-20.4)$ & $18.5(16.3-21.0)$ \\
\hline \multicolumn{9}{|c|}{ West South Central } \\
\hline$<100$ of $\mathrm{FPL}$ & $46.8(44.2-49.4)$ & $47.0(44.4-49.6)$ & $50.5(47.8-53.1)$ & $51.2(48.6-53.8)$ & $56.5(53.9-59.1)$ & $56.7(54.1-59.3)$ & $38.9(36.4-41.5)$ & $39.3(36.7-41.8)$ \\
\hline $\begin{array}{l}\geq 100 \%-\leq 400 \% \\
\text { of FPL }\end{array}$ & $73.1(71.3-74.8)$ & $72.9(71.1-74.7)$ & $63.9(62.0-65.8)$ & $63.3(61.4-65.2)$ & $62.5(60.6-64.4)$ & $62.1(60.2-64.0)$ & $21.5(20.0-23.0)$ & $21.4(19.9-23.0)$ \\
\hline$>400 \%$ of FPL & $94.9(93.9-95.7)$ & $94.8(93.8-95.6)$ & $80.6(78.9-82.3)$ & $78.4(76.3-80.3)$ & $72.5(70.6-74.3)$ & $71.4(69.2-73.4)$ & $5.2(4.3-6.2)$ & $5.1(4.3-6.1)$ \\
\hline Unknown & $70.1(67.3-72.8)$ & $69.5(66.5-72.3)$ & $57.6(54.6-60.5)$ & $59.0(56.1-61.9)$ & $60.3(57.2-63.3)$ & $61.4(58.3-64.4)$ & $18.6(16.5-20.9)$ & $20.2(17.9-22.8)$ \\
\hline
\end{tabular}

See table footnotes on next page. 
TABLE 3. (Continued) Crude and age-standardized* prevalence estimates of health insurance coverage, usual source of health care, routine checkup within the preceding 12 months, and cost barrier to health care need during the preceding 12 months among adults aged 18-64 years, by federal poverty level, state Medicaid expansion status, and expanded geographic regions - Behavioral Risk Factor Surveillance System, United States, 2014

\begin{tabular}{|c|c|c|c|c|c|c|c|c|}
\hline \multirow[b]{2}{*}{ Category } & \multicolumn{2}{|c|}{$\begin{array}{l}\text { Insured at time } \\
\text { of interview }^{\dagger}\end{array}$} & \multicolumn{2}{|c|}{$\begin{array}{l}\text { Usual source } \\
\text { of health care }\end{array}$} & \multicolumn{2}{|c|}{$\begin{array}{c}\text { Routine checkup } \\
\text { within preceding } 12 \text { mos }\end{array}$} & \multicolumn{2}{|c|}{$\begin{array}{l}\text { Cost barrier to health care need } \\
\text { during preceding } 12 \text { mos }\end{array}$} \\
\hline & $\begin{array}{c}\text { Crude } \\
\%^{\S}(95 \% \mathrm{Cl})\end{array}$ & $\begin{array}{l}\text { Age standardized } \\
\quad \%(95 \% \mathrm{Cl})\end{array}$ & $\begin{array}{c}\text { Crude } \\
\%(95 \% \mathrm{Cl})\end{array}$ & $\begin{array}{l}\text { Age standardized } \\
\quad \%(95 \% \mathrm{Cl})\end{array}$ & $\begin{array}{c}\text { Crude } \\
\%(95 \% \mathrm{Cl})\end{array}$ & $\begin{array}{l}\text { Age standardized } \\
\quad \%(95 \% \mathrm{Cl})\end{array}$ & $\begin{array}{c}\text { Crude } \\
\%(95 \% \mathrm{Cl})\end{array}$ & $\begin{array}{c}\text { Age standardized } \\
\%(95 \% \mathrm{Cl})\end{array}$ \\
\hline \multicolumn{9}{|l|}{ Mountain } \\
\hline$<100$ of FPL & $65.2(63.3-67.1)$ & $65.5(63.6-67.4)$ & $53.8(51.8-55.8)$ & $55.3(53.4-57.3)$ & $50.8(48.8-52.8)$ & $51.6(49.6-53.6)$ & $30.3(28.5-32.1)$ & $31.1(29.3-32.9)$ \\
\hline $\begin{array}{l}\geq 100 \%-\leq 400 \% \\
\text { of FPL }\end{array}$ & $80.5(79.4-81.5)$ & $80.4(79.2-81.4)$ & $64.3(63.0-65.5)$ & $63.8(62.5-65.0)$ & $54.1(52.9-55.4)$ & $53.8(52.6-55.0)$ & $20.5(19.5-21.5)$ & $20.5(19.5-21.5)$ \\
\hline$>400 \%$ of FPL & $95.9(95.4-96.4)$ & $95.6(95.0-96.2)$ & $78.3(77.3-79.3)$ & $76.0(74.7-77.3)$ & $64.8(63.7-65.8)$ & $62.6(61.3-64.0)$ & $6.1(5.6-6.7)$ & $6.3(5.7-7.1)$ \\
\hline Unknown & $78.3(76.4-80.2)$ & $77.5(75.4-79.4)$ & $63.0(60.9-65.1)$ & $63.1(60.9-65.2)$ & $57.5(55.3-59.6)$ & $56.8(54.6-59.0)$ & $17.8(16.1-19.6)$ & $19.3(17.4-21.4)$ \\
\hline \multicolumn{9}{|l|}{ Pacific } \\
\hline$<100$ of $\mathrm{FPL}$ & $70.1(67.5-72.5)$ & $69.8(67.2-72.3)$ & $58.8(56.2-61.4)$ & $59.4(56.8-62.0)$ & $57.7(55.0-60.3)$ & $57.8(55.1-60.4)$ & $25.9(23.7-28.2)$ & $26.3(24.0-28.7)$ \\
\hline $\begin{array}{l}\geq 100 \%-\leq 400 \% \\
\text { of FPL }\end{array}$ & $82.3(80.7-83.8)$ & $82.0(80.4-83.6)$ & $67.6(65.6-69.5)$ & $66.7(64.7-68.6)$ & $60.4(58.3-62.4)$ & $59.8(57.7-61.8)$ & $18.4(16.8-20.0)$ & $18.4(16.9-20.0)$ \\
\hline$>400 \%$ of FPL & $95.1(94.1-95.9)$ & 94.7 (93.5-95.6) & $83.3(81.8-84.6)$ & $80.8(79.1-82.5)$ & $65.1(63.3-66.9)$ & 63.7 (61.7-65.7) & $5.0(4.2-5.9)$ & $5.3(4.3-6.5)$ \\
\hline Unknown & $82.0(79.1-84.5)$ & $82.2(79.4-84.7)$ & $68.9(65.7-72.0)$ & $69.8(66.6-72.8)$ & $64.5(61.2-67.8)$ & $64.8(61.5-68.0)$ & $13.6(11.5-16.0)$ & $14.0(11.8-16.5)$ \\
\hline \multicolumn{9}{|l|}{ Overall } \\
\hline$<100$ of $\mathrm{FPL}$ & $64.2(63.2-65.1)$ & $64.2(63.2-65.1)$ & $60.2(59.2-61.1)$ & $61.0(60.1-61.9)$ & $59.6(58.7-60.6)$ & $59.9(59.0-60.9)$ & $32.5(31.6-33.4)$ & 32.9 (32.1-33.8) \\
\hline $\begin{array}{l}\geq 100 \%-\leq 400 \% \\
\text { of FPL }\end{array}$ & $81.2(80.8-81.7)$ & $80.8(80.3-81.3)$ & $71.1(70.6-71.7)$ & $70.0(69.4-70.5)$ & $64.2(63.6-64.8)$ & $63.4(62.8-64.0)$ & $19.4(19.0-19.9)$ & $19.5(19.0-20.0)$ \\
\hline$>400 \%$ of FPL & $96.1(95.8-96.3)$ & $95.8(95.5-96.1)$ & $84.0(83.5-84.4)$ & $81.6(81.1-82.2)$ & $70.7(70.2-71.2)$ & $69.2(68.6-69.8)$ & $5.1(4.9-5.4)$ & $5.3(5.0-5.6)$ \\
\hline Unknown & $80.5(79.7-81.2)$ & $80.0(79.1-80.8)$ & $69.4(68.5-70.3)$ & $70.0(69.1-70.8)$ & $65.8(65.0-66.7)$ & $65.6(64.7-66.5)$ & $16.3(15.6-16.9)$ & $17.2(16.5-18.0)$ \\
\hline
\end{tabular}

Abbreviations: $\mathrm{Cl}=$ confidence interval; $\mathrm{FPL}=$ federal poverty level; $\mathrm{n}=$ sample size; $\mathrm{N}=$ weighted population.

* Age-standardized to the 2000 projected population for the United States.

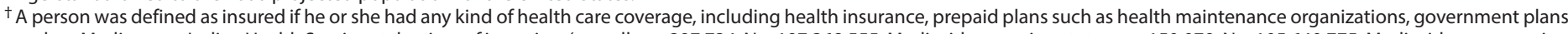

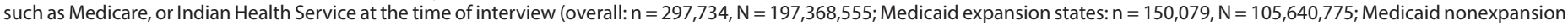
states: $\mathrm{n}=147,655, \mathrm{~N}=91,727,780)$.

$\S$ Weighted percentage.

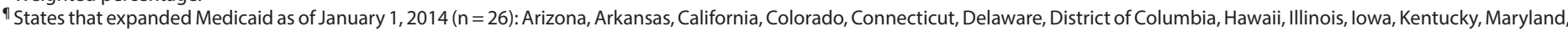
Massachusetts, Michigan, Minnesota, Nevada, New Jersey, New Mexico, New York, North Dakota, Ohio, Oregon, Rhode Island, Vermont, Washington, and West Virginia.

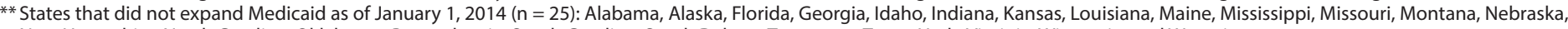
New Hampshire, North Carolina, Oklahoma, Pennsylvania, South Carolina, South Dakota, Tennessee, Texas, Utah, Virginia, Wisconsin, and Wyoming.

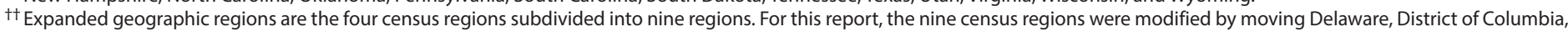

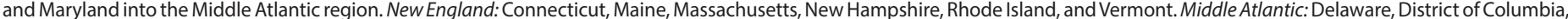

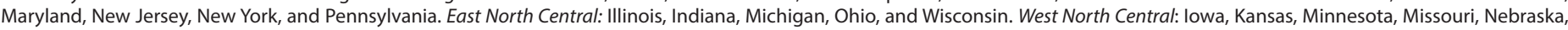

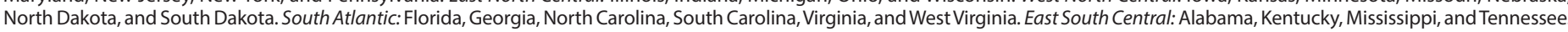

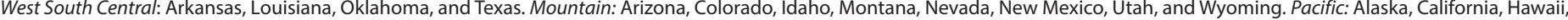
Oregon, and Washington. 
TABLE 4. Crude and age-standardized* prevalence estimates of clinical preventive services use among adults, by state Medicaid expansion status and expanded geographic regions - Behavioral Risk Factor Surveillance System, United States, 2014

\begin{tabular}{|c|c|c|c|c|c|c|}
\hline \multirow[b]{2}{*}{ Category } & \multicolumn{2}{|c|}{ Colorectal cancer screening $^{\dagger}$} & \multicolumn{2}{|c|}{ HIV test ${ }^{\S}$} & \multicolumn{2}{|c|}{ Influenza vaccination" } \\
\hline & $\begin{array}{c}\text { Crude } \\
\%^{* *}(95 \% \mathrm{Cl})\end{array}$ & $\begin{array}{c}\text { Age standardized } \\
\%(95 \% \mathrm{Cl})\end{array}$ & $\begin{array}{c}\text { Crude } \\
\%(95 \% \mathrm{Cl})\end{array}$ & $\begin{array}{c}\text { Age standardized } \\
\%(95 \% \mathrm{Cl})\end{array}$ & $\begin{array}{c}\text { Crude } \\
\%(95 \% \mathrm{Cl})\end{array}$ & $\begin{array}{c}\text { Age standardizec } \\
\%(95 \% \mathrm{Cl})\end{array}$ \\
\hline \multicolumn{7}{|l|}{ State Medicaid expansion status } \\
\hline Medicaid expansion states ${ }^{\dagger \dagger}$ & $61.8(61.1-62.6)$ & $61.1(60.3-61.8)$ & $41.8(41.3-42.3)$ & $43.2(42.7-43.7)$ & $34.3(33.8-34.8)$ & $33.6(33.1-34.1)$ \\
\hline Medicaid nonexpansion states $\$ \$$ & $59.5(58.7-60.2)$ & $58.6(57.8-59.3)$ & $42.0(41.5-42.4)$ & $43.3(42.8-43.8)$ & $33.4(32.9-33.8)$ & $32.8(32.3-33.2)$ \\
\hline \multicolumn{7}{|l|}{ Expanded geographic regions $s^{\text {กा }}$} \\
\hline New England & $71.1(70.0-72.2)$ & $70.5(69.3-71.7)$ & $41.1(40.2-42.0)$ & $43.4(42.5-44.3)$ & $39.0(38.1-39.9)$ & $38.2(37.2-39.1)$ \\
\hline Middle Atlantic & $62.8(61.4-64.1)$ & $62.2(60.9-63.5)$ & $46.3(45.3-47.2)$ & $47.8(46.8-48.7)$ & $34.3(33.4-35.2)$ & $33.5(32.6-34.4)$ \\
\hline East North Central & $60.8(59.5-62.0)$ & $60.1(58.9-61.4)$ & $35.5(34.6-36.3)$ & $37.2(36.3-38.2)$ & $32.8(32.0-33.6)$ & $32.1(31.3-33.0)$ \\
\hline West North Central & $61.1(60.0-62.1)$ & $60.3(59.2-61.4)$ & $32.0(31.3-32.8)$ & $33.7(32.9-34.4)$ & $38.1(37.4-38.9)$ & $37.4(36.6-38.1)$ \\
\hline South Atlantic & $61.2(60.0-62.4)$ & $60.1(58.9-61.3)$ & $48.5(47.7-49.4)$ & $50.0(49.1-50.9)$ & $32.0(31.2-32.7)$ & $31.3(30.6-32.1)$ \\
\hline East South Central & $58.4(56.9-60.0)$ & $57.4(55.8-59.0)$ & $43.2(42.0-44.4)$ & $44.8(43.6-46.0)$ & $35.0(33.9-36.1)$ & $34.2(33.1-35.3)$ \\
\hline West South Central & $54.9(53.0-56.8)$ & $54.1(52.2-56.0)$ & $40.4(39.2-41.6)$ & $41.1(40.0-42.3)$ & $34.5(33.5-35.7)$ & $34.1(33.0-35.2)$ \\
\hline Mountain & $57.4(56.3-58.4)$ & $56.2(55.1-57.3)$ & $37.2(36.4-38.0)$ & $38.1(37.3-38.8)$ & $32.7(32.0-33.4)$ & $32.3(31.7-33.0)$ \\
\hline Pacific & $61.0(58.9-62.9)$ & $60.0(58.0-62.0)$ & $43.8(42.5-45.0)$ & $44.8(43.6-46.1)$ & $32.6(31.4-33.8)$ & $32.0(30.9-33.2)$ \\
\hline Overall & $60.7(60.2-61.2)$ & $59.9(59.4-60.4)$ & $41.9(41.5-42.2)$ & $43.2(42.9-43.6)$ & $33.9(33.5-34.2)$ & $33.2(32.9-33.5)$ \\
\hline
\end{tabular}

Abbreviations: $\mathrm{Cl}=$ confidence interval; $\mathrm{n}=$ sample size; $\mathrm{N}=$ weighted population.

* Age standardized to the 2000 projected population for the United States.

${ }^{\dagger}$ Adults aged 50-64 years who have had a fecal occult blood test (FOBT) within the past year, or sigmoidoscopy within the past 5 years and an FOBT within the past

3 years, or colonoscopy within the past 10 years $(n=133,620, N=57,378,775)$.

$\S$ Adults aged 18-64 years ever tested for HIV $(n=269,889, N=174,047,283)$.

I Adults aged 18-64 years who received an influenza vaccination within the preceding 12 months $(\mathrm{n}=281,684, \mathrm{~N}=181,381,790)$.

** Weighted percentage.

+† States that expanded Medicaid as of January 1, $2014(\mathrm{n}=26)$ : Arizona, Arkansas, California, Colorado, Connecticut, Delaware, District of Columbia, Hawaii, Illinois, lowa, Kentucky, Maryland, Massachusetts, Michigan, Minnesota, Nevada, New Jersey, New Mexico, New York, North Dakota, Ohio, Oregon, Rhode Island, Vermont, Washington, and West Virginia.

$\S \S$ States that did not expand Medicaid as of January 1, $2014(\mathrm{n}=25)$ : Alabama, Alaska, Florida, Georgia, Idaho, Indiana, Kansas, Louisiana, Maine, Mississippi, Missouri, Montana, Nebraska, New Hampshire, North Carolina, Oklahoma, Pennsylvania, South Carolina, South Dakota, Tennessee, Texas, Utah, Virginia, Wisconsin, and Wyoming.

กी Expanded geographic regions are the four census regions subdivided into nine regions. For this report, the nine census regions were modified by moving Delaware, District of Columbia, and Maryland into the Middle Atlantic region. New England: Connecticut, Maine, Massachusetts, New Hampshire, Rhode Island, and Vermont. Middle Atlantic: Delaware, District of Columbia, Maryland, New Jersey, New York, and Pennsylvania. East North Central: Illinois, Indiana, Michigan, Ohio, and Wisconsin. West North Central: lowa, Kansas, Minnesota, Missouri, Nebraska, North Dakota, and South Dakota. South Atlantic: Florida, Georgia, North Carolina, South Carolina, Virginia, and West Virginia. East South Central: Alabama, Kentucky, Mississippi, and Tennessee. West South Central: Arkansas, Louisiana, Oklahoma, and Texas. Mountain: Arizona, Colorado, Idaho, Montana, Nevada, New Mexico, Utah, and Wyoming. Pacific: Alaska, California, Hawaii, Oregon, and Washington. 
TABLE 5. Crude and age-standardized* prevalence estimates of selected clinical preventive services use among adults, by federal poverty level, state Medicaid expansion status, and expanded geographic regions - Behavioral Risk Factor Surveillance System, United States, 2014

\begin{tabular}{|c|c|c|c|c|c|c|}
\hline \multirow[b]{2}{*}{ Category } & \multicolumn{2}{|c|}{ Colorectal cancer screening $^{\dagger}$} & \multicolumn{2}{|c|}{ HIV test ${ }^{\S}$} & \multicolumn{2}{|c|}{ Influenza vaccination" } \\
\hline & $\begin{array}{c}\text { Crude } \\
\%^{* *}(95 \% \mathrm{Cl})\end{array}$ & $\begin{array}{c}\text { Age standardized } \\
\%(95 \% \mathrm{Cl})\end{array}$ & $\begin{array}{c}\text { Crude } \\
\%(95 \% \mathrm{Cl})\end{array}$ & $\begin{array}{c}\text { Age standardized } \\
\%(95 \% \mathrm{Cl})\end{array}$ & $\begin{array}{c}\text { Crude } \\
\%(95 \% \mathrm{Cl})\end{array}$ & $\begin{array}{c}\text { Age standardized } \\
\%(95 \% \mathrm{Cl})\end{array}$ \\
\hline \multicolumn{7}{|c|}{ State Medicaid expansion status } \\
\hline $\begin{array}{l}\text { Medicaid expansion st } \\
<100 \text { of } \mathrm{FPL} \\
\geq 100 \%-\leq 400 \% \text { of FPL } \\
>400 \% \text { of FPL } \\
\text { Unknown }\end{array}$ & $\begin{array}{l}46.8(43.9-49.6) \\
56.5(55.2-57.9) \\
70.0(69.0-71.0) \\
62.1(60.2-63.9)\end{array}$ & $\begin{array}{l}46.8(44.0-49.7) \\
55.2(53.8-56.5) \\
69.6(68.5-70.6) \\
60.9(59.0-62.8)\end{array}$ & $\begin{array}{l}48.5(47.0-50.0) \\
43.0(42.1-43.9) \\
39.4(38.6-40.2) \\
37.8(36.5-39.0)\end{array}$ & $\begin{array}{l}49.1(47.6-50.6) \\
43.9(43.0-44.9) \\
40.6(39.7-41.5) \\
41.5(40.3-42.8)\end{array}$ & $\begin{array}{l}29.5(28.2-30.9) \\
30.9(30.1-31.7) \\
41.0(40.3-41.8) \\
31.6(30.4-32.8)\end{array}$ & $\begin{array}{l}29.9(28.6-31.3) \\
30.2(29.4-31.1) \\
39.4(38.5-40.3) \\
32.0(30.8-33.2)\end{array}$ \\
\hline $\begin{array}{l}\text { Medicaid nonexpansic } \\
<100 \text { of } \mathrm{FPL} \\
\geq 100 \%-\leq 400 \% \text { of FPL } \\
>400 \% \text { of FPL } \\
\text { Unknown }\end{array}$ & $\begin{array}{l}43.9(41.5-46.3) \\
56.3(55.2-57.5) \\
68.6(67.5-69.6) \\
56.3(54.2-58.5)\end{array}$ & $\begin{array}{l}43.8(41.5-46.2) \\
55.2(54.0-56.3) \\
67.9(66.9-69.0) \\
54.7(52.5-56.9)\end{array}$ & $\begin{array}{l}52.3(51.0-53.7) \\
42.9(42.1-43.7) \\
38.4(37.6-39.2) \\
34.4(33.0-35.8)\end{array}$ & $\begin{array}{l}52.4(51.1-53.7) \\
44.0(43.2-44.8) \\
39.0(38.1-39.9) \\
38.7(37.1-40.2)\end{array}$ & $\begin{array}{l}26.3(25.2-27.4) \\
31.4(30.7-32.1) \\
40.6(39.9-41.4) \\
30.7(29.4-32.0)\end{array}$ & $\begin{array}{l}26.5(25.4-27.6) \\
30.8(30.1-31.5) \\
39.1(38.2-40.0) \\
30.5(29.2-31.9)\end{array}$ \\
\hline \multicolumn{7}{|c|}{ Expanded geographic regions } \\
\hline $\begin{array}{l}\text { New England } \\
<100 \text { of FPL } \\
\geq 100 \%-\leq 400 \% \text { of FPL } \\
>400 \% \text { of FPL } \\
\text { Unknown }\end{array}$ & $\begin{array}{l}57.7(52.4-62.9) \\
65.9(63.7-68.0) \\
77.5(76.0-79.0) \\
67.3(64.1-70.3)\end{array}$ & $\begin{array}{l}57.7(52.4-62.9) \\
64.8(62.6-67.0) \\
77.2(75.6-78.7) \\
66.3(63.0-69.5)\end{array}$ & $\begin{array}{l}50.6(47.4-53.8) \\
42.4(40.7-44.0) \\
37.6(36.3-39.0) \\
41.3(39.2-43.4)\end{array}$ & $\begin{array}{l}51.9(48.9-54.8) \\
44.3(42.5-46.1) \\
40.3(38.7-41.8) \\
44.0(42.0-46.0)\end{array}$ & $\begin{array}{l}31.5(28.7-34.5) \\
36.1(34.6-37.7) \\
44.9(43.6-46.3) \\
35.9(34.0-37.9)\end{array}$ & $\begin{array}{l}31.9(29.1-34.8) \\
35.0(33.4-36.7) \\
43.9(42.2-45.6) \\
36.6(34.7-38.5)\end{array}$ \\
\hline $\begin{array}{l}\text { Middle Atlantic } \\
<100 \text { of FPL } \\
\geq 100 \%-\leq 400 \% \text { of FPL } \\
>400 \% \text { of FPL } \\
\text { Unknown }\end{array}$ & $\begin{array}{l}53.4(48.6-58.0) \\
58.5(56.1-60.8) \\
68.9(67.1-70.6) \\
60.5(56.5-64.3)\end{array}$ & $\begin{array}{l}53.3(48.7-57.8) \\
57.5(55.1-60.0) \\
68.6(66.8-70.3) \\
59.5(55.5-63.5)\end{array}$ & $\begin{array}{l}58.0(55.2-60.7) \\
47.7(46.0-49.4) \\
42.8(41.5-44.2) \\
39.6(36.9-42.4)\end{array}$ & $\begin{array}{l}58.0(55.2-60.6) \\
48.7(47.0-50.4) \\
44.2(42.6-45.7) \\
44.5(41.6-47.4)\end{array}$ & $\begin{array}{l}31.9(29.4-34.5) \\
29.8(28.3-31.3) \\
39.4(38.1-40.8) \\
33.6(31.2-36.2)\end{array}$ & $\begin{array}{l}32.1(29.7-34.6) \\
29.0(27.5-30.5) \\
37.8(36.3-39.3) \\
33.1(30.6-35.7)\end{array}$ \\
\hline $\begin{array}{l}\text { East North Central } \\
<100 \text { of FPL } \\
\geq 100 \%-\leq 400 \% \text { of FPL } \\
>400 \% \text { of FPL } \\
\text { Unknown }\end{array}$ & $\begin{array}{l}46.7(41.6-51.8) \\
56.8(54.6-59.0) \\
67.5(65.7-69.3) \\
60.5(57.8-63.1)\end{array}$ & $\begin{array}{l}47.1(42.2-52.1) \\
55.5(53.2-57.8) \\
67.2(65.3-69.0) \\
59.9(57.2-62.6)\end{array}$ & $\begin{array}{l}49.2(46.3-52.2) \\
34.5(33.0-36.1) \\
29.4(28.0-30.8) \\
37.4(35.6-39.2)\end{array}$ & $\begin{array}{l}49.6(46.7-52.4) \\
36.0(34.4-37.6) \\
30.7(29.2-32.2) \\
40.6(38.8-42.5)\end{array}$ & $\begin{array}{l}27.7(25.2-30.4) \\
30.5(29.1-32.0) \\
40.3(38.8-41.7) \\
28.2(26.6-29.8)\end{array}$ & $\begin{array}{l}28.3(25.8-31.0) \\
29.8(28.4-31.3) \\
38.7(37.1-40.4) \\
28.3(26.7-29.9)\end{array}$ \\
\hline $\begin{array}{l}\text { West North Central } \\
<100 \text { of FPL } \\
\geq 100 \%-\leq 400 \% \text { of FPL } \\
>400 \% \text { of FPL } \\
\text { Unknown }\end{array}$ & $\begin{array}{l}45.0(40.3-49.8) \\
54.4(52.5-56.2) \\
69.8(68.3-71.2) \\
59.2(55.8-62.5)\end{array}$ & $\begin{array}{l}45.1(40.4-49.9) \\
53.1(51.2-55.0) \\
69.3(67.8-70.7) \\
57.9(54.4-61.3)\end{array}$ & $\begin{array}{l}44.8(42.4-47.2) \\
33.9(32.7-35.2) \\
28.2(27.1-29.4) \\
25.3(23.1-27.5)\end{array}$ & $\begin{array}{l}46.1(43.8-48.4) \\
34.8(33.6-36.1) \\
29.3(28.0-30.6) \\
30.7(28.2-33.2)\end{array}$ & $\begin{array}{l}33.3(31.1-35.6) \\
34.3(33.2-35.5) \\
45.1(43.9-46.3) \\
34.0(31.8-36.2)\end{array}$ & $\begin{array}{l}34.2(32.0-36.5) \\
33.7(32.5-34.9) \\
43.5(42.1-44.9) \\
34.7(32.4-37.0)\end{array}$ \\
\hline $\begin{array}{l}\text { South Atlantic } \\
<100 \text { of FPL } \\
\geq 100 \%-\leq 400 \% \text { of FPL } \\
>400 \% \text { of FPL } \\
\text { Unknown }\end{array}$ & $\begin{array}{l}45.4(41.6-49.2) \\
58.9(56.9-60.8) \\
70.3(68.5-72.1) \\
59.1(55.7-62.5)\end{array}$ & $\begin{array}{l}44.9(41.3-48.7) \\
57.6(55.6-59.6) \\
69.7(67.8-71.5) \\
56.7(53.2-60.1)\end{array}$ & $\begin{array}{l}56.9(54.7-59.1) \\
49.5(48.1-50.9) \\
45.6(44.2-47.0) \\
41.3(38.9-43.8)\end{array}$ & $\begin{array}{l}57.1(55.0-59.3) \\
50.8(49.4-52.2) \\
46.2(44.6-47.8) \\
45.9(43.3-48.5)\end{array}$ & $\begin{array}{l}24.0(22.2-25.8) \\
30.6(29.4-31.8) \\
39.5(38.2-40.8) \\
29.0(27.0-31.1)\end{array}$ & $\begin{array}{l}24.2(22.4-26.0) \\
30.0(28.8-31.2) \\
38.1(36.6-39.6) \\
28.5(26.5-30.7)\end{array}$ \\
\hline
\end{tabular}

See table footnotes on next page. 
TABLE 5. (Continued) Crude and age-standardized* prevalence estimates of selected clinical preventive services use among adults, by federal poverty level, state Medicaid expansion status, and expanded geographic regions — Behavioral Risk Factor Surveillance System, United States, 2014

\begin{tabular}{|c|c|c|c|c|c|c|}
\hline \multirow[b]{2}{*}{ Category } & \multicolumn{2}{|c|}{ Colorectal cancer screening $^{\dagger}$} & \multicolumn{2}{|c|}{ HIV test t $^{\S}$} & \multicolumn{2}{|c|}{ Influenza vaccination? } \\
\hline & $\begin{array}{c}\text { Crude } \\
\% * *(95 \% \mathrm{Cl})\end{array}$ & $\begin{array}{c}\text { Age standardized } \\
\%(95 \% \mathrm{Cl})\end{array}$ & $\begin{array}{c}\text { Crude } \\
\%(95 \% \mathrm{CI})\end{array}$ & $\begin{array}{c}\text { Age standardized } \\
\%(95 \% \mathrm{CI})\end{array}$ & $\begin{array}{c}\text { Crude } \\
\%(95 \% \mathrm{Cl})\end{array}$ & $\begin{array}{c}\text { Age standardized } \\
\%(95 \% \mathrm{Cl})\end{array}$ \\
\hline \multicolumn{7}{|l|}{ East South Central } \\
\hline$<100$ of $\mathrm{FPL}$ & $43.9(39.8-48.0)$ & $43.6(39.6-47.7)$ & $55.1(52.3-57.9)$ & $54.6(51.8-57.3)$ & $27.5(25.2-29.9)$ & $27.8(25.5-30.2)$ \\
\hline$\geq 100 \%-\leq 400 \%$ of $F P L$ & $55.5(52.9-58.0)$ & $54.3(51.7-56.9)$ & $44.8(42.9-46.7)$ & $46.5(44.6-48.5)$ & $33.8(32.1-35.5)$ & $32.9(31.2-34.7)$ \\
\hline$>400 \%$ of $\mathrm{FPL}$ & $68.0(65.4-70.6)$ & $67.5(64.9-70.1)$ & $36.9(34.8-39.2)$ & $38.6(36.0-41.2)$ & $44.1(42.0-46.3)$ & $42.9(40.4-45.4)$ \\
\hline Unknown & $59.7(55.6-63.7)$ & $57.5(53.1-61.7)$ & $35.0(31.9-38.2)$ & $38.4(35.2-41.8)$ & $32.1(29.3-34.9)$ & $32.3(29.4-35.3)$ \\
\hline \multicolumn{7}{|l|}{ West South Central } \\
\hline$<100$ of FPL & $38.8(33.6-44.2)$ & $38.7(33.6-44.1)$ & $48.0(45.2-50.8)$ & $48.0(45.2-50.8)$ & $26.6(24.4-29.0)$ & $26.8(24.6-29.2)$ \\
\hline$\geq 100 \%-\leq 400 \%$ of FPL & $51.8(48.6-54.9)$ & $50.3(47.1-53.5)$ & $41.0(39.1-43.0)$ & $41.7(39.8-43.6)$ & $33.3(31.5-35.1)$ & $32.9(31.1-34.7)$ \\
\hline$>400 \%$ of $\mathrm{FPL}$ & $66.6(63.8-69.3)$ & $65.8(62.9-68.6)$ & $38.6(36.6-40.7)$ & $38.3(36.2-40.5)$ & $42.6(40.6-44.6)$ & $41.4(39.1-43.7)$ \\
\hline Unknown & $47.8(42.4-53.3)$ & $47.3(41.7-52.9)$ & $31.7(28.7-34.9)$ & $35.3(32.0-38.8)$ & $31.8(28.8-34.8)$ & $31.9(28.9-35.0)$ \\
\hline \multicolumn{7}{|l|}{ Mountain } \\
\hline$<100$ of $\mathrm{FPL}$ & $42.5(38.7-46.4)$ & $42.3(38.4-46.2)$ & $41.1(39.0-43.2)$ & 41.9 (39.9-43.9) & $28.3(26.6-30.2)$ & $29.1(27.3-30.9)$ \\
\hline$\geq 100 \%-\leq 400 \%$ of FPL & $51.6(49.7-53.5)$ & $50.0(48.1-51.9)$ & $38.1(36.8-39.4)$ & $38.4(37.2-39.7)$ & $30.2(29.1-31.3)$ & $30.0(28.8-31.1)$ \\
\hline$>400 \%$ of $\mathrm{FPL}$ & $66.3(64.7-67.7)$ & $65.4(63.9-66.9)$ & $35.9(34.8-37.1)$ & $36.1(34.8-37.4)$ & $38.6(37.6-39.7)$ & $36.7(35.4-38.0)$ \\
\hline Unknown & $56.3(53.1-59.4)$ & $53.8(50.4-57.1)$ & $32.3(30.0-34.7)$ & $36.3(33.8-38.8)$ & $30.6(28.6-32.7)$ & $30.7(28.6-32.9)$ \\
\hline \multicolumn{7}{|l|}{ Pacific } \\
\hline$<100$ of FPL & $43.1(37.2-49.1)$ & $43.2(37.3-49.3)$ & $44.1(41.1-47.0)$ & $45.0(42.1-48.0)$ & $28.1(25.5-30.9)$ & $28.2(25.7-31.0)$ \\
\hline$\geq 100 \%-\leq 400 \%$ of FPL & $55.1(51.6-58.6)$ & $53.6(50.0-57.1)$ & $46.4(44.2-48.7)$ & $46.9(44.7-49.1)$ & $28.3(26.5-30.3)$ & $27.8(25.9-29.7)$ \\
\hline$>400 \%$ of $\mathrm{FPL}$ & $71.4(68.6-74.0)$ & $70.6(67.8-73.3)$ & $44.5(42.6-46.5)$ & $45.3(43.2-47.4)$ & 39.8 (37.9-41.7) & $38.0(36.0-40.1)$ \\
\hline Unknown & $65.9(59.2-72.1)$ & $62.8(55.7-69.3)$ & $32.5(28.6-36.7)$ & $37.1(32.9-41.4)$ & $31.4(27.3-35.7)$ & $33.2(29.1-37.5)$ \\
\hline \multicolumn{7}{|l|}{ Overall } \\
\hline$<100$ of FPL & $45.4(43.5-47.2)$ & $45.4(43.5-47.2)$ & $50.3(49.3-51.3)$ & 50.7 (49.7-51.7) & $28.0(27.1-28.8)$ & $28.3(27.4-29.2)$ \\
\hline$\geq 100 \%-\leq 400 \%$ of $F P L$ & $56.4(55.5-57.3)$ & $55.2(54.2-56.1)$ & $43.0(42.3-43.6)$ & $44.0(43.4-44.6)$ & $31.2(30.6-31.7)$ & $30.5(30.0-31.1)$ \\
\hline$>400 \%$ of $\mathrm{FPL}$ & $69.4(68.6-70.1)$ & $68.8(68.1-69.6)$ & 38.9 (38.4-39.5) & $39.9(39.2-40.5)$ & $40.9(40.3-41.4)$ & $39.3(38.6-39.9)$ \\
\hline Unknown & $59.5(58.1-60.9)$ & $58.1(56.7-59.5)$ & $36.3(35.4-37.2)$ & $40.4(39.4-41.4)$ & $31.2(30.3-32.1)$ & $31.4(30.5-32.3)$ \\
\hline
\end{tabular}

Abbreviations: $\mathrm{Cl}=$ confidence interval; $\mathrm{FPL}=$ federal poverty level; $\mathrm{HIV}=$ human immunodeficiency virus; $\mathrm{n}=$ sample size; $\mathrm{N}=$ weighted population.

* Age standardized to the 2000 projected population for the United States.

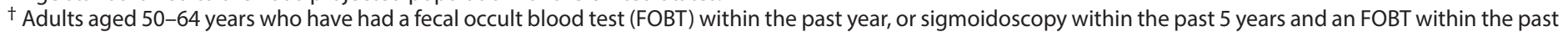

3 years, or colonoscopy within the past 10 years $(n=133,620, N=57,378,775)$.

$\S$ Adults aged 18-64 years ever tested for HIV $(n=269,889, \mathrm{~N}=174,047,283)$.

I Adults aged 18-64 years who received an influenza vaccination within the preceding 12 months $(n=281,684, N=181,381,790)$.

** Weighted percentage.

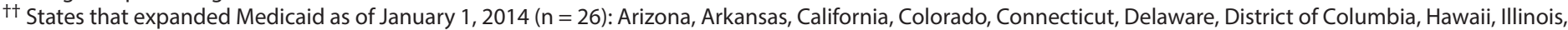

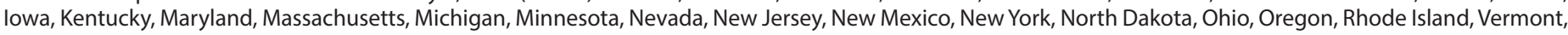
Washington, and West Virginia.

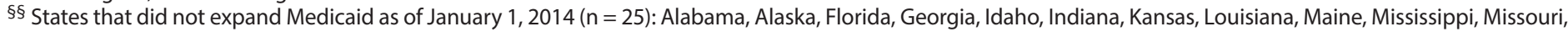

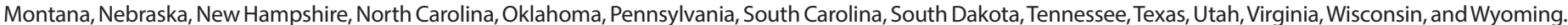

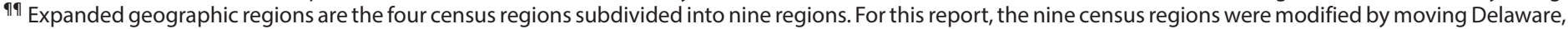

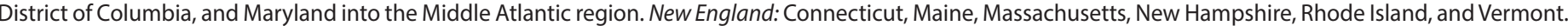

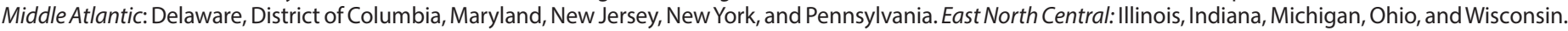

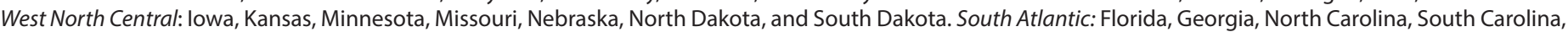

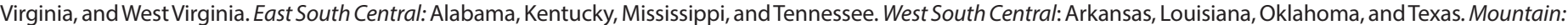
Arizona, Colorado, Idaho, Montana, Nevada, New Mexico, Utah, and Wyoming. Pacific: Alaska, California, Hawaii, Oregon, and Washington. 
TABLE 6. Crude and age-standardized* prevalence estimates of clinical preventive services use among women, by state Medicaid expansion status and expanded geographic regions - Behavioral Risk Factor Surveillance System, United States, 2014

\begin{tabular}{|c|c|c|c|c|}
\hline \multirow[b]{2}{*}{ Category } & \multicolumn{2}{|c|}{ Mammogram $^{\dagger}$} & \multicolumn{2}{|c|}{ Pap test ${ }^{\S}$} \\
\hline & $\begin{array}{c}\text { Crude } \\
\%^{\text {q }}(95 \% \mathrm{Cl})\end{array}$ & $\begin{array}{c}\text { Age standardized } \\
\%(95 \% \mathrm{Cl})\end{array}$ & $\begin{array}{c}\text { Crude } \\
\%(95 \% \mathrm{Cl})\end{array}$ & $\begin{array}{c}\text { Age standardized } \\
\%(95 \% \mathrm{Cl})\end{array}$ \\
\hline \multicolumn{5}{|l|}{ State Medicaid expansion status } \\
\hline Medicaid expansion states** & $78.6(77.8-79.4)$ & $78.5(77.6-79.3)$ & $83.0(82.4-83.6)$ & $83.0(82.3-83.6)$ \\
\hline Medicaid nonexpansion states ${ }^{\dagger \dagger}$ & $75.6(74.8-76.4)$ & $75.5(74.7-76.3)$ & $81.5(80.8-82.1)$ & $81.5(80.9-82.1)$ \\
\hline \multicolumn{5}{|l|}{ Expanded geographic regions ${ }^{\S \S}$} \\
\hline New England & $84.3(83.1-85.4)$ & $84.3(83.1-85.4)$ & $87.1(86.1-88.0)$ & $87.0(85.9-87.9)$ \\
\hline Middle Atlantic & $78.1(76.6-79.6)$ & $78.1(76.5-79.5)$ & $83.0(81.9-84.1)$ & $83.0(81.7-84.1)$ \\
\hline East North Central & $76.8(75.3-78.1)$ & $76.7(75.3-78.1)$ & $82.1(81.0-83.2)$ & $82.2(81.0-83.3)$ \\
\hline West North Central & $76.3(75.0-77.6)$ & $76.1(74.8-77.4)$ & $83.3(82.4-84.2)$ & $83.3(82.4-84.2)$ \\
\hline South Atlantic & $77.3(76.0-78.6)$ & $77.1(75.8-78.5)$ & $82.8(81.7-83.7)$ & $82.8(81.8-83.8)$ \\
\hline East South Central & $75.3(73.5-76.9)$ & $75.0(73.2-76.7)$ & $83.6(82.3-84.9)$ & $83.6(82.2-84.8)$ \\
\hline West South Central & $74.3(72.2-76.3)$ & $74.2(72.1-76.2)$ & $78.5(76.9-80.0)$ & $78.5(76.8-80.0)$ \\
\hline Mountain & $72.1(70.9-73.4)$ & $71.7(70.4-73.0)$ & $80.3(79.3-81.2)$ & $80.3(79.2-81.2)$ \\
\hline Pacific & $80.1(77.9-82.1)$ & $79.9(77.6-81.9)$ & $82.5(80.9-84.0)$ & $82.4(80.8-83.9)$ \\
\hline Overall & $77.2(76.6-77.8)$ & $77.1(76.5-77.7)$ & $82.3(81.8-82.7)$ & $82.3(81.9-82.8)$ \\
\hline
\end{tabular}

Abbreviations: $\mathrm{Cl}$ = confidence interval; $\mathrm{n}=$ sample size; $\mathrm{N}=$ weighted population; $\mathrm{Pap}=$ Papanicolaou.

${ }^{*}$ Age standardized to the 2000 projected population for the United States.

+ Within the past 2 years among women aged $50-64$ years $(n=79,880, N=30,796,537)$.

$\S$ Within the past 3 years among women aged 21-64 years who have not had a hysterectomy $(n=118,135, N=68,270,683)$.

" Weighted percentage.

** States that expanded Medicaid as of January 1, $2014(n=26)$ : Arizona, Arkansas, California, Colorado, Connecticut, Delaware, District of Columbia, Hawaii, Illinois, lowa, Kentucky, Maryland, Massachusetts, Michigan, Minnesota, Nevada, New Jersey, New Mexico, New York, North Dakota, Ohio, Oregon, Rhode Island, Vermont, Washington, and West Virginia.

+t States that did not expand Medicaid as of January 1, 2014 ( $n=25)$ : Alabama, Alaska, Florida, Georgia, Idaho, Indiana, Kansas, Louisiana, Maine, Mississippi, Missouri, Montana, Nebraska, New Hampshire, North Carolina, Oklahoma, Pennsylvania, South Carolina, South Dakota, Tennessee, Texas, Utah, Virginia, Wisconsin, and Wyoming.

$\S \S$ Expanded geographic regions are the four census regions subdivided into nine regions. For this report, the nine census regions were modified by moving Delaware, District of Columbia, and Maryland into the Middle Atlantic region. New England: Connecticut, Maine, Massachusetts, New Hampshire, Rhode Island, and Vermont. Middle Atlantic: Delaware, District of Columbia, Maryland, New Jersey, New York, and Pennsylvania. East North Central: Illinois, Indiana, Michigan, Ohio, and Wisconsin. West North Central: lowa, Kansas, Minnesota, Missouri, Nebraska, North Dakota, and South Dakota. South Atlantic: Florida, Georgia, North Carolina, South Carolina, Virginia, and West Virginia. East South Central: Alabama, Kentucky, Mississippi, and Tennessee. West South Central: Arkansas, Louisiana, Oklahoma, and Texas. Mountain: Arizona, Colorado, Idaho, Montana, Nevada, New Mexico, Utah, and Wyoming. Pacific: Alaska, California, Hawaii, Oregon, and Washington. 
TABLE 7. Crude and age-standardized* prevalence estimates of breast and cervical cancer screenings among women, by federal poverty level, state Medicaid expansion status, and expanded geographic regions - Behavioral Risk Factor Surveillance System, United States, 2014

\begin{tabular}{|c|c|c|c|c|}
\hline \multirow[b]{2}{*}{ Category } & \multicolumn{2}{|c|}{ Mammogram $^{\dagger}$} & \multicolumn{2}{|c|}{ Pap test ${ }^{\S}$} \\
\hline & $\begin{array}{c}\text { Crude } \\
\% \text { ฯ }(95 \% \mathrm{Cl})\end{array}$ & $\begin{array}{c}\text { Age standardized } \\
\%(95 \% \mathrm{Cl})\end{array}$ & $\begin{array}{c}\text { Crude } \\
\%(95 \% \mathrm{Cl})\end{array}$ & $\begin{array}{c}\text { Age standardized } \\
\%(95 \% \mathrm{Cl})\end{array}$ \\
\hline \multicolumn{5}{|c|}{ State Medicaid expansion status } \\
\hline $\begin{array}{l}\text { Medicaid expansion st } \\
<100 \text { of } \mathrm{FPL} \\
\geq 100 \%-\leq 400 \% \text { of } \mathrm{FPL} \\
>400 \% \text { of } \mathrm{FPL} \\
\text { Unknown }\end{array}$ & $\begin{array}{l}71.3(68.0-74.4) \\
74.7(73.2-76.1) \\
83.3(82.2-84.4) \\
80.6(78.6-82.4)\end{array}$ & $\begin{array}{l}71.4(68.1-74.5) \\
74.5(73.0-76.0) \\
83.3(82.1-84.4) \\
80.4(78.2-82.3)\end{array}$ & $\begin{array}{l}78.1(76.4-79.8) \\
81.0(79.8-82.1) \\
89.3(88.4-90.1) \\
79.0(77.3-80.7)\end{array}$ & $\begin{array}{l}77.2(75.3-78.9) \\
81.0(79.7-82.1) \\
89.3(88.3-90.2) \\
79.0(77.3-80.7)\end{array}$ \\
\hline $\begin{array}{l}\text { Medicaid nonexpansic } \\
<100 \text { of } \mathrm{FPL} \\
\geq 100 \%-\leq 400 \% \text { of } \mathrm{FPL} \\
>400 \% \text { of } \mathrm{FPL} \\
\text { Unknown }\end{array}$ & $\begin{array}{l}63.9(61.2-66.6) \\
72.3(71.0-73.6) \\
83.6(82.4-84.7) \\
75.8(73.4-78.1)\end{array}$ & $\begin{array}{l}64.0(61.2-66.6) \\
72.1(70.8-73.5) \\
83.5(82.3-84.6) \\
75.0(72.4-77.5)\end{array}$ & $\begin{array}{l}73.8(72.1-75.4) \\
80.3(79.2-81.2) \\
89.9(89.0-90.7) \\
77.1(75.0-79.0)\end{array}$ & $\begin{array}{l}72.2(70.4-73.9) \\
80.3(79.3-81.3) \\
90.1(89.2-91.0) \\
77.1(75.0-79.0)\end{array}$ \\
\hline \multicolumn{5}{|c|}{ Expanded geographic regions $s^{\S \S}$} \\
\hline $\begin{array}{l}\text { New England } \\
<100 \text { of FPL } \\
\geq 100 \%-\leq 400 \% \text { of FPL } \\
>400 \% \text { of FPL } \\
\text { Unknown }\end{array}$ & $\begin{array}{l}77.9(72.5-82.5) \\
79.5(77.1-81.8) \\
88.6(87.2-89.9) \\
83.7(80.5-86.5)\end{array}$ & $\begin{array}{l}77.9(72.5-82.5) \\
79.4(76.8-81.7) \\
88.7(87.2-89.9) \\
83.5(80.0-86.4)\end{array}$ & $\begin{array}{l}81.3(77.5-84.5) \\
86.1(84.4-87.7) \\
92.0(90.9-93.0) \\
82.5(79.8-84.8)\end{array}$ & $\begin{array}{l}81.5(77.9-84.7) \\
86.2(84.3-87.9) \\
92.5(91.2-93.6) \\
82.7(80.1-85.0)\end{array}$ \\
\hline $\begin{array}{l}\text { Middle Atlantic } \\
<100 \text { of FPL } \\
\geq 100 \%-\leq 400 \% \text { of FPL } \\
>400 \% \text { of FPL } \\
\text { Unknown }\end{array}$ & $\begin{array}{l}74.3(69.2-78.8) \\
74.1(71.3-76.7) \\
81.2(79.0-83.2) \\
81.3(76.8-85.1)\end{array}$ & $\begin{array}{l}74.5(69.5-78.9) \\
74.1(71.2-76.8) \\
81.2(79.0-83.1) \\
81.1(76.2-85.2)\end{array}$ & $\begin{array}{l}78.4(75.2-81.4) \\
82.2(80.3-84.0) \\
88.3(86.5-89.8) \\
75.2(71.2-78.8)\end{array}$ & $\begin{array}{l}78.0(74.8-80.9) \\
82.3(80.3-84.2) \\
88.1(86.1-89.9) \\
74.8(70.7-78.5)\end{array}$ \\
\hline $\begin{array}{l}\text { East North Central } \\
<100 \text { of FPL } \\
\geq 100 \%-\leq 400 \% \text { of FPL } \\
>400 \% \text { of FPL } \\
\text { Unknown }\end{array}$ & $\begin{array}{l}63.9(57.9-69.5) \\
72.8(70.3-75.2) \\
82.6(80.5-84.5) \\
79.4(76.4-82.2)\end{array}$ & $\begin{array}{l}63.9(57.9-69.4) \\
72.5(69.8-75.0) \\
82.6(80.5-84.5) \\
79.3(76.2-82.1)\end{array}$ & $\begin{array}{l}78.1(74.8-81.1) \\
79.1(76.9-81.2) \\
88.9(87.4-90.3) \\
79.0(76.5-81.4)\end{array}$ & $\begin{array}{l}75.8(72.3-78.9) \\
79.2(76.9-81.3) \\
89.2(87.6-90.7) \\
79.1(76.5-81.4)\end{array}$ \\
\hline $\begin{array}{l}\text { West North Central } \\
<100 \text { of FPL } \\
\geq 100 \%-\leq 400 \% \text { of FPL } \\
>400 \% \text { of FPL } \\
\text { Unknown }\end{array}$ & $\begin{array}{l}58.0(52.0-63.8) \\
70.9(68.6-73.1) \\
84.3(82.6-85.9) \\
77.4(73.4-80.8)\end{array}$ & $\begin{array}{l}58.0(52.0-63.8) \\
70.6(68.2-72.8) \\
84.2(82.5-85.8) \\
76.7(72.5-80.4)\end{array}$ & $\begin{array}{l}72.9(69.6-75.9) \\
80.6(78.9-82.2) \\
91.0(90.0-92.0) \\
81.0(78.2-83.5)\end{array}$ & $\begin{array}{l}69.8(66.4-73.0) \\
80.6(78.9-82.2) \\
91.4(90.3-92.4) \\
81.0(78.2-83.5)\end{array}$ \\
\hline $\begin{array}{l}\text { South Atlantic } \\
<100 \text { of FPL } \\
\geq 100 \%-\leq 400 \% \text { of FPL } \\
>400 \% \text { of FPL } \\
\text { Unknown }\end{array}$ & $\begin{array}{l}64.6(60.0-69.0) \\
74.0(71.7-76.1) \\
86.5(84.8-88.0) \\
77.6(74.1-80.8)\end{array}$ & $\begin{array}{l}64.6(60.0-69.0) \\
73.8(71.5-76.1) \\
86.4(84.6-87.9) \\
76.5(72.6-79.9)\end{array}$ & $\begin{array}{l}73.5(70.5-76.2) \\
81.5(79.8-83.1) \\
91.8(90.6-92.9) \\
79.7(76.3-82.7)\end{array}$ & $\begin{array}{l}72.0(69.1-74.8) \\
81.7(80.0-83.2) \\
91.9(90.6-93.1) \\
79.3(75.9-82.4)\end{array}$ \\
\hline
\end{tabular}

See table footnotes on next page. 
TABLE 7. (Continued) Crude and age-standardized* prevalence estimates of breast and cervical cancer screenings among women, by federal poverty level, state Medicaid expansion status, and expanded geographic regions — Behavioral Risk Factor Surveillance System, United States, 2014

\begin{tabular}{|c|c|c|c|c|}
\hline \multirow[b]{2}{*}{ Category } & \multicolumn{2}{|c|}{ Mammogram $^{\dagger}$} & \multicolumn{2}{|c|}{ Pap test ${ }^{\S}$} \\
\hline & $\begin{array}{c}\text { Crude } \\
\% \uparrow(95 \% \mathrm{Cl})\end{array}$ & $\begin{array}{c}\text { Age standardized } \\
\%(95 \% \mathrm{Cl})\end{array}$ & $\begin{array}{c}\text { Crude } \\
\%(95 \% \mathrm{Cl})\end{array}$ & $\begin{array}{c}\text { Age standardized } \\
\%(95 \% \mathrm{Cl})\end{array}$ \\
\hline \multicolumn{5}{|l|}{ East South Central } \\
\hline$<100$ of FPL & $61.0(55.9-65.8)$ & $60.4(55.3-65.3)$ & 78.5 (75.3-81.4) & 76.5 (73.3-79.4) \\
\hline$\geq 100 \%-\leq 400 \%$ of $\mathrm{FPL}$ & 74.1 (71.4-76.6) & $74.0(71.2-76.6)$ & 81.5 (79.1-83.6) & $81.5(79.1-83.6)$ \\
\hline$>400 \%$ of $\mathrm{FPL}$ & $84.2(81.4-86.6)$ & $84.1(81.3-86.5)$ & $92.2(90.3-93.7)$ & $92.6(90.7-94.2)$ \\
\hline Unknown & 75.9 (70.9-80.2) & $75.6(70.4-80.1)$ & $83.0(79.0-86.4)$ & $83.1(79.0-86.4)$ \\
\hline \multicolumn{5}{|l|}{ West South Central } \\
\hline$<100$ of $\mathrm{FPL}$ & $67.4(61.7-72.7)$ & 67.5 (61.9-72.6) & 71.9 (68.2-75.3) & 70.7 (66.8-74.3) \\
\hline$\geq 100 \%-\leq 400 \%$ of $\mathrm{FPL}$ & $72.4(69.0-75.6)$ & $72.2(68.7-75.4)$ & 77.9 (75.1-80.4) & $77.8(75.0-80.3)$ \\
\hline$>400 \%$ of $\mathrm{FPL}$ & 80.7 (77.2-83.7) & 80.7 (77.2-83.7) & 87.5 (84.9-89.8) & $87.8(85.1-90.1)$ \\
\hline Unknown & 71.1 (64.2-77.2) & $70.2(62.9-76.6)$ & $74.2(69.3-78.5)$ & 74.5 (69.8-78.7) \\
\hline \multicolumn{5}{|l|}{ Mountain } \\
\hline$<100$ of FPL & $65.2(60.7-69.4)$ & $65.1(60.6-69.4)$ & 73.7 (71.1-76.2) & $72.3(69.7-74.8)$ \\
\hline$\geq 100 \%-\leq 400 \%$ of $\mathrm{FPL}$ & $66.8(64.6-69.0)$ & $66.2(63.8-68.5)$ & $79.6(78.0-81.2)$ & $79.5(77.8-81.0)$ \\
\hline$>400 \%$ of $\mathrm{FPL}$ & 79.6 (77.8-81.2) & $79.3(77.6-81.0)$ & $87.6(86.1-88.9)$ & $87.8(86.2-89.3)$ \\
\hline Unknown & $70.4(66.8-73.8)$ & $68.8(64.8-72.5)$ & $74.2(70.6-77.5)$ & $74.3(70.8-77.5)$ \\
\hline \multicolumn{5}{|l|}{ Pacific } \\
\hline$<100$ of $\mathrm{FPL}$ & 72.1 (64.9-78.3) & $72.3(65.3-78.4)$ & $78.8(75.1-82.0)$ & 77.7 (73.9-81.1) \\
\hline$\geq 100 \%-\leq 400 \%$ of $\mathrm{FPL}$ & 76.8 (72.9-80.2) & 76.7 (72.7-80.2) & 79.8 (76.8-82.6) & $79.8(76.7-82.5)$ \\
\hline$>400 \%$ of $\mathrm{FPL}$ & $85.0(82.2-87.4)$ & 84.8 (81.9-87.3) & 89.1 (86.7-91.1) & $88.9(86.3-91.0)$ \\
\hline Unknown & $85.0(78.7-89.7)$ & $85.8(79.7-90.3)$ & 78.7 (72.9-83.6) & $78.8(73.1-83.5)$ \\
\hline \multicolumn{5}{|l|}{ Overall } \\
\hline$<100$ of $\mathrm{FPL}$ & $67.7(65.5-69.7)$ & $67.7(65.5-69.7)$ & 76.0 (74.8-77.2) & $74.8(73.5-76.0)$ \\
\hline$\geq 100 \%-\leq 400 \%$ of $\mathrm{FPL}$ & 73.5 (72.5-74.5) & $73.3(72.3-74.3)$ & $80.6(79.8-81.4)$ & 80.7 (79.9-81.4) \\
\hline$>400 \%$ of $\mathrm{FPL}$ & $83.4(82.6-84.2)$ & $83.4(82.6-84.2)$ & 89.5 (88.9-90.1) & 89.7 (89.0-90.3) \\
\hline Unknown & 78.4 (76.8-79.8) & 77.9 (76.3-79.5) & 78.2 (76.9-79.5) & 78.2 (76.9-79.5) \\
\hline
\end{tabular}

Abbreviations: $\mathrm{Cl}=$ confidence interval; $\mathrm{FPL}=$ federal poverty level; $\mathrm{n}=$ sample size; $\mathrm{N}=$ weighted population; $\mathrm{Pap}=\mathrm{Papanicolaou}$.

* Age standardized to the 2000 projected population for the United States.

† Within past 2 years among women aged $50-64$ years $(n=79,880, N=30,796,537)$.

$\S$ Within past 3 years among women aged $21-64$ years who have not had a hysterectomy $(n=118,135, N=68,270,683)$.

I Weighted percentage.

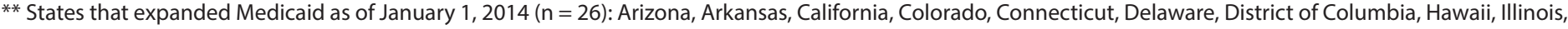

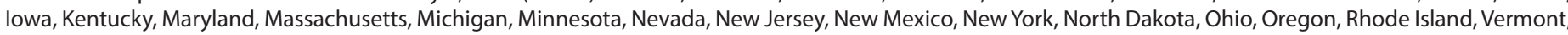
Washington, and West Virginia.

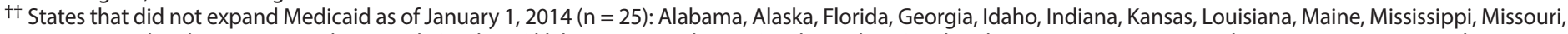

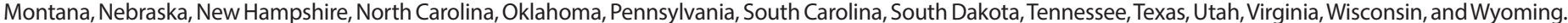

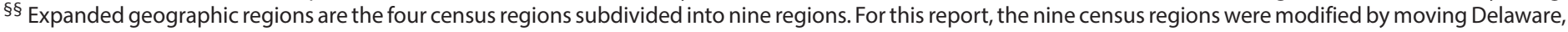

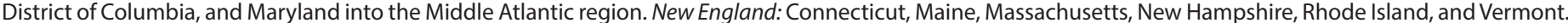

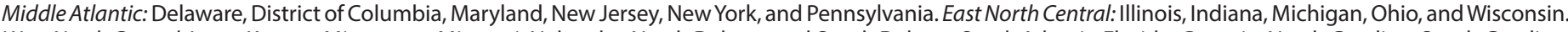

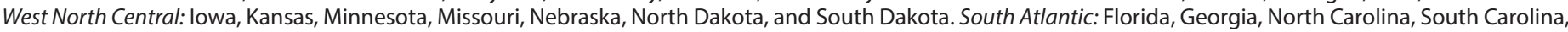

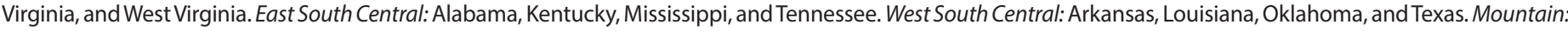
Arizona, Colorado, Idaho, Montana, Nevada, New Mexico, Utah, and Wyoming. Pacific: Alaska, California, Hawaii, Oregon, and Washington. 
TABLE 8. Crude and age-standardized* prevalence estimates of no primary source of health insurance coverage, public health plan coverage, and private health insurance coverage at the time of interview among adults aged 18-64 years, by state Medicaid expansion status and federal poverty level — Behavioral Risk Factor Surveillance System, 43 states, ${ }^{\dagger} 2014$

\begin{tabular}{|c|c|c|c|c|c|c|c|}
\hline \multirow[b]{2}{*}{ Category } & \multirow[b]{2}{*}{$n^{\S}$} & \multicolumn{2}{|c|}{$\begin{array}{c}\text { No primary source of } \\
\text { health insurance coverage }\end{array}$} & \multicolumn{2}{|c|}{$\begin{array}{l}\text { Public health plan } \\
\text { coverage }^{* *}\end{array}$} & \multicolumn{2}{|c|}{$\begin{array}{l}\text { Private health insurance } \\
\text { coverage }^{\dagger+}\end{array}$} \\
\hline & & $\begin{array}{c}\text { Crude } \\
\% \S \S(95 \% \mathrm{Cl})\end{array}$ & $\begin{array}{c}\text { Age standardized } \\
\%(95 \% \mathrm{Cl})\end{array}$ & $\begin{array}{c}\text { Crude } \\
\%(95 \% \mathrm{CI})\end{array}$ & $\begin{array}{c}\text { Age standardized } \\
\%(95 \% \mathrm{CI})\end{array}$ & $\begin{array}{c}\text { Crude } \\
\%(95 \% \mathrm{Cl})\end{array}$ & $\begin{array}{c}\text { Age standardized } \\
\%(95 \% \mathrm{Cl})\end{array}$ \\
\hline $\begin{array}{l}\text { Medicaid } \\
\text { expansion } \\
\text { states }\end{array}$ & 124,776 & $14.2(13.8-14.6)$ & $15.0(14.6-15.5)$ & $21.1(20.7-21.5)$ & $21.1(20.7-21.6)$ & $64.7(64.2-65.2)$ & $63.9(63.3-64.4)$ \\
\hline$<100$ of FPL & 13,467 & $29.8(28.4-31.2)$ & $29.6(28.2-31.0)$ & $49.8(48.2-51.3)$ & $50.7(49.2-52.2)$ & $20.5(19.2-21.8)$ & $19.7(18.6-21.0)$ \\
\hline$\geq 100 \%-\leq 400 \%$ of FPL & 40,723 & $16.7(16.0-17.5)$ & $17.3(16.6-18.2)$ & $22.6(21.9-23.4)$ & $22.1(21.3-22.9)$ & $60.6(59.7-61.5)$ & 60.5 (59.6-61.5) \\
\hline$>400 \%$ of $\mathrm{FPL}$ & 50,819 & $3.3(2.9-3.6)$ & $3.6(3.2-4.0)$ & $5.1(4.7-5.4)$ & $5.1(4.7-5.6)$ & $91.7(91.2-92.1)$ & 91.3 (90.7-91.9) \\
\hline Unknown & 19,767 & $17.7(16.7-18.8)$ & $18.3(17.3-19.4)$ & $25.4(24.4-26.4)$ & $25.7(24.6-26.8)$ & $56.9(55.7-58.1)$ & $56.0(54.8-57.2)$ \\
\hline $\begin{array}{l}\text { Medicaid } \\
\text { nonexpansion } \\
\text { states }^{* * *}\end{array}$ & 101,440 & $19.0(18.6-19.5)$ & 19.9 (19.4-20.4) & $17.6(17.2-18.0)$ & $17.2(16.8-17.6)$ & $63.4(62.9-63.9)$ & $62.9(62.3-63.4)$ \\
\hline$<100$ of FPL & 13,194 & $41.7(40.3-43.1)$ & $41.6(40.2-42.9)$ & $37.1(35.8-38.4)$ & 37.9 (36.6-39.2) & $21.2(20.1-22.4)$ & $20.6(19.5-21.7)$ \\
\hline$\geq 100 \%-\leq 400 \%$ of FPL & 39,400 & $20.1(19.4-20.8)$ & $20.7(20.0-21.5)$ & $17.5(16.8-18.1)$ & $16.7(16.1-17.3)$ & $62.5(61.6-63.3)$ & $62.6(61.7-63.4)$ \\
\hline$>400 \%$ of FPL & 36,609 & $3.8(3.5-4.2)$ & $4.4(3.9-4.9)$ & $5.9(5.5-6.3)$ & $5.6(5.2-6.1)$ & $90.2(89.7-90.8)$ & $90.0(89.3-90.6)$ \\
\hline Unknown & 12,237 & $23.5(22.1-24.8)$ & $24.5(23.1-26.0)$ & $21.2(20.0-22.4)$ & $20.5(19.3-21.7)$ & $55.4(53.9-56.8)$ & $55.0(53.5-56.6)$ \\
\hline Overall & 226,216 & $16.3(16.0-16.6)$ & $17.1(16.8-17.5)$ & $19.6(19.3-19.9)$ & 19.4 (19.1-19.7) & $64.1(63.8-64.5)$ & $63.4(63.0-63.8)$ \\
\hline$<100$ of FPL & 26,661 & $35.3(34.3-36.3)$ & $35.1(34.1-36.1)$ & $43.9(42.9-44.9)$ & $44.8(43.8-45.8)$ & $20.8(19.9-21.7)$ & $20.1(19.3-21.0)$ \\
\hline$\geq 100 \%-\leq 400 \%$ of FPL & 80,123 & $18.3(17.8-18.9)$ & $19.0(18.4-19.5)$ & $20.2(19.7-20.7)$ & $19.5(19.0-20.1)$ & $61.5(60.9-62.1)$ & $61.5(60.8-62.1)$ \\
\hline$>400 \%$ of FPL & 87,428 & $3.5(3.3-3.8)$ & $3.9(3.6-4.3)$ & $5.4(5.2-5.7)$ & $5.3(5.0-5.7)$ & $91.1(90.7-91.4)$ & 90.7 (90.3-91.2) \\
\hline Unknown & 32,004 & $19.8(19.0-20.6)$ & 20.5 (19.6-21.4) & $23.9(23.1-24.7)$ & $24.0(23.1-24.8)$ & $56.3(55.4-57.3)$ & $55.6(54.6-56.5)$ \\
\hline
\end{tabular}

Abbreviations: $\mathrm{Cl}=$ confidence interval; $\mathrm{FPL}=$ federal poverty level; $\mathrm{n}=$ sample size.

* Age standardized to the 2000 projected population for the United States.

† Alabama, Alaska, Arizona, Colorado, Connecticut, Delaware, District of Columbia, Georgia, Idaho, Illinois, Indiana, lowa, Kentucky, Louisiana, Maine, Maryland, Massachusetts, Michigan, Minnesota, Mississippi, Missouri, Montana, Nebraska, Nevada, New Hampshire, New Jersey, New Mexico, New York, North Carolina, North Dakota, Ohio, Oklahoma, Oregon, Pennsylvania, Rhode Island, South Carolina, Tennessee, Utah, Vermont, Virginia, Washington, West Virginia, and Wisconsin. Data from Missouri are available from the Missouri Department of Health and Senior Services.

$\S$ Unweighted sample size.

"Includes persons who, when asked about their primary source of health care coverage, said they had none and persons who did not have any kind of health care coverage at the time of interview.

** Public health insurance includes Medicare; Medicaid or other state program; TRICARE (formerly CHAMPUS), Veterans Affairs, or military plan; Alaska Native, Indian Health Service, Tribal Health Services, or some other source.

${ }^{+\dagger}$ Private health insurance includes a plan purchased through an employer or union (includes plans purchased through another person's employer) or a plan that they or another family member purchased on their own.

$\S \S$ Weighted percentage.

१ศ States that expanded Medicaid as of January 1, $2014(\mathrm{n}=23)$ : Arizona, Colorado, Connecticut, Delaware, District of Columbia, Illinois, lowa, Kentucky, Maryland, Massachusetts, Michigan, Minnesota, Nevada, New Jersey, New Mexico, New York, North Dakota, Ohio, Oregon, Rhode Island, Vermont, Washington, and West Virginia.

*** States that did not expand Medicaid as of January 1, $2014(n=20)$ : Alabama, Alaska, Georgia, Idaho, Indiana, Louisiana, Maine, Mississippi, Missouri, Montana, Nebraska, New Hampshire, North Carolina, Oklahoma, Pennsylvania, South Carolina, Tennessee, Utah, Virginia, and Wisconsin. 
TABLE 9. Crude and age-standardized* prevalence estimates of health care access and clinical preventive services use among adults aged 18-64 years with no primary source of health insurance coverage, public health plan coverage, or private health insurance coverage at the time of interview, by state Medicaid expansion status - Behavioral Risk Factor Surveillance System, 43 states, ${ }^{\dagger} 2014$

\begin{tabular}{|c|c|c|c|c|c|c|c|}
\hline \multirow[b]{2}{*}{ Category } & \multirow[b]{2}{*}{$n^{\S}$} & \multicolumn{2}{|c|}{$\begin{array}{l}\text { No primary source } \\
\text { of health insurance coverage }\end{array}$} & \multicolumn{2}{|c|}{$\begin{array}{l}\text { Public health plan } \\
\text { coverage } \mathrm{e}^{* *}\end{array}$} & \multicolumn{2}{|c|}{$\begin{array}{c}\text { Private health insurance } \\
\text { coverage }^{\dagger \dagger}\end{array}$} \\
\hline & & $\begin{array}{c}\text { Crude } \\
\%{ }^{\S \S}(95 \% \mathrm{Cl})\end{array}$ & $\begin{array}{l}\text { Age standardized } \\
\%(95 \% \mathrm{Cl})\end{array}$ & $\begin{array}{c}\text { Crude } \\
\%(95 \% \mathrm{Cl})\end{array}$ & $\begin{array}{l}\text { Age standardized } \\
\%(95 \% \mathrm{Cl})\end{array}$ & $\begin{array}{c}\text { Crude } \\
\%(95 \% \mathrm{Cl})\end{array}$ & $\begin{array}{l}\text { Age standardized } \\
\%(95 \% \mathrm{Cl})\end{array}$ \\
\hline \multicolumn{8}{|l|}{ Medicaid expansion states } \\
\hline \multicolumn{8}{|l|}{ Health care access } \\
\hline Usual source of health care & 124,317 & $41.3(39.8-42.8)$ & $42.5(41.0-44.0)$ & $80.8(79.9-81.7)$ & $79.8(78.8-80.7)$ & $83.7(83.2-84.2)$ & $82.0(81.5-82.6)$ \\
\hline $\begin{array}{l}\text { Routine checkup within } \\
\text { preceding } 12 \text { mos }\end{array}$ & 123,374 & $42.1(40.6-43.7)$ & $42.7(41.2-44.2)$ & $73.6(72.5-74.6)$ & $72.7(71.6-73.8)$ & $70.3(69.8-70.9)$ & $69.0(68.4-69.6)$ \\
\hline $\begin{array}{l}\text { Cost barrier to health care need } \\
\text { during preceding } 12 \mathrm{mos}\end{array}$ & 124,504 & $41.5(40.0-43.1)$ & $41.7(40.2-43.2)$ & $18.3(17.4-19.2)$ & $18.3(17.4-19.2)$ & $8.1(7.8-8.5)$ & $8.4(8.0-8.8)$ \\
\hline $\begin{array}{l}\text { Cost barrier to prescribed } \\
\text { medication need during } \\
\text { preceding } 12 \text { mos }\end{array}$ & 124,142 & $16.1(14.9-17.3)$ & $16.6(15.5-17.8)$ & $13.8(13.0-14.6)$ & $13.7(12.9-14.5)$ & $5.6(5.3-5.9)$ & $5.7(5.3-6.0)$ \\
\hline $\begin{array}{l}\text { Medical bills being paid off over } \\
\text { time during preceding } 12 \text { mos }\end{array}$ & 123,471 & $24.3(23.0-25.6)$ & $24.5(23.3-25.9)$ & $20.4(19.5-21.3)$ & $20.2(19.2-21.2)$ & $19.4(18.9-19.9)$ & $19.8(19.3-20.3)$ \\
\hline \multicolumn{8}{|l|}{ CPS } \\
\hline $\begin{array}{l}\text { Mammogram within past } 2 \mathrm{yrs} \\
\text { (women aged } 50-64 \mathrm{yrs} \text { ) }\end{array}$ & 35,376 & $48.5(44.7-52.2)$ & $48.5(44.8-52.3)$ & $75.5(73.7-77.3)$ & $75.3(73.4-77.1)$ & $82.0(81.1-82.8)$ & $81.9(81.0-82.7)$ \\
\hline $\begin{array}{l}\text { Pap test within past } 3 \text { yrs } \\
\text { (women aged } 21-64 \text { yrs who } \\
\text { have not had a hysterectomy) }\end{array}$ & 51,860 & $67.5(65.1-69.9)$ & $66.2(63.8-68.5)$ & $80.7(79.2-82.1)$ & $80.6(79.1-82.0)$ & $87.0(86.3-87.7)$ & $86.9(86.1-87.6)$ \\
\hline $\begin{array}{l}\text { Colorectal cancer screening } \\
\text { (adults aged } 50-64 \text { yrs) }\end{array}$ & 58,596 & $32.2(29.5-35.0)$ & $32.3(29.6-35.1)$ & $61.3(59.6-63.0)$ & $59.8(58.0-61.5)$ & $66.5(65.6-67.3)$ & $65.9(65.0-66.7)$ \\
\hline $\begin{array}{l}\text { HIV test }{ }^{\text {t+† }} \text { (adults aged } \\
18-64 \text { yrs) }\end{array}$ & 112,626 & $43.7(42.0-45.3)$ & $42.7(41.1-44.3)$ & $54.4(53.2-55.6)$ & $56.0(54.8-57.2)$ & $36.5(35.9-37.1)$ & $38.6(37.9-39.2)$ \\
\hline $\begin{array}{l}\text { Influenza vaccination within } \\
\text { preceding } 12 \text { mos (adults aged } \\
18-64 \text { yrs) }\end{array}$ & 117,754 & $18.2(16.9-19.5)$ & $18.5(17.3-19.7)$ & $36.6(35.5-37.7)$ & $35.6(34.4-36.8)$ & $37.9(37.3-38.5)$ & $36.7(36.1-37.3)$ \\
\hline \multicolumn{8}{|l|}{ Medicaid nonexpansion states ${ }^{\S \S \S}$} \\
\hline \multicolumn{8}{|l|}{ Health care access } \\
\hline Usual source of health care & 101,077 & $41.3(40.1-42.6)$ & $42.8(41.6-44.0)$ & $81.5(80.5-82.5)$ & $79.9(78.7-80.9)$ & $81.4(80.8-81.9)$ & $79.6(79.0-80.2)$ \\
\hline $\begin{array}{l}\text { Routine checkup within } \\
\text { preceding } 12 \text { mos }\end{array}$ & 100,265 & $41.0(39.7-42.4)$ & $41.4(40.1-42.7)$ & $78.3(77.3-79.3)$ & $77.0(75.8-78.1)$ & $70.2(69.6-70.7)$ & $68.8(68.1-69.4)$ \\
\hline $\begin{array}{l}\text { Cost barrier to health care need } \\
\text { during preceding } 12 \mathrm{mos}\end{array}$ & 101,208 & $45.5(44.1-46.8)$ & $46.0(44.7-47.3)$ & $18.1(17.2-19.1)$ & $18.4(17.4-19.5)$ & $9.6(9.2-10.0)$ & $9.8(9.4-10.2)$ \\
\hline $\begin{array}{l}\text { Cost barrier to prescribed } \\
\text { medication need during } \\
\text { preceding } 12 \mathrm{mos}\end{array}$ & 100,841 & $20.4(19.3-21.4)$ & $21.0(20.0-22.0)$ & $15.4(14.6-16.3)$ & $15.7(14.7-16.7)$ & $7.2(6.8-7.5)$ & $7.2(6.8-7.6)$ \\
\hline $\begin{array}{l}\text { Medical bills being paid off over } \\
\text { time during preceding } 12 \text { mos }\end{array}$ & 100,304 & $30.7(29.5-31.9)$ & $31.0(29.8-32.2)$ & $24.8(23.8-25.8)$ & $24.5(23.4-25.7)$ & $24.7(24.2-25.3)$ & $25.2(24.6-25.7)$ \\
\hline \multicolumn{8}{|l|}{ CPS } \\
\hline $\begin{array}{l}\text { Mammogram within past } 2 \mathrm{yrs} \\
\text { (women aged } 50-64 \mathrm{yrs} \text { ) }\end{array}$ & 27,283 & $47.2(44.3-50.1)$ & $47.1(44.2-50.0)$ & $73.8(71.9-75.6)$ & $73.6(71.5-75.5)$ & $81.0(80.1-81.8)$ & $80.8(79.9-81.7)$ \\
\hline $\begin{array}{l}\text { Pap test within past } 3 \text { yrs } \\
\text { (women aged } 21-64 \text { yrs who } \\
\text { have not had a hysterectomy) }\end{array}$ & 39,447 & $67.5(65.5-69.4)$ & $65.7(63.8-67.6)$ & $82.1(80.5-83.6)$ & $82.1(80.5-83.6)$ & $87.6(86.9-88.2)$ & $87.7(87.0-88.4)$ \\
\hline $\begin{array}{l}\text { Colorectal cancer screening } \\
\text { (adults aged } 50-64 \text { yrs) }\end{array}$ & 45,802 & $29.1(27.1-31.2)$ & $29.1(27.1-31.1)$ & $64.7(63.1-66.2)$ & $63.1(61.4-64.8)$ & $65.4(64.6-66.3)$ & $64.7(63.9-65.6)$ \\
\hline $\begin{array}{l}\text { HIV test } \\
18-64 \mathrm{yrs} \text { ) }\end{array}$ & 93,094 & $47.0(45.6-48.4)$ & $46.4(45.1-47.8)$ & $55.3(54.1-56.6)$ & $58.3(57.0-59.6)$ & $35.5(34.9-36.1)$ & $37.3(36.6-38.0)$ \\
\hline $\begin{array}{l}\text { Influenza vaccination within } \\
\text { preceding } 12 \text { mos (adults aged } \\
18-64 \mathrm{yrs} \text { ) }\end{array}$ & 96,771 & $17.4(16.4-18.4)$ & $17.6(16.6-18.6)$ & $41.6(40.4-42.9)$ & $40.1(38.7-41.4)$ & $37.8(37.2-38.4)$ & $36.7(36.1-37.4)$ \\
\hline
\end{tabular}

See table footnotes on next page. 
TABLE 9. (Continued) Crude and age-standardized* prevalence estimates of health care access and clinical preventive services use among adults aged 18-64 years with no primary source of health insurance coverage, public health plan coverage, or private health insurance coverage at the time of interview, by state Medicaid expansion status - Behavioral Risk Factor Surveillance System, 43 states, ${ }^{\dagger} 2014$

\begin{tabular}{|c|c|c|c|c|c|c|c|}
\hline \multirow[b]{2}{*}{ Category } & \multirow[b]{2}{*}{$n^{\S}$} & \multicolumn{2}{|c|}{$\begin{array}{l}\text { No primary source } \\
\text { of health insurance coverage }\end{array}$} & \multicolumn{2}{|c|}{$\begin{array}{c}\text { Public health plan } \\
\text { coverage } \mathrm{e}^{* *}\end{array}$} & \multicolumn{2}{|c|}{$\begin{array}{c}\text { Private health insurance } \\
\text { coverage }^{\dagger+}\end{array}$} \\
\hline & & $\begin{array}{c}\text { Crude } \\
\% \S \S(95 \% \mathrm{Cl})\end{array}$ & $\begin{array}{c}\text { Age standardized } \\
\%(95 \% \mathrm{Cl})\end{array}$ & $\begin{array}{c}\text { Crude } \\
\%(95 \% \mathrm{Cl})\end{array}$ & $\begin{array}{l}\text { Age standardized } \\
\%(95 \% \mathrm{Cl})\end{array}$ & $\begin{array}{c}\text { Crude } \\
\%(95 \% \mathrm{Cl})\end{array}$ & $\begin{array}{l}\text { Age standardized } \\
\%(95 \% \mathrm{Cl})\end{array}$ \\
\hline \multicolumn{8}{|l|}{ Overall } \\
\hline \multicolumn{8}{|l|}{ Health care access } \\
\hline Usual source of health care & 225,394 & $41.3(40.3-42.3)$ & $42.7(41.7-43.6)$ & $81.1(80.4-81.7)$ & $79.8(79.1-80.5)$ & $82.7(82.4-83.0)$ & $81.0(80.6-81.4)$ \\
\hline $\begin{array}{l}\text { Routine checkup within } \\
\text { preceding } 12 \text { mos }\end{array}$ & 223,639 & $41.6(40.6-42.6)$ & $42.0(41.0-43.0)$ & $75.4(74.7-76.2)$ & $74.4(73.5-75.2)$ & $70.3(69.9-70.7)$ & $68.9(68.4-69.3)$ \\
\hline $\begin{array}{l}\text { Cost barrier to health care need } \\
\text { during preceding } 12 \mathrm{mos}\end{array}$ & 225,712 & $43.5(42.5-44.5)$ & $43.9(42.9-44.9)$ & $18.2(17.6-18.9)$ & $18.3(17.7-19.0)$ & $8.8(8.5-9.0)$ & $9.0(8.7-9.3)$ \\
\hline $\begin{array}{l}\text { Cost barrier to prescribed } \\
\text { medication need during } \\
\text { preceding } 12 \text { months }\end{array}$ & 224,983 & $18.2(17.5-19.0)$ & $18.8(18.1-19.6)$ & $14.4(13.9-15.0)$ & $14.4(13.8-15.1)$ & $6.3(6.1-6.5)$ & $6.3(6.1-6.6)$ \\
\hline $\begin{array}{l}\text { Medical bills being paid off over } \\
\text { time during preceding } 12 \text { mos }\end{array}$ & 223,775 & $27.5(26.6-28.4)$ & $27.8(26.9-28.7)$ & $22.1(21.4-22.8)$ & $21.9(21.1-22.6)$ & $21.7(21.3-22.1)$ & $22.1(21.7-22.5)$ \\
\hline \multicolumn{8}{|l|}{ CPS } \\
\hline $\begin{array}{l}\text { Mammogram within past } 2 \mathrm{yrs} \\
\text { (women aged } 50-64 \mathrm{yrs} \text { ) }\end{array}$ & 62,659 & $47.8(45.5-50.1)$ & $47.8(45.4-50.1)$ & $74.8(73.5-76.1)$ & $74.6(73.1-75.9)$ & $81.5(80.9-82.2)$ & $81.4(80.8-82.1)$ \\
\hline $\begin{array}{l}\text { Pap test within past } 3 \text { yrs } \\
\text { (women aged } 21-64 \text { yrs who } \\
\text { have not had a hysterectomy) }\end{array}$ & 91,307 & $67.5(66.0-69.0)$ & $65.9(64.4-67.4)$ & $81.2(80.1-82.3)$ & $81.1(80.0-82.2)$ & $87.2(86.8-87.7)$ & $87.2(86.7-87.7)$ \\
\hline $\begin{array}{l}\text { Colorectal cancer screening } \\
\text { (adults aged 50-64 yrs) }\end{array}$ & 104,398 & $30.6(28.9-32.3)$ & $30.6(28.9-32.3)$ & $62.7(61.5-63.9)$ & $61.2(59.9-62.4)$ & $66.0(65.4-66.6)$ & $65.4(64.8-66.0)$ \\
\hline $\begin{array}{l}\text { HIV test }{ }^{t+\dagger} \text { (adults aged } \\
18-64 \text { yrs) }\end{array}$ & 205,720 & $45.3(44.3-46.4)$ & $44.6(43.6-45.7)$ & $54.8(53.9-55.7)$ & $56.9(56.0-57.8)$ & $36.1(35.6-36.5)$ & $38.0(37.5-38.5)$ \\
\hline $\begin{array}{l}\text { Influenza vaccination during } \\
\text { preceding } 12 \text { mos (adults aged } \\
18-64 \text { yrs) }\end{array}$ & 214,525 & $17.8(17.0-18.6)$ & $18.0(17.2-18.8)$ & $38.6(37.7-39.4)$ & $37.4(36.5-38.2)$ & $37.9(37.4-38.3)$ & $36.7(36.3-37.2)$ \\
\hline
\end{tabular}

Abbreviations: $\mathrm{Cl}=$ confidence interval; $\mathrm{CPS}=$ clinical preventive services; $\mathrm{HIV}=$ human immunodeficiency virus; $\mathrm{n}=$ sample size; Pap = Papanicolaou.

* Age standardized to the 2000 projected population for the United States.

† Alabama, Alaska, Arizona, Colorado, Connecticut, Delaware, District of Columbia, Georgia, Idaho, Illinois, Indiana, lowa, Kentucky, Louisiana, Maine, Maryland, Massachusetts, Michigan, Minnesota, Mississippi, Missouri, Montana, Nebraska, Nevada, New Hampshire, New Jersey, New Mexico, New York, North Carolina, North Dakota, Ohio, Oklahoma, Oregon, Pennsylvania, Rhode Island, South Carolina, Tennessee, Utah, Vermont, Virginia, Washington, West Virginia, and Wisconsin. Data from Missouri are available from the Missouri Department of Health and Senior Services.

§Unweighted sample size.

II Includes persons who, when asked about their primary source of health care coverage, said they had none and persons who did not have any kind of health care coverage at the time of interview.

** Public health insurance includes Medicare; Medicaid or other state program; TRICARE (formerly CHAMPUS), Veterans Affairs, or military plan; Alaska Native, Indian Health Service, Tribal Health Services, or some other source.

t+ Private health insurance includes a plan purchased through an employer or union (includes plans purchased through another person's employer) or a plan that they or another family member purchased on their own.

$\S \S$ Weighted percentage.

११ States that expanded Medicaid as of January 1, 2014 ( $n=23)$ : Arizona, Colorado, Connecticut, Delaware, District of Columbia, Illinois, lowa, Kentucky, Maryland, Massachusetts, Michigan, Minnesota, Nevada, New Jersey, New Mexico, New York, North Dakota, Ohio, Oregon, Rhode Island, Vermont, Washington, and West Virginia.

*** Adults aged 50-64 years who have had a fecal occult blood test (FOBT) within the past year, or sigmoidoscopy within the past 5 years and an FOBT within the past 3 years, or colonoscopy within the past 10 years.

${ }^{++t}$ Adults aged 18-64 years ever tested for HIV.

$\S \S \S$ States that did not expand Medicaid as of January 1, 2014 ( $n=20)$ : Alabama, Alaska, Georgia, Idaho, Indiana, Louisiana, Maine, Mississippi, Missouri, Montana, Nebraska, New Hampshire, North Carolina, Oklahoma, Pennsylvania, South Carolina, Tennessee, Utah, Virginia, and Wisconsin. 
TABLE 10. Crude and age-standardized* prevalence estimates of number of medical care visits during the preceding 12 months among adults aged 18-64 years with no primary source of health insurance coverage, public health plan coverage, and private health insurance coverage at the time of interview, by state Medicaid expansion status - Behavioral Risk Factor Surveillance System, 43 states, ${ }^{\dagger} 2014$

\begin{tabular}{|c|c|c|c|c|c|c|c|}
\hline \multirow[b]{2}{*}{ Category } & \multirow[b]{2}{*}{$n^{\S}$} & \multicolumn{2}{|c|}{$\begin{array}{c}\text { No primary source of } \\
\text { health insurance coverage }\end{array}$} & \multicolumn{2}{|c|}{$\begin{array}{l}\text { Public health plan } \\
\text { coverage } \mathrm{e}^{* *}\end{array}$} & \multicolumn{2}{|c|}{$\begin{array}{c}\text { Private health insurance } \\
\text { coverage }^{\dagger+}\end{array}$} \\
\hline & & $\begin{array}{c}\text { Crude } \\
\%{ }^{\S \S}(95 \% \mathrm{Cl})\end{array}$ & $\begin{array}{l}\text { Age standardized } \\
\quad \%(95 \% \mathrm{Cl})\end{array}$ & $\begin{array}{c}\text { Crude } \\
\%(95 \% \mathrm{Cl})\end{array}$ & $\begin{array}{l}\text { Age standardized } \\
\%(95 \% \mathrm{Cl})\end{array}$ & $\begin{array}{c}\text { Crude } \\
\%(95 \% \mathrm{Cl})\end{array}$ & $\begin{array}{l}\text { Age standardized } \\
\%(95 \% \mathrm{Cl})\end{array}$ \\
\hline $\begin{array}{l}\text { Medicaid } \\
\text { expansion } \\
\text { states } ๆ \text { ๆी }\end{array}$ & 121,366 & & & & & & \\
\hline None & 14,735 & $39.0(37.4-40.6)$ & $38.8(37.3-40.4)$ & $10.3(9.5-11.0)$ & $10.5(9.8-11.4)$ & $11.3(10.9-11.6)$ & $11.8(11.4-12.3)$ \\
\hline $1-2$ visits & 43,392 & $36.4(34.8-37.9)$ & $36.0(34.5-37.6)$ & $27.8(26.8-28.9)$ & $28.4(27.3-29.6)$ & $39.1(38.5-39.7)$ & $39.3(38.7-39.9)$ \\
\hline$\geq 3$ visits & 63,239 & $24.6(23.3-26.0)$ & $25.1(23.8-26.5)$ & $61.9(60.8-63.1)$ & $61.0(59.8-62.2)$ & $49.7(49.1-50.3)$ & $48.9(48.2-49.5)$ \\
\hline $\begin{array}{l}\text { Medicaid } \\
\text { nonexpansion } \\
\text { states*** }\end{array}$ & 98,600 & & & & & & \\
\hline None & 13,774 & $35.4(34.1-36.8)$ & $35.2(33.9-36.5)$ & $8.0(7.3-8.7)$ & $8.4(7.6-9.2)$ & $11.4(11.0-11.8)$ & $11.9(11.4-12.3)$ \\
\hline $1-2$ visits & 36,981 & $37.4(36.1-38.7)$ & $37.2(35.9-38.5)$ & $25.9(24.8-27.0)$ & $26.9(25.7-28.2)$ & $40.4(39.7-41.0)$ & $40.6(40.0-41.3)$ \\
\hline$\geq 3$ visits & 47,845 & $27.2(26.0-28.4)$ & $27.6(26.4-28.7)$ & $66.1(64.9-67.3)$ & $64.7(63.3-66.0)$ & $48.2(47.6-48.8)$ & $47.5(46.8-48.2)$ \\
\hline Overall & 219,966 & & & & & & \\
\hline None & 28,509 & $37.2(36.2-38.2)$ & $37.0(36.0-38.0)$ & $9.4(8.8-9.9)$ & $9.7(9.2-10.3)$ & $11.3(11.0-11.6)$ & $11.8(11.5-12.2)$ \\
\hline $1-2$ visits & 80,373 & $36.9(35.9-37.9)$ & $36.6(35.6-37.6)$ & $27.1(26.3-27.9)$ & $27.9(27.0-28.7)$ & $39.6(39.2-40.1)$ & $39.9(39.4-40.3)$ \\
\hline$\geq 3$ visits & 111,084 & $25.9(25.0-26.8)$ & $26.4(25.5-27.3)$ & $63.6(62.7-64.4)$ & $62.4(61.5-63.3)$ & $49.1(48.6-49.5)$ & $48.3(47.8-48.7)$ \\
\hline
\end{tabular}

Abbreviations: $\mathrm{Cl}=$ confidence interval; $\mathrm{n}=$ sample size.

${ }^{*}$ Age standardized to the 2000 projected population for the United States.

† Alabama, Alaska, Arizona, Colorado, Connecticut, Delaware, District of Columbia, Georgia, Idaho, Illinois, Indiana, lowa, Kentucky, Louisiana, Maine, Maryland, Massachusetts, Michigan, Minnesota, Mississippi, Missouri, Montana, Nebraska, Nevada, New Hampshire, New Jersey, New Mexico, New York, North Carolina, North Dakota, Ohio, Oklahoma, Oregon, Pennsylvania, Rhode Island, South Carolina, Tennessee, Utah, Vermont, Virginia, Washington, West Virginia, and Wisconsin. Data from Missouri are available from the Missouri Department of Health and Senior Services.

§Unweighted sample size.

"Includes persons who, when asked about their primary source of health care coverage, said they had none and persons who did not have any kind of health care coverage at the time of interview.

** Public health insurance includes Medicare; Medicaid or other state program; TRICARE (formerly CHAMPUS), Veterans Affairs, or military plan; Alaska Native, Indian Health Service, Tribal Health Services, or some other source.

t+ Private health insurance includes a plan purchased through an employer or union (includes plans purchased through another person's employer) or a plan that they or another family member purchased on their own.

$\S \S$ Weighted percentage.

ๆศ States that expanded Medicaid as of January 1, $2014(n=23)$ : Arizona, Colorado, Connecticut, Delaware, District of Columbia, Illinois, lowa, Kentucky, Maryland, Massachusetts, Michigan, Minnesota, Nevada, New Jersey, New Mexico, New York, North Dakota, Ohio, Oregon, Rhode Island, Vermont, Washington, and West Virginia.

*** States that did not expand Medicaid as of January 1, 2014 ( $n=20)$ : Alabama, Alaska, Georgia, Idaho, Indiana, Louisiana, Maine, Mississippi, Missouri, Montana, Nebraska, New Hampshire, North Carolina, Oklahoma, Pennsylvania, South Carolina, Tennessee, Utah, Virginia, and Wisconsin. 
TABLE 11. Crude and age-standardized* prevalence estimates of satisfaction with received health care during the preceding 12 months among adults aged 18-64 years with no primary source of health insurance coverage, public health plan coverage, and private health insurance coverage at the time of interview, by state Medicaid expansion status - Behavioral Risk Factor Surveillance System, 43 states, ${ }^{\dagger} 2014$

\begin{tabular}{|c|c|c|c|c|c|c|c|}
\hline \multirow[b]{2}{*}{ Category } & \multirow[b]{2}{*}{$n^{\S}$} & \multicolumn{2}{|c|}{$\begin{array}{l}\text { No primary source of } \\
\text { health insurance coverage }\end{array}$} & \multicolumn{2}{|c|}{$\begin{array}{l}\text { Public health plan } \\
\text { coverage }{ }^{* *}\end{array}$} & \multicolumn{2}{|c|}{$\begin{array}{c}\text { Private health insurance } \\
\text { coverage }^{\dagger+}\end{array}$} \\
\hline & & $\begin{array}{c}\text { Crude } \\
\% \S \S(95 \% \mathrm{Cl})\end{array}$ & $\begin{array}{l}\text { Age standardized } \\
\%(95 \% \mathrm{Cl})\end{array}$ & $\begin{array}{c}\text { Crude } \\
\%(95 \% \mathrm{Cl})\end{array}$ & $\begin{array}{l}\text { Age standardized } \\
\%(95 \% \mathrm{Cl})\end{array}$ & $\begin{array}{c}\text { Crude } \\
\%(95 \% \mathrm{Cl})\end{array}$ & $\begin{array}{l}\text { Age standardized } \\
\quad \%(95 \% \mathrm{Cl})\end{array}$ \\
\hline $\begin{array}{l}\text { Medicaid } \\
\text { expansion } \\
\text { states }\end{array}$ & 105,704 & & & & & & \\
\hline Very satisfied & 70,024 & $46.0(43.9-48.1)$ & $46.9(44.9-48.9)$ & $58.7(57.5-60.0)$ & $58.3(57.0-59.6)$ & $67.1(66.5-67.7)$ & $66.1(65.4-66.8)$ \\
\hline Somewhat satisfied & 32,424 & $42.5(40.4-44.6)$ & $41.8(39.8-43.9)$ & $36.8(35.6-38.0)$ & $37.2(35.9-38.5)$ & $30.6(30.0-31.2)$ & $31.6(30.9-32.2)$ \\
\hline Not at all satisfied & 3,256 & $11.5(10.2-13.0)$ & $11.3(10.0-12.7)$ & $4.5(4.0-5.0)$ & $4.5(4.0-5.1)$ & $2.3(2.1-2.5)$ & $2.3(2.1-2.5)$ \\
\hline $\begin{array}{l}\text { Medicaid } \\
\text { nonexpansion } \\
\text { states*** }\end{array}$ & 83,969 & & & & & & \\
\hline Very satisfied & 54,670 & $45.4(43.7-47.1)$ & $45.9(44.3-47.6)$ & $61.4(60.1-62.6)$ & $60.6(59.2-62.0)$ & $66.9(66.2-67.5)$ & $66.3(65.6-67.0)$ \\
\hline Somewhat satisfied & 26,484 & $42.9(41.2-44.6)$ & $42.5(40.9-44.2)$ & $34.1(32.9-35.4)$ & $34.6(33.3-36.0)$ & $30.7(30.1-31.3)$ & $31.2(30.5-31.9)$ \\
\hline Not at all satisfied & 2,815 & $11.7(10.6-12.9)$ & $11.5(10.5-12.7)$ & $4.5(4.0-5.1)$ & $4.8(4.1-5.5)$ & $2.4(2.2-2.7)$ & $2.5(2.2-2.7)$ \\
\hline Overall & 189,673 & & & & & & \\
\hline Very satisfied & 124,694 & $45.7(44.4-47.0)$ & $46.4(45.1-47.7)$ & $59.8(58.9-60.7)$ & $59.2(58.2-60.2)$ & $67.0(66.6-67.5)$ & $66.2(65.7-66.7)$ \\
\hline Somewhat satisfied & 58,908 & $42.7(41.4-44.0)$ & $42.2(40.9-43.5)$ & $35.7(34.8-36.6)$ & $36.2(35.3-37.2)$ & $30.6(30.2-31.1)$ & $31.4(30.9-31.9)$ \\
\hline Not at all satisfied & 6,071 & $11.6(10.8-12.6)$ & $11.4(10.6-12.3)$ & $4.5(4.1-4.9)$ & $4.6(4.2-5.0)$ & $2.3(2.2-2.5)$ & $2.4(2.2-2.6)$ \\
\hline
\end{tabular}

Abbreviations: $\mathrm{Cl}=$ confidence interval; $\mathrm{n}=$ sample size.

* Age standardized to the 2000 projected population for the United States.

† Alabama, Alaska, Arizona, Colorado, Connecticut, Delaware, District of Columbia, Georgia, Idaho, Illinois, Indiana, lowa, Kentucky, Louisiana, Maine, Maryland, Massachusetts, Michigan, Minnesota, Mississippi, Missouri, Montana, Nebraska, Nevada, New Hampshire, New Jersey, New Mexico, New York, North Carolina, North Dakota, Ohio, Oklahoma, Oregon, Pennsylvania, Rhode Island, South Carolina, Tennessee, Utah, Vermont, Virginia, Washington, West Virginia, and Wisconsin. Data from Missouri are available from the Missouri Department of Health and Senior Services.

$\S$ Unweighted sample size.

"Includes persons who, when asked about their primary source of health care coverage, said they had none and persons who did not have any kind of health care coverage at the time of interview.

** Public health insurance includes Medicare; Medicaid or other state program; TRICARE (formerly CHAMPUS), Veterans Affairs, or military plan; Alaska Native, Indian Health Service, Tribal Health Services, or some other source.

t+ Private health insurance includes a plan purchased through an employer or union (includes plans purchased through another person's employer) or a plan that they or another family member purchased on their own.

$\S \S$ Weighted percentage.

กी States that expanded Medicaid as of January 1, 2014 ( $n=23)$ : Arizona, Colorado, Connecticut, Delaware, District of Columbia, Illinois, lowa, Kentucky, Maryland, Massachusetts, Michigan, Minnesota, Nevada, New Jersey, New Mexico, New York, North Dakota, Ohio, Oregon, Rhode Island, Vermont, Washington, and West Virginia.

** States that did not expand Medicaid as of January 1, 2014 ( $n=20)$ : Alabama, Alaska, Georgia, Idaho, Indiana, Louisiana, Maine, Mississippi, Missouri, Montana, Nebraska, New Hampshire, North Carolina, Oklahoma, Pennsylvania, South Carolina, Tennessee, Utah, Virginia, and Wisconsin. 
TABLE 12. Crude and age-standardized* prevalence estimates of continuous health insurance during 12 months before interview, with a gap in health insurance during 12 months before interview, or no health insurance for $>12$ months before interview among adults aged 18-64 years, by state Medicaid expansion status and federal poverty level — Behavioral Risk Factor Surveillance System, 43 states, ${ }^{\dagger} 2014$

\begin{tabular}{|c|c|c|c|c|c|c|c|}
\hline \multirow[b]{2}{*}{ Category } & \multirow[b]{2}{*}{$n^{\S}$} & \multicolumn{2}{|c|}{$\begin{array}{l}\text { Continuously insured } \\
\text { during } 12 \text { mos before interview }\end{array}$} & \multicolumn{2}{|c|}{$\begin{array}{l}\text { Gap in insurance } \\
\text { during } 12 \text { mos before interview }\end{array}$} & \multicolumn{2}{|c|}{$\begin{array}{c}\text { No health insurance } \\
\text { for }>12 \text { mos before interview }\end{array}$} \\
\hline & & $\begin{array}{c}\text { Crude } \\
\%{ }^{\text {I }}(95 \% \mathrm{Cl})\end{array}$ & $\begin{array}{l}\text { Age standardized } \\
\quad \%(95 \% \mathrm{Cl})\end{array}$ & $\begin{array}{c}\text { Crude } \\
\%(95 \% \mathrm{Cl})\end{array}$ & $\begin{array}{l}\text { Age standardized } \\
\%(95 \% \mathrm{Cl})\end{array}$ & $\begin{array}{c}\text { Crude } \\
\%(95 \% \mathrm{Cl})\end{array}$ & $\begin{array}{c}\text { Age standardized } \\
\%(95 \% \mathrm{Cl})\end{array}$ \\
\hline $\begin{array}{l}\text { Medicaid } \\
\text { expansion } \\
\text { states** }\end{array}$ & 125,265 & $78.5(78.0-78.9)$ & 77.4 (76.9-77.9) & $12.5(12.1-12.8)$ & $13.0(12.6-13.4)$ & $9.1(8.7-9.4)$ & $9.6(9.3-10.0)$ \\
\hline$<100$ of FPL & 13,524 & $57.4(55.9-58.9)$ & $57.6(56.1-59.1)$ & $22.0(20.8-23.2)$ & $21.9(20.7-23.1)$ & 20.6 (19.3-21.9) & $20.6(19.3-21.9)$ \\
\hline$\geq 100 \%-\leq 400 \%$ of FPL & 40,770 & $73.2(72.4-74.1)$ & $72.4(71.5-73.3)$ & $15.6(15.0-16.3)$ & $16.1(15.4-16.8)$ & $11.1(10.5-11.8)$ & $11.5(10.8-12.2)$ \\
\hline$>400 \%$ of FPL & 50,798 & $94.0(93.6-94.4)$ & 93.5 (92.9-94.0) & $4.1(3.8-4.5)$ & $4.6(4.2-5.0)$ & $1.8(1.6-2.1)$ & $2.0(1.7-2.3)$ \\
\hline Unknown & 20,173 & $75.3(74.2-76.4)$ & $74.4(73.2-75.5)$ & $14.8(14.0-15.8)$ & $15.1(14.2-16.0)$ & $9.9(9.1-10.7)$ & $10.5(9.7-11.4)$ \\
\hline $\begin{array}{l}\text { Medicaid } \\
\text { nonexpansion } \\
\text { states }{ }^{\dagger \dagger}\end{array}$ & 101,883 & $74.5(74.0-75.0)$ & $73.4(72.9-73.9)$ & $12.2(11.8-12.6)$ & $12.8(12.4-13.2)$ & $13.3(12.9-13.7)$ & $13.9(13.5-14.3)$ \\
\hline$<100$ of $\mathrm{FPL}$ & 13,180 & $48.5(47.1-49.9)$ & $48.6(47.3-50.0)$ & $20.7(19.6-21.9)$ & $20.5(19.4-21.6)$ & $30.8(29.5-32.1)$ & $30.9(29.6-32.2)$ \\
\hline$\geq 100 \%-\leq 400 \%$ of FPL & 39,417 & $71.3(70.5-72.0)$ & $70.4(69.5-71.2)$ & $14.5(13.9-15.1)$ & $15.0(14.3-15.6)$ & $14.2(13.6-14.9)$ & $14.6(14.0-15.3)$ \\
\hline$>400 \%$ of FPL & 36,650 & $93.0(92.5-93.4)$ & $91.9(91.2-92.6)$ & $4.8(4.4-5.2)$ & $5.6(5.1-6.2)$ & $2.3(2.0-2.6)$ & $2.5(2.1-2.8)$ \\
\hline Unknown & 12,636 & $72.1(70.7-73.5)$ & $70.1(68.6-71.6)$ & $12.8(11.8-13.8)$ & $13.3(12.2-14.4)$ & $15.1(14.0-16.3)$ & $16.6(15.4-18.0)$ \\
\hline Overall & 227,148 & $76.7(76.4-77.1)$ & $75.6(75.3-76.0)$ & $12.3(12.1-12.6)$ & $12.9(12.6-13.2)$ & $10.9(10.7-11.2)$ & $11.5(11.2-11.7)$ \\
\hline$<100$ of FPL & 26,704 & $53.3(52.3-54.3)$ & $53.5(52.4-54.5)$ & $21.4(20.6-22.3)$ & $21.2(20.4-22.1)$ & $25.3(24.4-26.2)$ & $25.3(24.4-26.2)$ \\
\hline$\geq 100 \%-\leq 400 \%$ of FPL & 80,187 & $72.3(71.7-72.9)$ & $71.4(70.8-72.1)$ & $15.1(14.6-15.6)$ & $15.6(15.1-16.1)$ & $12.6(12.2-13.1)$ & $13.0(12.5-13.5)$ \\
\hline$>400 \%$ of FPL & 87,448 & $93.6(93.3-93.9)$ & $92.8(92.4-93.2)$ & $4.4(4.1-4.7)$ & $5.0(4.7-5.3)$ & $2.0(1.8-2.2)$ & $2.2(1.9-2.4)$ \\
\hline Unknown & 32,809 & $74.1(73.3-75.0)$ & $72.9(72.0-73.8)$ & $14.1(13.4-14.8)$ & $14.4(13.7-15.1)$ & $11.8(11.2-12.5)$ & $12.7(12.0-13.4)$ \\
\hline
\end{tabular}

Abbreviations: $\mathrm{Cl}=$ confidence interval; $\mathrm{FPL}=$ federal poverty level; $\mathrm{n}=$ sample size.

${ }^{*}$ Age standardized to the 2000 projected population for the United States.

† Alabama, Alaska, Arizona, Colorado, Connecticut, Delaware, District of Columbia, Georgia, Idaho, Illinois, Indiana, lowa, Kentucky, Louisiana, Maine, Maryland, Massachusetts, Michigan, Minnesota, Mississippi, Missouri, Montana, Nebraska, Nevada, New Hampshire, New Jersey, New Mexico, New York, North Carolina, North Dakota, Ohio, Oklahoma, Oregon, Pennsylvania, Rhode Island, South Carolina, Tennessee, Utah, Vermont, Virginia, Washington, West Virginia, and Wisconsin. Data from Missouri are available from the Missouri Department of Health and Senior Services.

§ Unweighted sample size.

I Weighted percentage.

** States that expanded Medicaid as of January 1, 2014 ( $n=23)$ : Arizona, Colorado, Connecticut, Delaware, District of Columbia, Illinois, lowa, Kentucky, Maryland, Massachusetts, Michigan, Minnesota, Nevada, New Jersey, New Mexico, New York, North Dakota, Ohio, Oregon, Rhode Island, Vermont, Washington, and West Virginia.

${ }^{+\dagger}$ States that did not expand Medicaid as of January 1, 2014 ( $\left.n=20\right)$ : Alabama, Alaska, Georgia, Idaho, Indiana, Louisiana, Maine, Mississippi, Missouri, Montana, Nebraska, New Hampshire, North Carolina, Oklahoma, Pennsylvania, South Carolina, Tennessee, Utah, Virginia, and Wisconsin. 
TABLE 13. Crude and age-standardized* prevalence estimates of health care access and clinical preventive services use among adults aged 18-64 years with continuous health insurance during 12 months before interview, with a gap in health insurance during 12 months before interview, or no health insurance for $>12$ months before interview, by state Medicaid expansion status - Behavioral Risk Factor Surveillance System, 43 states, ${ }^{\dagger} 2014$

\begin{tabular}{|c|c|c|c|c|c|c|c|}
\hline \multirow[b]{2}{*}{ Category } & \multirow[b]{2}{*}{$n^{\S}$} & \multicolumn{2}{|c|}{$\begin{array}{c}\text { Continuously insured } \\
\text { during } 12 \text { mos before interview }\end{array}$} & \multicolumn{2}{|c|}{$\begin{array}{c}\text { Gap in insurance } \\
\text { during } 12 \text { mos before interview }\end{array}$} & \multicolumn{2}{|c|}{$\begin{array}{c}\text { No health insurance } \\
\text { for }>12 \text { mos before interview }\end{array}$} \\
\hline & & $\begin{array}{c}\text { Crude } \\
\%{ }^{\text {q }}(95 \% \mathrm{Cl})\end{array}$ & $\begin{array}{l}\text { Age standardized } \\
\quad \%(95 \% \mathrm{Cl})\end{array}$ & $\begin{array}{c}\text { Crude } \\
\%(95 \% \mathrm{Cl})\end{array}$ & $\begin{array}{l}\text { Age standardized } \\
\quad \%(95 \% \mathrm{Cl})\end{array}$ & $\begin{array}{c}\text { Crude } \\
\%(95 \% \mathrm{Cl})\end{array}$ & $\begin{array}{l}\text { Age standardized } \\
\quad \%(95 \% \mathrm{Cl})\end{array}$ \\
\hline \multicolumn{8}{|l|}{ Medicaid expansion states** } \\
\hline \multicolumn{8}{|l|}{ Health care access } \\
\hline Usual source of health care & 124,779 & $84.5(84.1-85.0)$ & $83.0(82.5-83.5)$ & $63.9(62.4-65.4)$ & $64.8(63.3-66.2)$ & $35.3(33.5-37.2)$ & $36.2(34.4-38.0)$ \\
\hline $\begin{array}{l}\text { Routine checkup within } \\
\text { preceding } 12 \text { mos }\end{array}$ & 123,846 & $72.7(72.2-73.2)$ & $71.4(70.8-71.9)$ & $59.0(57.5-60.5)$ & $59.3(57.8-60.7)$ & $32.6(30.8-34.5)$ & $33.0(31.2-34.9)$ \\
\hline $\begin{array}{l}\text { Cost barrier to health care } \\
\text { need during preceding } \\
12 \text { mos }\end{array}$ & 124,994 & $7.3(7.0-7.6)$ & $7.3(7.0-7.7)$ & $40.4(38.9-41.9)$ & $40.8(39.3-42.2)$ & $45.4(43.4-47.3)$ & $45.1(43.2-47.0)$ \\
\hline $\begin{array}{l}\text { Cost barrier to prescribed } \\
\text { medication need during } \\
\text { preceding } 12 \text { mos }\end{array}$ & 125,023 & $5.9(5.6-6.2)$ & $5.9(5.6-6.2)$ & $21.7(20.5-22.9)$ & $22.1(21.0-23.3)$ & $15.6(14.3-17.1)$ & $15.8(14.5-17.3)$ \\
\hline $\begin{array}{l}\text { Medical bills being paid off } \\
\text { over time during } \\
\text { preceding } 12 \text { mos }\end{array}$ & 124,291 & $18.1(17.7-18.5)$ & $18.3(17.8-18.7)$ & $31.2(29.9-32.6)$ & $31.4(30.1-32.8)$ & $23.4(21.9-25.1)$ & $23.5(22.0-25.1)$ \\
\hline \multicolumn{8}{|l|}{ CPS } \\
\hline $\begin{array}{l}\text { Mammogram within } \\
\text { past } 2 \text { yrs (women aged } \\
50-64 \text { yrs) }\end{array}$ & 35,542 & $81.9(81.0-82.6)$ & $81.8(80.9-82.6)$ & $64.7(61.5-67.8)$ & $64.7(61.5-67.7)$ & $38.2(33.8-42.8)$ & $38.2(33.8-42.9)$ \\
\hline $\begin{array}{l}\text { Pap test within past } 3 \text { yrs } \\
\text { (women aged } 21-64 \text { yrs } \\
\text { who have not had a } \\
\text { hysterectomy) }\end{array}$ & 51,970 & $86.0(85.4-86.7)$ & $85.9(85.2-86.6)$ & $77.5(75.6-79.4)$ & $76.8(74.9-78.6)$ & $61.8(58.5-65.1)$ & $60.6(57.4-63.7)$ \\
\hline $\begin{array}{l}\text { Colorectal cancer } \\
\text { screening } \\
50-64 \text { yrs) }\end{array}$ & 58,808 & $66.7(65.9-67.5)$ & $65.9(65.1-66.7)$ & $44.9(42.3-47.4)$ & $44.8(42.3-47.4)$ & $24.7(21.6-28.0)$ & $24.9(21.8-28.2)$ \\
\hline $\begin{array}{l}\text { HIV test }{ }^{\$ \S} \text { (adults aged } \\
18-64 \text { yrs) }\end{array}$ & 112,951 & $39.4(38.8-40.0)$ & $41.6(41.0-42.2)$ & $50.9(49.4-52.5)$ & $50.9(49.4-52.4)$ & $41.7(39.7-43.7)$ & $40.4(38.5-42.4)$ \\
\hline $\begin{array}{l}\text { Influenza vaccination within } \\
\text { preceding } 12 \text { mos (adults } \\
\text { aged } 18-64 \text { yrs) }\end{array}$ & 118,125 & $38.7(38.2-39.3)$ & $37.5(36.9-38.1)$ & $26.1(24.7-27.5)$ & $26.3(25.0-27.7)$ & $14.4(13.1-15.9)$ & $14.7(13.4-16.2)$ \\
\hline \multicolumn{8}{|c|}{ Medicaid nonexpansion states } \\
\hline \multicolumn{8}{|c|}{ Health care access } \\
\hline Usual source of health care & 101,488 & $82.6(82.2-83.1)$ & $80.8(80.3-81.4)$ & $63.3(61.7-64.9)$ & $65.2(63.8-66.6)$ & $38.1(36.6-39.7)$ & $38.9(37.4-40.3)$ \\
\hline $\begin{array}{l}\text { Routine checkup within } \\
\text { preceding } 12 \text { mos }\end{array}$ & 100,686 & $73.3(72.8-73.8)$ & $71.8(71.3-72.4)$ & $59.2(57.7-60.8)$ & $59.9(58.4-61.4)$ & $34.8(33.3-36.4)$ & $35.2(33.7-36.7)$ \\
\hline $\begin{array}{l}\text { Cost barrier to health care } \\
\text { need during preceding } \\
12 \text { mos }\end{array}$ & 101,648 & $8.2(7.9-8.6)$ & $8.2(7.9-8.6)$ & $41.5(39.9-43.1)$ & $41.9(40.4-43.4)$ & $48.5(47.0-50.1)$ & $48.7(47.2-50.2)$ \\
\hline $\begin{array}{l}\text { Cost barrier to prescribed } \\
\text { medication need during } \\
\text { preceding } 12 \text { mos }\end{array}$ & 101,740 & $7.3(7.0-7.6)$ & $7.3(6.9-7.6)$ & $23.2(21.9-24.5)$ & $23.9(22.7-25.3)$ & $20.4(19.2-21.6)$ & $20.7(19.5-21.9)$ \\
\hline $\begin{array}{l}\text { Medical bills being paid off } \\
\text { over time during } \\
\text { preceding } 12 \text { mos }\end{array}$ & 101,146 & $23.2(22.7-23.7)$ & $23.4(22.9-24.0)$ & $37.3(35.8-38.8)$ & $37.7(36.2-39.2)$ & $30.2(28.8-31.6)$ & $30.3(28.9-31.7)$ \\
\hline \multicolumn{8}{|l|}{ CPS } \\
\hline $\begin{array}{l}\text { Mammogram within } \\
\text { past } 2 \text { yrs (women aged } \\
50-64 \text { yrs) }\end{array}$ & 27,479 & $80.6(79.8-81.4)$ & $80.5(79.7-81.3)$ & $61.0(57.6-64.3)$ & $61.0(57.6-64.3)$ & $40.8(37.7-44.0)$ & $40.7(37.5-43.9)$ \\
\hline $\begin{array}{l}\text { Pap test within past } 3 \text { yrs } \\
\text { (women aged } 21-64 \text { yrs } \\
\text { who have not had a } \\
\text { hysterectomy) }\end{array}$ & 39,471 & $87.3(86.6-87.9)$ & $87.5(86.8-88.1)$ & $79.4(77.3-81.4)$ & $78.0(76.0-79.9)$ & $63.1(60.7-65.4)$ & $61.5(59.2-63.7)$ \\
\hline $\begin{array}{l}\text { Colorectal cancer } \\
\text { screening } \\
50-64 \text { yrs) (adults aged }\end{array}$ & 46,090 & $66.5(65.7-67.3)$ & $65.6(64.8-66.4)$ & $44.7(42.0-47.4)$ & $44.4(41.8-47.1)$ & $24.3(22.1-26.6)$ & $24.3(22.2-26.6)$ \\
\hline $\begin{array}{l}\text { HIV test }{ }^{\S \S} \text { (adults aged } \\
18-64 \text { yrs) }\end{array}$ & 93,395 & $38.3(37.7-38.9)$ & $40.5(39.9-41.2)$ & $50.0(48.3-51.6)$ & $49.5(47.9-51.0)$ & $46.8(45.1-48.4)$ & $46.1(44.5-47.7)$ \\
\hline $\begin{array}{l}\text { Influenza vaccination within } \\
\text { preceding } 12 \text { mos (adults } \\
\text { aged } 18-64 \text { yrs) }\end{array}$ & 97,135 & $39.6(39.0-40.2)$ & $38.4(37.8-39.0)$ & $26.2(24.8-27.6)$ & $26.6(25.2-28.0)$ & $14.9(13.8-16.1)$ & $15.1(14.0-16.2)$ \\
\hline
\end{tabular}

See table footnotes on next page. 
TABLE 13. (Continued) Crude and age-standardized* prevalence estimates of health care access and clinical preventive services use among adults aged 18-64 years with continuous health insurance during 12 months before interview, with a gap in health insurance during 12 months before interview, or no health insurance for $>12$ months before interview, by state Medicaid expansion status - Behavioral Risk Factor Surveillance System, 43 states, ${ }^{\dagger} 2014$

\begin{tabular}{|c|c|c|c|c|c|c|c|}
\hline \multirow[b]{2}{*}{ Category } & \multirow[b]{2}{*}{$n^{\S}$} & \multicolumn{2}{|c|}{$\begin{array}{l}\text { Continuously insured } \\
\text { during } 12 \text { mos before interview }\end{array}$} & \multicolumn{2}{|c|}{$\begin{array}{c}\text { Gap in insurance } \\
\text { during } 12 \text { mos before interview }\end{array}$} & \multicolumn{2}{|c|}{$\begin{array}{c}\text { No health insurance } \\
\text { for }>12 \text { mos before interview }\end{array}$} \\
\hline & & $\begin{array}{c}\text { Crude } \\
\% \text { ๆ }(95 \% \mathrm{Cl})\end{array}$ & $\begin{array}{l}\text { Age standardized } \\
\%(95 \% \mathrm{Cl})\end{array}$ & $\begin{array}{c}\text { Crude } \\
\%(95 \% \mathrm{Cl})\end{array}$ & $\begin{array}{c}\text { Age standardized } \\
\%(95 \% \mathrm{Cl})\end{array}$ & $\begin{array}{c}\text { Crude } \\
\%(95 \% \mathrm{Cl})\end{array}$ & $\begin{array}{l}\text { Age standardized } \\
\quad \%(95 \% \mathrm{Cl})\end{array}$ \\
\hline \multicolumn{8}{|l|}{ Overall } \\
\hline \multicolumn{8}{|l|}{ Health care access } \\
\hline Usual source of health care & 226,267 & $83.7(83.4-84.1)$ & $82.1(81.7-82.4)$ & $63.7(62.6-64.7)$ & $64.9(63.9-65.9)$ & $36.8(35.6-38.0)$ & $37.6(36.5-38.8)$ \\
\hline $\begin{array}{l}\text { Routine checkup within } \\
\text { preceding } 12 \text { mos }\end{array}$ & 224,532 & $72.9(72.6-73.3)$ & $71.6(71.2-72.0)$ & $59.1(58.0-60.2)$ & $59.5(58.5-60.6)$ & $33.8(32.6-35.0)$ & $34.2(33.0-35.4)$ \\
\hline $\begin{array}{l}\text { Cost barrier to health care } \\
\text { need during preceding } \\
12 \text { mos }\end{array}$ & 226,642 & $7.7(7.5-7.9)$ & $7.7(7.5-8.0)$ & $40.9(39.8-42.0)$ & $41.3(40.2-42.3)$ & $47.0(45.8-48.3)$ & $47.1(45.8-48.3)$ \\
\hline $\begin{array}{l}\text { Cost barrier to prescribed } \\
\text { medication need during } \\
\text { preceding } 12 \text { mos }\end{array}$ & 226,763 & $6.5(6.3-6.7)$ & $6.5(6.2-6.7)$ & $22.3(21.4-23.2)$ & $22.9(22.0-23.8)$ & $18.1(17.2-19.1)$ & $18.4(17.5-19.3)$ \\
\hline $\begin{array}{l}\text { Medical bills being paid off } \\
\text { over time during } \\
\text { preceding } 12 \text { mos }\end{array}$ & 225,437 & $20.2(19.9-20.6)$ & $20.4(20.1-20.8)$ & $33.8(32.8-34.9)$ & $34.1(33.1-35.1)$ & $27.0(26.0-28.1)$ & $27.1(26.1-28.1)$ \\
\hline \multicolumn{8}{|l|}{ CPS } \\
\hline $\begin{array}{l}\text { Mammogram within } \\
\text { past } 2 \text { years (women aged } \\
50-64 \text { yrs) }\end{array}$ & 63,021 & $81.3(80.8-81.9)$ & $81.2(80.6-81.8)$ & $63.2(60.8-65.4)$ & $63.1(60.8-65.4)$ & $39.7(37.1-42.4)$ & $39.7(37.1-42.4)$ \\
\hline $\begin{array}{l}\text { Pap test within past } 3 \text { yrs } \\
\text { (women aged } 21-64 \text { yrs } \\
\text { who have not had a } \\
\text { hysterectomy) }\end{array}$ & 91,441 & $86.5(86.1-87.0)$ & $86.6(86.1-87.1)$ & $78.3(76.9-79.7)$ & $77.3(76.0-78.6)$ & $62.6(60.6-64.5)$ & $61.1(59.2-62.9)$ \\
\hline $\begin{array}{l}\text { Colorectal cancer } \\
\text { screening }^{\dagger \dagger} \text { (adults aged } \\
50-64 \text { yrs) }\end{array}$ & 104,898 & $66.6(66.1-67.2)$ & $65.8(65.2-66.3)$ & $44.8(42.9-46.7)$ & $44.7(42.8-46.5)$ & $24.5(22.6-26.4)$ & $24.6(22.8-26.5)$ \\
\hline $\begin{array}{l}\text { HIV test }{ }^{\$ \$} \text { (adults aged } \\
18-64 \text { yrs) }\end{array}$ & 206,346 & $38.9(38.5-39.4)$ & $41.2(40.7-41.6)$ & $50.5(49.4-51.7)$ & $50.3(49.2-51.4)$ & $44.4(43.1-45.7)$ & $43.5(42.2-44.7)$ \\
\hline $\begin{array}{l}\text { Influenza vaccination within } \\
\text { preceding } 12 \text { mos (adults } \\
\text { aged } 18-64 \text { yrs) }\end{array}$ & 215,260 & $39.1(38.7-39.5)$ & $37.9(37.5-38.3)$ & $26.1(25.1-27.1)$ & $26.5(25.5-27.4)$ & $14.7(13.8-15.6)$ & $14.9(14.1-15.8)$ \\
\hline
\end{tabular}

Abbreviations: $\mathrm{Cl}=$ confidence interval; $\mathrm{CPS}=$ clinical preventive services; $\mathrm{HIV}=$ human immunodeficiency virus; $\mathrm{n}=$ sample size; Pap = Papanicolaou.

${ }^{*}$ Age standardized to the 2000 projected population for the United States.

† Alabama, Alaska, Arizona, Colorado, Connecticut, Delaware, District of Columbia, Georgia, Idaho, Illinois, Indiana, lowa, Kentucky, Louisiana, Maine, Maryland, Massachusetts, Michigan, Minnesota, Mississippi, Missouri, Montana, Nebraska, Nevada, New Hampshire, New Jersey, New Mexico, New York, North Carolina, North Dakota, Ohio, Oklahoma, Oregon, Pennsylvania, Rhode Island, South Carolina, Tennessee, Utah, Vermont, Virginia, Washington, West Virginia, and Wisconsin. Data from Missouri are available from the Missouri Department of Health and Senior Services.

$\$$ Unweighted sample size.

Weighted percentage.

** States that expanded Medicaid as of January 1, 2014 ( $n=23)$ : Arizona, Colorado, Connecticut, Delaware, District of Columbia, Illinois, lowa, Kentucky, Maryland, Massachusetts, Michigan, Minnesota, Nevada, New Jersey, New Mexico, New York, North Dakota, Ohio, Oregon, Rhode Island, Vermont, Washington, and West Virginia.

${ }^{\dagger \dagger}$ Adults aged 50-64 years who had a fecal occult blood test (FOBT) within the past year, or sigmoidoscopy within the past 5 years and an FOBT within the past 3 years, or colonoscopy within the past 10 years.

$\$ \$$ Adults aged 18-64 years ever tested for HIV.

95 States that did not expand Medicaid as of January 1, 2014 ( $n=20)$ : Alabama, Alaska, Georgia, Idaho, Indiana, Louisiana, Maine, Mississippi, Missouri, Montana, Nebraska, New Hampshire, North Carolina, Oklahoma, Pennsylvania, South Carolina, Tennessee, Utah, Virginia, and Wisconsin. 
TABLE 14. Crude and age-standardized* prevalence estimates of number of medical care visits during preceding 12 months among adults aged 18-64 years with continuous health insurance during 12 months before interview, with a gap in health insurance during 12 months before interview, or no health insurance for $>12$ months before interview, by state Medicaid expansion status - Behavioral Risk Factor Surveillance System, 43 states, ${ }^{\dagger} 2014$

\begin{tabular}{|c|c|c|c|c|c|c|c|}
\hline \multirow[b]{2}{*}{ Category } & \multirow[b]{2}{*}{$n^{\S}$} & \multicolumn{2}{|c|}{$\begin{array}{l}\text { Continuously insured } \\
\text { during } 12 \text { mos before interview }\end{array}$} & \multicolumn{2}{|c|}{$\begin{array}{l}\text { Gap in insurance } \\
\text { during } 12 \text { mos before interview }\end{array}$} & \multicolumn{2}{|c|}{$\begin{array}{c}\text { No health insurance } \\
\text { for }>12 \text { mos before interview }\end{array}$} \\
\hline & & $\begin{array}{c}\text { Crude } \\
\% \text { ๆ }(95 \% \mathrm{Cl})\end{array}$ & $\begin{array}{l}\text { Age standardized } \\
\%(95 \% \mathrm{Cl})\end{array}$ & $\begin{array}{c}\text { Crude } \\
\%(95 \% \mathrm{Cl})\end{array}$ & $\begin{array}{c}\text { Age standardized } \\
\%(95 \% \mathrm{Cl})\end{array}$ & $\begin{array}{c}\text { Crude } \\
\%(95 \% \mathrm{Cl})\end{array}$ & $\begin{array}{l}\text { Age standardized } \\
\%(95 \% \mathrm{Cl})\end{array}$ \\
\hline $\begin{array}{l}\text { Medicaid } \\
\text { expansion } \\
\text { states** }^{* *}\end{array}$ & 122,126 & & & & & & \\
\hline None & 14,791 & 10.3 ( 9.9-10.6) & $10.8(10.4-11.2)$ & $19.0(17.8-20.3)$ & $19.0(17.8-20.2)$ & $47.1(45.2-49.1)$ & $47.0(45.0-48.9)$ \\
\hline $1-2$ visits & 43,642 & $36.7(36.2-37.3)$ & $37.2(36.6-37.8)$ & $35.2(33.7-36.7)$ & $35.0(33.6-36.4)$ & $34.8(33.0-36.8)$ & 34.7 (32.9-36.6) \\
\hline$\geq 3$ visits & 63,693 & $53.0(52.4-53.6)$ & $52.0(51.4-52.6)$ & $45.8(44.3-47.3)$ & $46.1(44.6-47.6)$ & $18.0(16.6-19.5)$ & $18.4(17.0-19.8)$ \\
\hline $\begin{array}{l}\text { Medicaid } \\
\text { nonexpansion } \\
\text { states }^{+\dagger}\end{array}$ & 99,381 & & & & & & \\
\hline None & 13,838 & $10.2(9.8-10.5)$ & $10.7(10.3-11.1)$ & $17.3(16.1-18.5)$ & $17.3(16.1-18.5)$ & $40.7(39.1-42.3)$ & $40.4(38.9-42.0)$ \\
\hline $1-2$ visits & 37,280 & $37.7(37.1-38.3)$ & $38.2(37.6-38.8)$ & 37.9 (36.3-39.5) & $37.4(35.9-39.0)$ & $35.6(34.1-37.1)$ & $35.5(34.0-37.0)$ \\
\hline$\geq 3$ visits & 48,263 & $52.2(51.6-52.7)$ & $51.1(50.4-51.7)$ & $44.8(43.2-46.4)$ & $45.3(43.8-46.8)$ & $23.7(22.5-25.1)$ & $24.1(22.8-25.4)$ \\
\hline Overall & 221,507 & & & & & & \\
\hline None & 28,629 & $10.2(10.0-10.5)$ & $10.8(10.5-11.1)$ & $18.3(17.4-19.2)$ & $18.2(17.4-19.1)$ & $43.7(42.5-45.0)$ & $43.5(42.2-44.7)$ \\
\hline $1-2$ visits & 80,922 & $37.1(36.7-37.5)$ & $37.6(37.2-38.0)$ & $36.3(35.3-37.4)$ & $36.0(35.0-37.1)$ & $35.2(34.0-36.4)$ & $35.1(34.0-36.3)$ \\
\hline$\geq 3$ visits & 111,956 & $52.6(52.2-53.1)$ & $51.6(51.2-52.1)$ & $45.4(44.3-46.5)$ & $45.7(44.6-46.8)$ & $21.0(20.1-22.0)$ & $21.4(20.5-22.4)$ \\
\hline
\end{tabular}

Abbreviations: $\mathrm{Cl}=$ confidence interval; $\mathrm{n}=$ sample size.

* Age standardized to the 2000 projected population for the United States.

† Alabama, Alaska, Arizona, Colorado, Connecticut, Delaware, District of Columbia, Georgia, Idaho, Illinois, Indiana, lowa, Kentucky, Louisiana, Maine, Maryland, Massachusetts, Michigan, Minnesota, Mississippi, Missouri, Montana, Nebraska, Nevada, New Hampshire, New Jersey, New Mexico, New York, North Carolina, North Dakota, Ohio, Oklahoma, Oregon, Pennsylvania, Rhode Island, South Carolina, Tennessee, Utah, Vermont, Virginia, Washington, West Virginia, and Wisconsin. Data from Missouri are available from the Missouri Department of Health and Senior Services.

§ Unweighted sample size.

I Weighted percentage.

** States that expanded Medicaid as of January 1, $2014(n=23)$ : Arizona, Colorado, Connecticut, Delaware, District of Columbia, Illinois, lowa, Kentucky, Maryland, Massachusetts, Michigan, Minnesota, Nevada, New Jersey, New Mexico, New York, North Dakota, Ohio, Oregon, Rhode Island, Vermont, Washington, and West Virginia.

+† States that did not expand Medicaid as of January 1, 2014 ( $n=20)$ : Alabama, Alaska, Georgia, Idaho, Indiana, Louisiana, Maine, Mississippi, Missouri, Montana, Nebraska, New Hampshire, North Carolina, Oklahoma, Pennsylvania, South Carolina, Tennessee, Utah, Virginia, and Wisconsin. 
TABLE 15. Crude and age-standardized* prevalence estimates of satisfaction with received health care among adults aged 18-64 years with continuous health insurance during 12 months before interview, with a gap in health insurance during 12 months before interview, or no health insurance for >12 months before interview, by state Medicaid expansion status - Behavioral Risk Factor Surveillance System, 43 states, ${ }^{\dagger} 2014$

\begin{tabular}{|c|c|c|c|c|c|c|c|}
\hline \multirow[b]{2}{*}{ Category } & \multirow[b]{2}{*}{$n^{\S}$} & \multicolumn{2}{|c|}{$\begin{array}{l}\text { Continuously insured } \\
\text { during } 12 \text { mos before interview }\end{array}$} & \multicolumn{2}{|c|}{$\begin{array}{l}\text { Gap in insurance } \\
\text { during } 12 \text { mos before interview }\end{array}$} & \multicolumn{2}{|c|}{$\begin{array}{c}\text { No health insurance } \\
\text { for }>12 \text { mos before interview }\end{array}$} \\
\hline & & $\begin{array}{c}\text { Crude } \\
\% \text { ๆ }(95 \% \mathrm{Cl})\end{array}$ & $\begin{array}{l}\text { Age standardized } \\
\%(95 \% \mathrm{Cl})\end{array}$ & $\begin{array}{c}\text { Crude } \\
\%(95 \% \mathrm{Cl})\end{array}$ & $\begin{array}{c}\text { Age standardized } \\
\%(95 \% \mathrm{Cl})\end{array}$ & $\begin{array}{c}\text { Crude } \\
\%(95 \% \mathrm{Cl})\end{array}$ & $\begin{array}{c}\text { Age standardized } \\
\%(95 \% \mathrm{Cl})\end{array}$ \\
\hline $\begin{array}{l}\text { Medicaid } \\
\text { expansion } \\
\text { states** }^{* *}\end{array}$ & 106,389 & & & & & & \\
\hline Very satisfied & 70,469 & $66.8(66.3-67.4)$ & $66.0(65.3-66.6)$ & $46.8(45.1-48.5)$ & $47.1(45.4-48.8)$ & $45.1(42.4-47.8)$ & $46.2(43.6-48.8)$ \\
\hline Somewhat satisfied & 32,649 & $30.7(30.2-31.3)$ & $31.6(31.0-32.2)$ & $45.3(43.6-47.1)$ & $45.0(43.3-46.6)$ & $42.0(39.3-44.7)$ & $41.2(38.7-43.9)$ \\
\hline Not at all satisfied & 3,271 & $2.4(2.3-2.6)$ & $2.4(2.3-2.6)$ & $7.8(7.0-8.8)$ & $7.9(7.0-8.9)$ & $12.9(11.2-14.9)$ & $12.6(10.9-14.5)$ \\
\hline $\begin{array}{l}\text { Medicaid } \\
\text { nonexpansion } \\
\text { states }^{\dagger \dagger}\end{array}$ & 84,673 & & & & & & \\
\hline Very satisfied & 55,103 & $67.2(66.6-67.8)$ & $66.6(66.0-67.3)$ & $49.4(47.6-51.2)$ & $49.8(48.0-51.5)$ & 43.9 (41.9-45.9) & $44.0(42.0-46.1)$ \\
\hline Somewhat satisfied & 26,741 & $30.3(29.7-30.8)$ & $30.8(30.1-31.4)$ & $43.8(42.0-45.6)$ & $43.4(41.7-45.1)$ & $42.6(40.6-44.7)$ & $42.5(40.6-44.6)$ \\
\hline Not at all satisfied & 2,829 & $2.5(2.3-2.8)$ & $2.6(2.3-2.8)$ & $6.8(6.0-7.8)$ & $6.8(6.0-7.8)$ & $13.5(12.1-15.0)$ & $13.4(12.0-14.9)$ \\
\hline Overall & 191,062 & & & & & & \\
\hline Very satisfied & 125,572 & $67.0(66.6-67.4)$ & $66.2(65.8-66.7)$ & $47.9(46.7-49.2)$ & $48.3(47.1-49.5)$ & $44.4(42.8-46.1)$ & $44.9(43.3-46.5)$ \\
\hline Somewhat satisfied & 59,390 & $30.5(30.1-30.9)$ & $31.3(30.8-31.7)$ & 44.7 (43.4-45.9) & $44.3(43.1-45.5)$ & $42.3(40.7-44.0)$ & $42.0(40.4-43.7)$ \\
\hline Not at all satisfied & 6,100 & $2.5(2.3-2.6)$ & $2.5(2.4-2.7)$ & $7.4(6.8-8.1)$ & $7.5(6.8-8.1)$ & $13.2(12.1-14.5)$ & $13.1(12.0-14.3)$ \\
\hline
\end{tabular}

Abbreviations: $\mathrm{Cl}=$ confidence interval; $\mathrm{n}=$ sample size.

* Age standardized to the 2000 projected population for the United States.

† Alabama, Alaska, Arizona, Colorado, Connecticut, Delaware, District of Columbia, Georgia, Idaho, Illinois, Indiana, lowa, Kentucky, Louisiana, Maine, Maryland, Massachusetts, Michigan, Minnesota, Mississippi, Missouri, Montana, Nebraska, Nevada, New Hampshire, New Jersey, New Mexico, New York, North Carolina, North Dakota, Ohio, Oklahoma, Oregon, Pennsylvania, Rhode Island, South Carolina, Tennessee, Utah, Vermont, Virginia, Washington, West Virginia, and Wisconsin. Data from Missouri are available from the Missouri Department of Health and Senior Services.

§ Unweighted sample size.

I Weighted percentage.

** States that expanded Medicaid as of January 1, 2014 ( $n=23)$ : Arizona, Colorado, Connecticut, Delaware, District of Columbia, Illinois, lowa, Kentucky, Maryland, Massachusetts, Michigan, Minnesota, Nevada, New Jersey, New Mexico, New York, North Dakota, Ohio, Oregon, Rhode Island, Vermont, Washington, and West Virginia.

${ }^{+\dagger}$ States that did not expand Medicaid as of January 1, $2014(n=20)$ : Alabama, Alaska, Georgia, Idaho, Indiana, Louisiana, Maine, Mississippi, Missouri, Montana, Nebraska, New Hampshire, North Carolina, Oklahoma, Pennsylvania, South Carolina, Tennessee, Utah, Virginia, and Wisconsin. 




The Morbidity and Mortality Weekly Report (MMWR) Series is prepared by the Centers for Disease Control and Prevention (CDC) and is available free of charge in electronic format. To receive an electronic copy each week, visit $M M W R$ 's free subscription page at https://www.cdc.gov/mmwr $/ \mathrm{mmwrsubscribe.html}$. Paper copy subscriptions are available through the Superintendent of Documents, U.S. Government Printing Office, Washington, DC 20402; telephone 202-512-1800.

Readers who have difficulty accessing this PDF file may access the HTML file at https://www.cdc.gov/mmwr/volumes/66/ss/ss6607a1.htm?s_cid=ss6607a1_w. Address all inquiries about the $M M W R$ Series, including material to be considered for publication, to Executive Editor, MMWR Series, Mailstop E-90, CDC, 1600 Clifton Rd., N.E., Atlanta, GA 30329-4027 or to mmwrq@cdc.gov.

All material in the MMWR Series is in the public domain and may be used and reprinted without permission; citation as to source, however, is appreciated. Use of trade names and commercial sources is for identification only and does not imply endorsement by the U.S. Department of Health and Human Services.

References to non-CDC sites on the Internet are provided as a service to $M M W R$ readers and do not constitute or imply endorsement of these organizations or their programs by CDC or the U.S. Department of Health and Human Services. CDC is not responsible for the content of these sites. URL addresses listed in $M M W R$ were current as of the date of publication.

ISSN: 1546-0738 (Print) 